DANIEL BALADELLI MAZULQUIM

\title{
Projeto e fabricação de nanoestruturas plasmônicas para aplicações em óptica difrativa
}

Texto apresentado à Escola de Engenharia de São Carlos, Universidade de São Paulo, como parte dos requisitos para obtenção do título de Doutor em Ciências, Programa de Engenharia Elétrica.

Área de concentração: Telecomunicações

Orientador: Prof. Dr. Luiz Gonçalves Neto Coorientador: Prof. Dr. Ben-Hur Viana Borges

São Carlos

2016

Trata-se da versão corrigida da tese. A versão original encontra-se disponível na EESC/USP que aloja o Programa de Pós-Graduação em Engenharia Elétrica. 
AUTORIZO A REPRODUÇÃO TOTAL OU PARCIAL DESTE TRABALHO,

POR QUALQUER MEIO CONVENCIONAL OU ELETRONICO, PARA FINS DE ESTUDO E PESQUISA, DESDE QUE CITADA A FONTE.

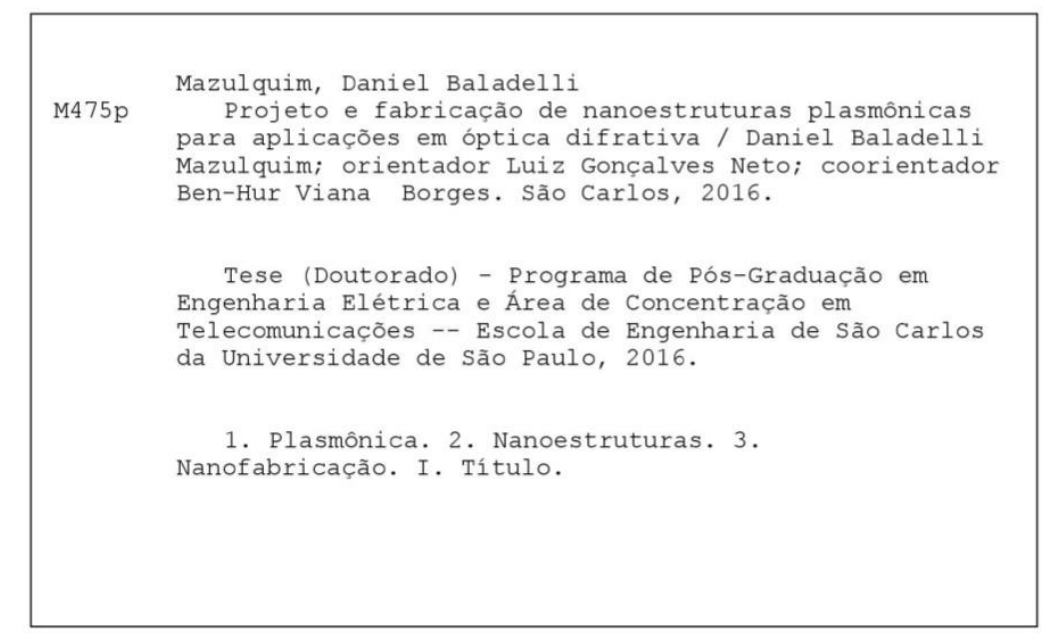




\section{FOLHA DE JULGAMENTO}

Candidato: Bacharel DANIEL BALADELLI MAZULQUIM.

Título da tese: "Projeto e fabricação de nanoestruturas plasmônicas para aplicações em óptica difrativa".

Data da defesa: 01/07/2016

\section{Comissāo Julgadora:}

Prof. Associado Luiz Gonçalves Neto (Orientador) (Escola de Engenharia de São Carlos/EESC)

Prof. Dr. Emiliano Rezende Martins

(Escola de Engenharia de São Carlos/EESC)

Prof. Associado Euclydes Marega Junior (Instituto de Física de São Carlos/IFSC)

Prof. Dr. Luís Alberto Mijam Barêa (Universidade Federal de São Carlos/UFSCar)

Prof. Associado Ronaldo Domingues Mansano (Escola Politécnica/EP-USP)
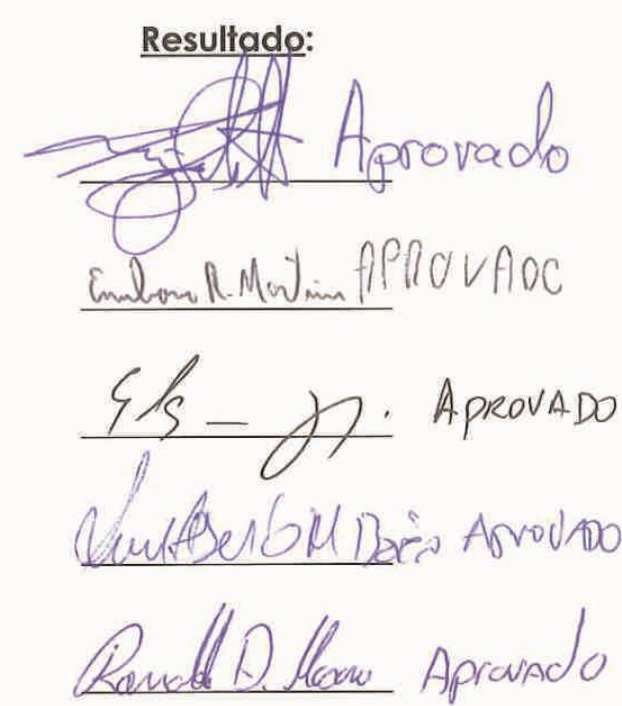

Coordenador do Programa de Pós-Graduação em Engenharia Elétrica: Prof. Associado Luis Fernando Costa Alberto

Presidente da Comissão de Pós-Graduação: Prof. Associado Luis Fernando Costa Alberto 

Aos meus pais, João e Wania. 

-Que queres tu, meu pobre Diabo? As capas de algodão têm agora franjas de seda, como as de veludo tiveram franjas de algodão. Que queres tu? É a eterna contradição humana.

Gazeta de Notícias, 12 de fevereiro de 1883. Machado de Assis. 



\section{AgradeCIMENTOS}

À Universidade de São Paulo, Escola de Engenharia de São Carlos, Departamento de Engenharia Elétrica, pela oportunidade de realizar o doutorado.

Ao orientador, Prof. Dr. Luiz Gonçalves Neto.

Ao coorientador, Prof. Dr. Ben-Hur Viana Borges.

Ao CNPq e à CAPES, pelo auxílio financeiro.

À University of Texas at Arlington (UTA), na figura do professor Robert Magnusson.

Ao VTT Technical Research Centre of Finland, na figura de Marianne Hiltunen.

À Secretaria de Pós-Graduação do Departamento de Engenharia Elétrica.

Aos meus pais, João e Wania.

À Isabel e seus pais, José e Maria.

Aos amigos da Telecom - SEL/EESC/USP. Um agradecimento especial ao mestre Leone Veiga Muniz pela ajuda com as simulações no HFSS.

Aos amigos do Nanophotonics Device Group, UTA. Um agradecimento especial ao Dr. Kyu Jin Lee pelos ensinamentos, dentro e fora do laboratório.

Aos amigos do IFSC/USP.

Aos amigos do Caaso.

Aos amigos de São Carlos.

Aos amigos de Boituva.

Aos amigos de Arlington, TX.

E tantas outras pessoas que, mesmo sem saber, contribuíram para esse processo.

Obrigado! 



\section{RESUMO}

MAZULQUIM, D. B. Projeto e fabricação de nanoestruturas plasmônicas para aplicações em óptica difrativa. 2016. Tese (Doutorado) - Escola de Engenharia de São Carlos, Universidade de São Paulo, 2016.

A plasmônica é a área que faz a junção entre fotônica e nanoestruturas. As implicações tecnológicas resultantes do acoplamento entre campos eletromagnéticos e oscilações eletrônicas em um material condutor fazem desta área uma das mais excitantes da óptica atualmente. Neste contexto, o objetivo deste trabalho é o projeto, fabricação e caracterização de nanoestruturas metálicas visando aplicações em óptica difrativa, incluindo filtros e lentes. Inicialmente, uma extensa revisão bibliográfica permitiu definir quais tipos de estruturas seriam abordadas, levando em conta tanto a capacidade computacional para fazer a modelagem numérica quanto a infraestrutura necessária na fabricação dos elementos. A primeira estrutura analisada foi um filtro óptico baseado em ressonância de modo guiado e ressonância plasmônica. Foram projetados e fabricados três filtros operando no azul, verde e vermelho. Resultados experimentais mostraram eficiência acima de $80 \%$ e largura de banda em torno de $20 \mathrm{~nm}$, consideravelmente menor que os $\sim 60 \mathrm{~nm}$ obtidos previamente na literatura considerando estrutura semelhante. Foi possível verificar as cores puras associadas à ressonância de modo guiado. Além disso, foi demonstrado como gerar as três cores primárias-azul, verde e vermelho-usando apenas o filtro vermelho. A segunda estrutura proposta consiste em uma lente tipo zonas de Fresnel integrada com um filme metálico. Resultados numéricos identificaram uma estrutura ressonante do tipo Fabry-Perot que possibilita uma redução dos lóbulos laterais gerada pela lente por um fator 3.0 na polarização TM e 4.8 na polarização TE. A estrutura foi fabricada usando litografia por nanoimpressão. Por fim, a terceira estrutura analisada foi um holograma binário baseado em metassuperfície, cuja célula básica é composta de um ressoador tipo nanorod. Foi proposta uma geometria na qual a diferença de fase entre os elementos é igual a $\pi$ independente do comprimento de onda. Assim, o holograma pode operar em uma faixa espectral definida pela largura de banda transmitida. É descrito o inicio da fabricação do elemento usando litografia por feixe de elétrons.

Palavras-chave: Plasmônica, Nanoestruturas, Nanofabricação 



\begin{abstract}
MAZULQUIM, D. B. Design and fabrication of plasmonic nanostructures for applications in diffractive optics. 2016. Tese (Doutorado) - Escola de Engenharia de São Carlos, Universidade de São Paulo, 2016.

Plasmonics is a field of study that merge photonics and nanostructures. The advanced technological implications makes it one of the most exciting field in Optics in current days. Therefore the objective of this study is the design and fabrication of metallic nanostructures aiming at applications in diffractive optics. Firstly, an extensive literature review allowed to define what types of structures would be addressed, taking into account both software simulations and the required infrastructure for the elements' fabrication. The first analyzed structure was an optical color filter based on guided mode resonance and surface plasmon resonance. Three filters, operating in blue, green and red, were designed and fabricated using interferometric lithography. Experimental results show above $80 \%$ efficiency and $\sim 20 \mathrm{~nm}$ bandwidth, which is significantly smaller than $\sim 60 \mathrm{~nm}$ previously obtained in the literature with similar structures. It was possible to show the pure colors associated with the modal resonance. Furthermore, it was shown how to obtain the primary red, blue, and green colors using only the red filter. The second structure proposed consists of Fresnel zones plates integrated with a metallic film. Numerical results show a resonant structure which enables side lobe reduction by a factor 3.0 in the TM polarization and 4.8 in the TE polarization. This structure was fabricated using nanoimprint lithography. The third analyzed structure was a binary hologram based on metasurface whose basic cell is composed of a nanorod metallic resonator. The phase difference between two elements is equal to $\pi$, regardless of the wavelength; thus, the hologram operates in a spectral band defined by transmitted bandwidth. The first steps of its fabrication process using electron beam lithography are presented and described.
\end{abstract}

Keywords: Plasmonics, Nanostructures, Nanofabrication 



\section{SUMÁRIO}

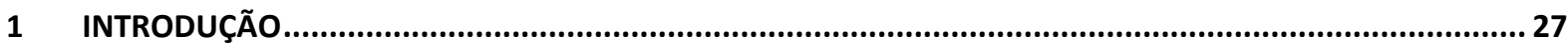

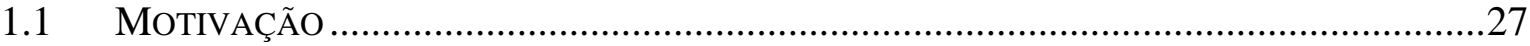

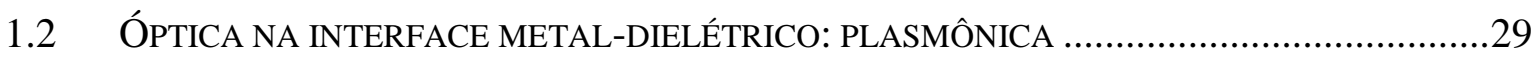

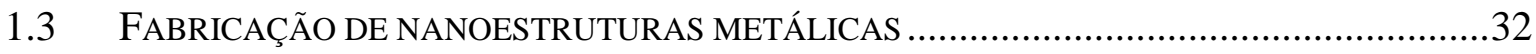

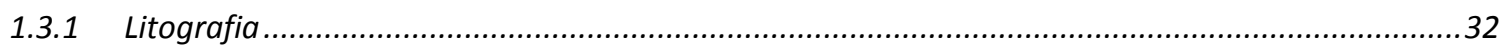

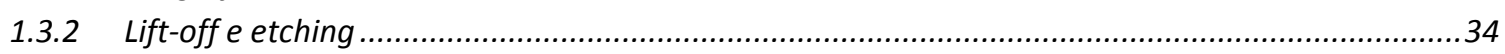

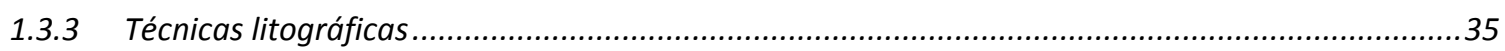

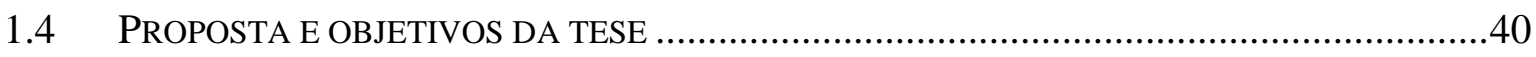

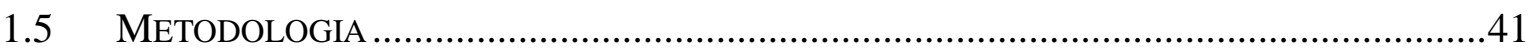

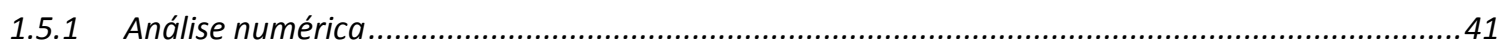

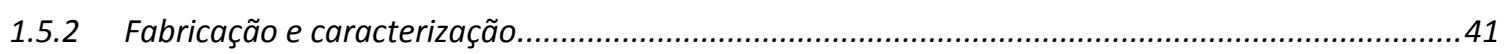

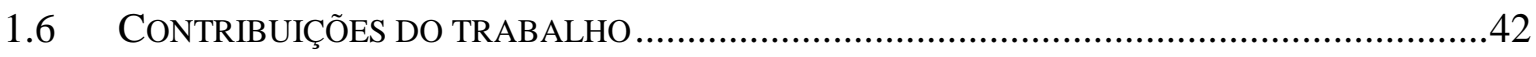

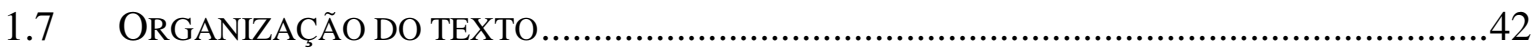

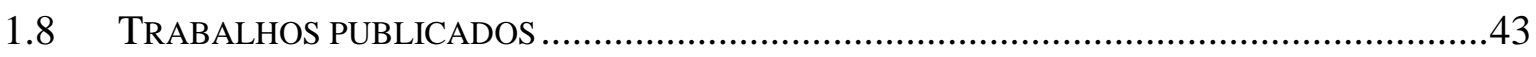

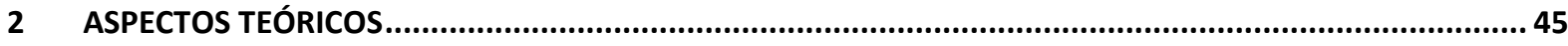

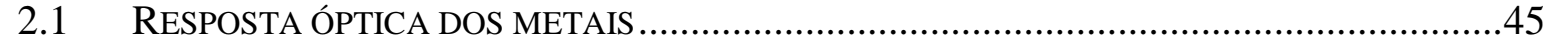

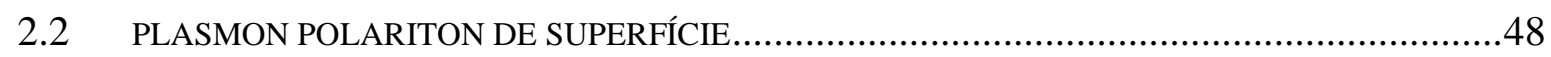

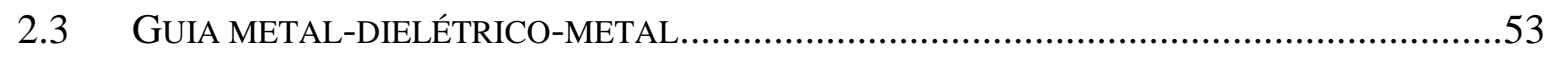

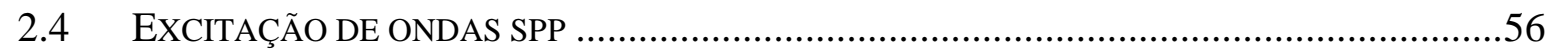

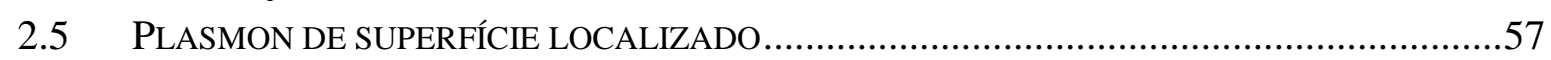

3 FILTROS ÓPTICOS BASEADOS EM MODOS RESSONANTES E PLÁSMONS DE SUPERFÍCIE..........................59

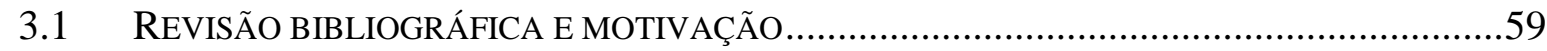

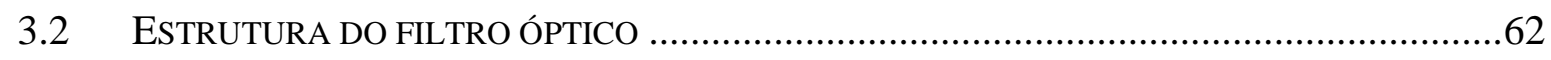

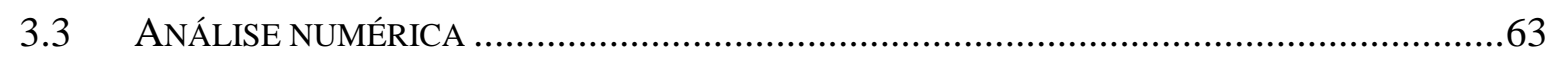

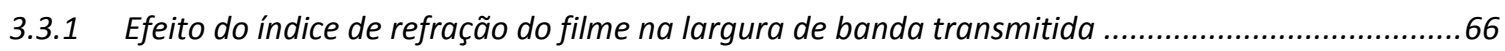

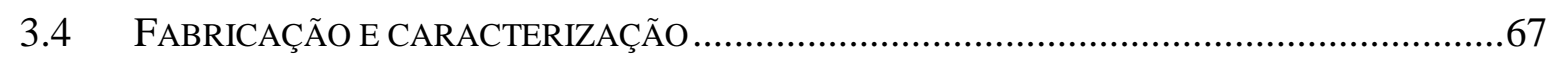

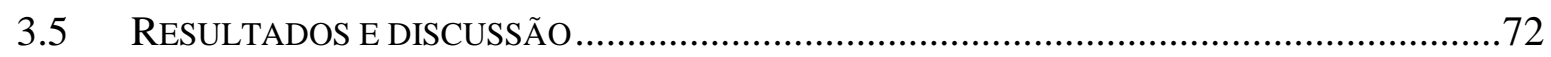

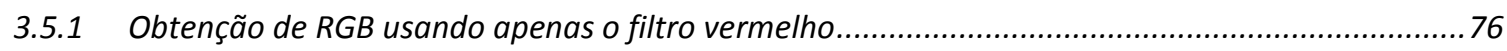

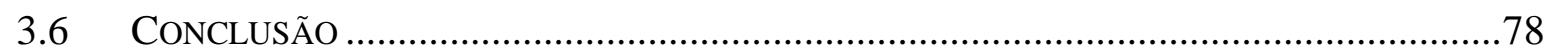

4 LENTE ÓPTICA BASEADA EM ZONAS DE FRESNEL LINEAR INTEGRADA COM FILME METÁLICO................ 81

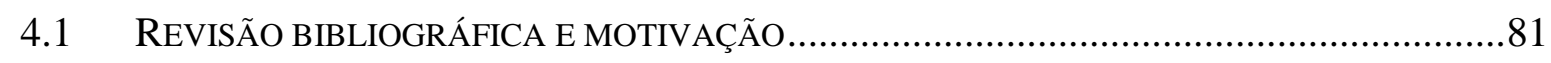

4.2 ESTRUTURA DA LENTE FZP MODIFICADA E PARÂMETROS DAS SIMULAÇÕES .................84

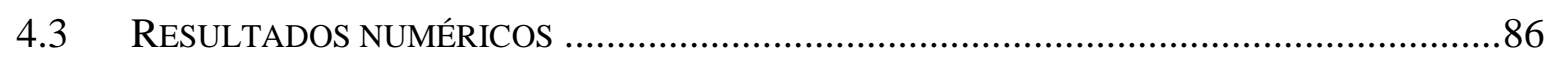

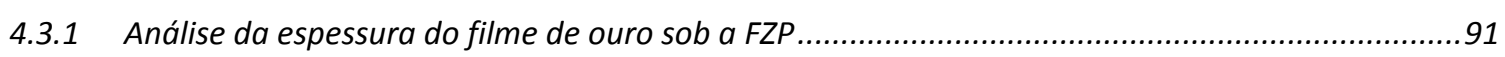

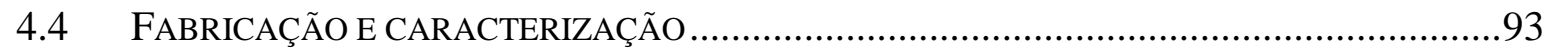

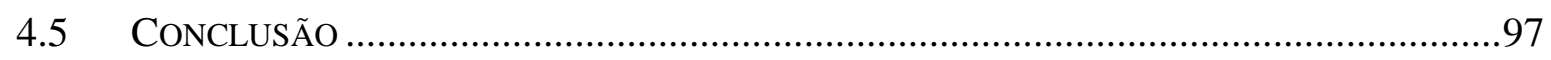

5 TRABALHO FUTURO - HOLOGRAMA BINÁRIO BASEADO EM RESSOADOR METÁLICO TIPO NANOROD . 99

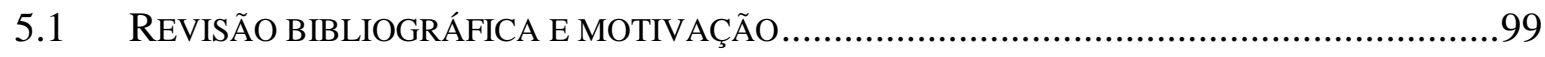

5.2 ESTRUTURA E ANÁLISE NUMÉRICA …................................................................... 101 


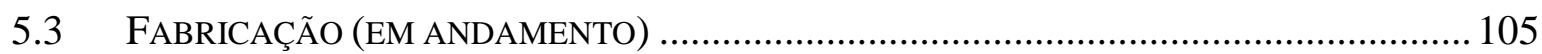

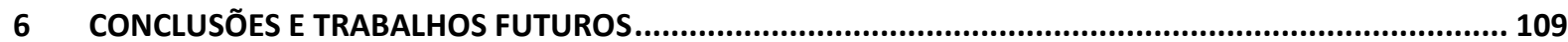

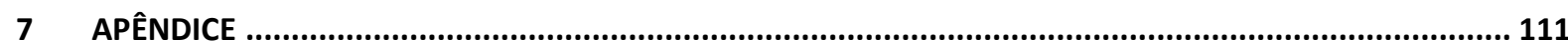

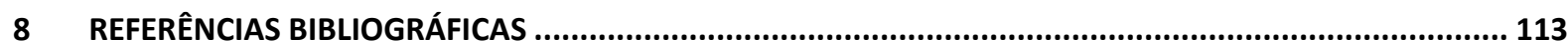




\section{LiSTA DE FigurAS}

FIGURA 1.1 - $\quad$ (A) DIFERENTES DOMÍNIOS EM TERMOS DE VELOCIDADE DE OPERAÇÃO E DIMENSÃO DO DISPOSITIVO, ADAPTADO DE [10] E (B) NÚMERO ANUAL DE PUBLICAÇÕES NA ÁREA DE PLASMÔNICA E DE CRISTAIS FOTÔNICOS PARA EFEITO DE COMPARAÇÃO, ADAPTADO DE [11].

FIGURA 1.2 - CONFIGURAÇÃO BÁSICA DE UM DISPOSITIVO PLASMÔNICO, NO QUAL O REGIME DIFRATIVO É USADO PARA EXCITAR E DESACOPLAR A LUZ EMITIDA, ADAPTADO DE [14].

FIGURA 1.3-PROCESSO LITOGRÁFICO PADRÃO USANDO FOTORESISTE POSITIVO E NEGATIVO. APÓS A REVELAÇÃO TEM-SE UM PADRÃO TRANSFERIDO PARA O FOTORESISTE.

FIGURA 1.4-ESPESSURA DO FILME EM FUNÇÃO DA VELOCIDADE DE ROTAÇÃO PARA O FOTORESISTE COMERCIAL 495PMMA, TIPOS A2, A4 E A6, ADAPTADO DE [75].

FIGURA 1.5 - DOIS PROCESSOS DE FABRICAÇÃO DE NANOESTRUTURAS METÁLICAS: (1) USANDO LIFT-OFF E (2) USANDO ETCHING.

FIGURA 1.6 -DOIS ARRANJOS EXPERIMENTAIS USADOS NA FABRICAÇÃO DE GRADES PERIÓDICAS, ADAPTADO DE [89]...................37

FIGURA 1.7- SISTEMA EBL TíPICO, COMPOSTO DE UMA CÂMARA DE VÁCUO, UMA FONTE DE ELÉTRONS E UMA COLUNA CONTENDO TODOS OS ELEMENTOS PARA O FOCO E VARREDURA, ALÉM DO CONTROLE ON/OFF DO FEIXE DE ELÉTRONS. UM SISTEMA COMPUTACIONAL AUTOMÁTICO FAZ A CORRELAÇÃO ENTRE O DESENHO DO PADRÃO E A VARREDURA DO FEIXE.

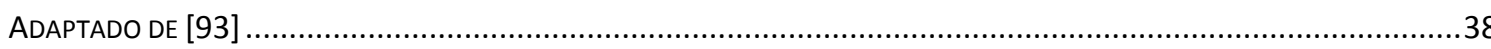

FIGURA 1.8- $\quad$ (A) PROCESSO PADRÃO DE FABRICAÇÃO LITOGRÁFICA POR NANOIMPRESSÃO. IMAGENS DE MICROSCOPIA ELETRÔNICA DE VARREDURA (B) DO MOLDE E (C) DO PADRÃO OBTIDO NO POLÍMERO. AdAPTADO DE $[98,99]$

Figura 2.1 - CONSTANTES ÓPtICAS dos METAIS USADOS NESTE TRABALHO. PARTE REAL (A,C) E IMAGINÁRIA (B,D) DA PERMISSIVIDADE DO (OURO, ALUMÍNIO). CíRCULOS AZUIS E VERMELHOS REPRESENTAM OS DADOS EXPERIMENTAIS DE JOHNSON \& CHRISTY [108] E PALIK [109], RESPECTIVAMENTE. AS LINHAS PRETAS MOSTRAM A INTERPOLAÇÃO USADA NAS ANÁLISES NUMÉRICAS.

FIGURA 2.2 - VISUALIZAÇÃO DA ONDA SPP, RESULTADO DO ACOPLAMENTO ENTRE O CAMPO ELETROMAGNÉTICO E AS CARGAS LIVRES NA SUPERFÍCIE DO METAL, ADAPTADO DE [116]. NA POLARIZAÇÃO TM TEM-SE AS COMPONENTES DE CAMPO ELETROMAGNÉTICO $\mathrm{H}_{\mathrm{y}}, \mathrm{E}_{\mathrm{x}} \mathrm{E} \mathrm{E}_{\mathrm{z}}$.

FIGURA 2.3 - CAMPO EVANESCENTE |EZ| DA ONDA SPP, ADAPTADO DE [116].....

FIGURA 2.4 - CURVAS DE DISPERSÃO PARA O AR, MEIO DIELÉTRICO $\left(E_{D}>1\right)$ E ONDA SPP NA INTERFACE METAL/AR, ADAPTADO DE [116]....

FIGURA 2.5 - GEOMETRIA DO GUIA METAL-ISOLANTE-METAL (MIM). (I) DIELÉTRICO E (II) E (III) METAL................................53

FiguRA 2.6 - PERFIL dos CAMPOS ELETROMAGNÉTICOS DE UM GUIA METAL-ISOLANTE-METAL PARA O MOdO SIMÉTRICO (A) Hy, (B)

$E_{x} E(C) E_{z}$

FIGURA 3.1- ESTRUTURA DE DIFERENTES FILTROS ÓPTICOS OPERANDO NO VISÍVEL, COM A RESPECTIVA RESPOSTA ESPECTRAL. (A) FILTRO PURAMENTE DIELÉTRICO BASEADO EM GMR, OPERANDO EM REFLEXÃO [123], (B) FILTRO BASEADO EM CAVIDADE FABRY-PEROT [126], (C) FILTRO PLASMÔNICO COM ABERTURA CIRCULAR E TRIANGULAR [139] E (D) FILTRO INCORPORANDO GMR E GRADE METÁLICA [142].

FIGURA 3.2- ESTRUTURA DO FILTRO ÓPTICO INCORPORANDO GMR E RESSONÂNCIA PLASMÔNICA. OS PARÂMETROS N $N_{S}, N_{F} E N_{C}$ DENOTAM O ÍNDICE DE REFRAÇÃO DO VIDRO, DO FILME DE $\mathrm{AL}_{2} \mathrm{O}_{3}$ E DO AR, RESPECTIVAMENTE. $\Lambda$ É O PERÍODO, F É O FILL FACTOR E T $\mathrm{T}_{\mathrm{G}} \mathrm{T}_{\mathrm{F}}$ SÃO AS ESPESSURAS DA GRADE DE ALUMÍNIO E DO FILME DE $\mathrm{AL}_{2} \mathrm{O}_{3}$, RESPECTIVAMENTE. I $\mathrm{I}_{0} \mathrm{I}_{\mathrm{T}}$ INDICAM A ONDA INCIDENTE E TRANSMITIDA, RESPECTIVAMENTE.

FIgURA 3.3 - AMBIENTE DE SIMULAÇÃO NUMÉRICA E PARÂMETROS GEOMÉTRICOS DOS FILTROS ÓPTICOS. NO DETALHE É MOSTRADO A DISCRETIZAÇÃO ESPACIAL DE UMA PARTE DA ESTRUTURA.

FIGURA 3.4- RESPOSTA ESPECTRAL CALCULADA EM FUNÇÃO DA ESPESSURA DO FILME DE $\mathrm{AL}_{2} \mathrm{O}_{3}$ PARA OS FILTROS (A) AZUL ( $\Lambda=290$ NM), (B) VERDE $(\Lambda=350 \mathrm{NM})$ E (C) VERMELHO $(\Lambda=430 \mathrm{NM})$. OS PARÂMETROS FIXOS SÃO $\mathrm{T}_{G}=40 \mathrm{NM}$ E $F=0.67$. ESPECTRO DE TRANSMISSÃO COM T $T_{F}=200$ NM, CORRESPONDENTE AS LINHAS PONTILHADAS BRANCAS EM (A)-(C), PARA OS FILTROS (D) AZUL, (E) VERDE E (F) VERMELHO. NO DETALHE EM (D) É MOSTRADO A AMPLITUDE AUTO NORMALIZADA DO CAMPO 
MAGNÉTICO ( $|\mathbf{H}|$ ) CORRESPONDENTE AO PICO (I) E AO MÍNIMO DE TRANSMISSÃO (II). AS LINHAS VERTICAIS PONTILHADAS EM (D)-(F) INDICAM OS COMPRIMENTOS DE ONDA DA ANOMALIA RAYLEIGH.

FIGURA 3.5- ESPECTROS DE TRANSMISSÃO CALCULADOS PARA O FILTRO AZUL CONSIDERANDO TRÊS ÍNDICES DE REFRAÇÃO DIFERENTES PARA O FILME DIELÉTRICO (A) $N_{F}=2.5$, (B) $N_{F}=2.0$, AND (C) $N_{F}=1.7$. A LARGURA DE BANDA TRANSMITIDA (FWHM) É MOSTRADA NAS POSIÇÕES (A) $T_{F}=100 \mathrm{NM}$, (B) $T_{F}=150 \mathrm{NM}$, AND (C) $T_{F}=190$ NM. OS PARÂMETROS FIXOS NAS SIMULAÇÕES SÃO $\Lambda=290 \mathrm{NM}, \mathrm{F}=0.67, \mathrm{~T}_{G}=40 \mathrm{NM}$, AND $\mathrm{N}_{S}=1.518$.

FIGURA 3.6 - CARACTERIZAÇÃO DO FILME DE $\mathrm{AL}_{2} \mathrm{O}_{3}$ REALIZADA POR ELIPSOMETRIA. (A) ÍNDICE DE REFRAÇÃO E (B) ESPESSURA DO FILME. OS PONTOS EM (A) REPRESENTAM OS VALORES EXPERIMENTAIS E A LINHA REPRESENTA A INTERPOLAÇÃO POLINOMIAL USADO NA ANÁLISE NUMÉRICA.

FIGURA 3.7 - (A) ESQUEMA DO SISTEMA INTERFEROMÉTRICO USADO NA FABRICAÇÃO DOS FILTROS ÓPTICOS, (B) VISÃO GERAL MOSTRANDO O ESPELHO DE LLOYD, A ABERTURA E O SUPORTE DA AMOSTRA E (C) IMAGEM DO SISTEMA INTERFEROMÉTRICO USADO [148].

FIGURA 3.8 - IMAGENS OBTIDAS POR AFM. O PERÍOdo DAS GRADES É $\Lambda \approx 290$ NM, REFERENTE AO FILTRO AZUL. SÃO MOSTRADOS AS IMAGENS REFERENTES A TRÊS TEMPOS DE EXPOSIÇÃO NO SISTEMA INTERFEROMÉTRICO (A) 16 SEGUNDOS, $\mathrm{F}_{\mathrm{A}} \approx$ 0.63, (B) 24 SEGUNDOS, $\mathrm{F}_{\mathrm{B}} \approx 0.53$ E (C) 32 SEGUNDOS, $\mathrm{F}_{\mathrm{C}} \approx 0.42$. O FILL FACTOR DO RESISTE E DA GRADE METÁLICA SÃO

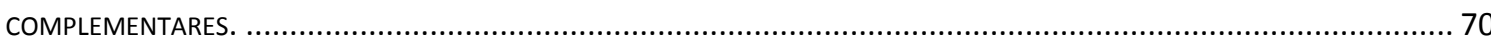

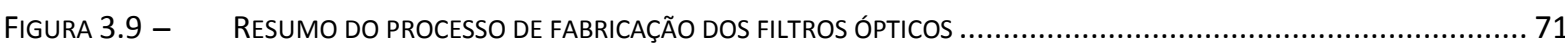

FIGURA 3.10 - IMAGENS OBTIDAS POR AFM E VERIFICAÇÃO DOS PARÂMETROS GEOMÉTRICOS DOS FILTROS FABRICADOS $(A, B)$ AZUL, (C,D) VERDE E (D,E) VERMELHO.

FIGURA 3.11- (A) MONTAGEM EXPERIMENTAL PARA MEDIDA DA RESPOSTA ÓPTICA DOS FILTROS FABRICADOS. (B) ESPECTRO DA FONTE DE LUZ BRANCA USADA E (C) IMAGEM QUE É GERADA PELO ANALISADOR DE ESPECTRO ÓPTICO.

FIGURA 3.12 - ESPECTRO DE TRANSMISSÃO MEDIDO (LINHA CONTÍNUA) DOS FILTROS FABRICADOS (A) AZUL, (B) VERDE E (C) VERMELHO EM COMPARAÇÃO COM OS ESPECTROS SIMULADOS USANDO OS VALORES GEOMÉTRICOS FABRICADOS (LINHA PONTILHADA). (D)-(F) MOSTRAM AS CORES ASSOCIADAS A TRANSMISSÃO ( $\left.T_{0}\right)$ E (G)-(I) MOSTRAM AS CORES PURAS ASSOCIADAS AOS MODOS RESSONANTES.

FIGURA 3.13- (A) MONTAGEM EXPERIMENTAL USANDO O FILTRO AZUL, COM DESTAQUE PARA A COR ASSOCIADA AO MODO PROPAGANTE E A COR TRANSMITIDA PELO FILTRO (TO) E (B) FILTRO ÓPTICO FABRICADO COM 9 CONDIÇÕES DE FABRICAÇÃO DIFERENTES.

FIGURA 3.14- (A) MONTAGEM EXPERIMENTAL PARA OBTENÇÃO DAS TRÊS CORES PRIMÁRIAS RGB USANDO O FILTRO VERMELHO, (B) ESPECTRO INICIAL DA FONTE, (C) ESPECTRO MODIFICADO USANDO FILTRO VERDE QUALQUER, (D) ESPECTRO MEDIDO APÓS O FEIXE PASSAR PELO FILTRO VERMELHO FABRICADO E (E) FOTOGRAFIA OBTIDA POR CIMA DA MONTAGEM EXPERIMENTAL POR CIMA (EIXO Y).

FIGURA 3.15- MONTAGEM EXPERIMENTAL PARA OBTENÇÃO DAS TRÊS CORES PRIMÁRIAS RGB USANDO O FILTRO VERMELHO. (A) FOTO TIRADA MOSTRANDO A COR AZUL (A) NA REFLEXÃO E (B) NA TRANSMISSÃO. 78

FIGURA 4.1- ESTRUTURA DE DIFERENTES LENTES METÁLICAS E O RESPECTIVO PERFIL DO FOCO GERADO. (A) LENTE BASEADA EM NANO FENDAS [156], (B) LENTE BASEADA EM FENDA ÚNICA E GRADES DIELÉTRICAS [158] E (C) LENTE COMBINANDO METAL COM FZP PARA GERAÇÃO DE FOCO COM PROPRIEDADES ABAIXO DO LIMITE DE DIFRAÇÃO [166].

FIGURA 4.2 - ESTRUTURA INCORPORANDO PLACAS DE ZONAS DE FRESNEL (FZP) COM FILME METÁLICO. (A) SEÇÃO TRANSVERSAL (PLANO XY) E (B) VISÃO GERAL DO DISPOSITIVO. O PADRÃO DE INTENSIDADE É CALCULADO VARIANDO A DISTÂNCIA FZP-FILME, VARIÁVEL D EM (A), PARA POLARIZAÇÃO INCIDENTE TM E TE. 84

FIGURA 4.3 - AMBIENTE DE SIMULAÇÃO NUMÉRICA E PARÂMETROS GEOMÉTRICOS DA FZP. NO DETALHE É MOSTRADO A DISCRETIZAÇÃO ESPECIAL DE UMA PARTE DA ESTRUTURA; ABAIXO SÃO MOSTRADOS OS RAIOS DA FZP CALCULADOS PELA EQUAÇÃO 4.1, CONSIDERANDO $F=1 \mathrm{MME} \Lambda_{0}=633 \mathrm{NM}$.

FIGURA 4.4- OBTENÇÃO DO PARÂMETRO R, DEFINIDO COMO A RAZÃO ENTRE A INTENSIDADE NO PICO (I I $)$ E A INTENSIDADE DO MAIOR LÓBULO LATERAL ( $\left.I_{L}\right)$. (A) PADRÃO DE INTENSIDADE TRANSMITIDA E (B) INTENSIDADE NA POSIÇÃO FOCAL, REPRESENTADA PELA LINHA VERMELHA EM (A). . .86

FIGURA 4.5 - PADRÃO DA INTENSIDADE TRANSMITIDA PELA FZP COM E SEM O FILME PARA POLARIZAÇÃO INCIDENTE TM E TE. PolARIZAÇÃo TM (A) SEM O FILME E (B) COM O FILME, D = 480 NM. POLARIZAÇÃo TE (C) SEM O FILME E (D) COM O FILME, D 
= 490 NM. A POSIÇÃO FOCAL EM (A), (B), (C) E (D) É 1.17 MM, 1.20 MM, 1.02 MM, AND 1.12 MM, RESPECTIVAMENTE. OS RETÂNGULOS BRANCOS INDICAM A SEÇÃO TRANSVERSAL DA FZP.

FIGURA 4.6- GEOMETRIA DA LENTE FZP.

Figura 4.7- PERFIL DA INTENSIDAde NO POSIÇÃO FOCAL AO LONGO do EIXO X PARA POLARIZAÇÃO INCIDENTE (A) TM E (B) TE.

LINHAS AZUL E VERMELHA REPRESENTAM OS PERFIS DE INTENSIDADE COM E SEM O FILME, RESPECTIVAMENTE....................88

FIGURA 4.8- $\quad$ (A) CÁLCULO DO PARÂMETRO R, DEFINIDO COMO A RAZÃO ENTRE A INTENSIDADE NO FOCO E A INTENSIDADE DO MAIOR LÓBULO LATERAL, COMO FUNÇÃO DA DISTÂNCIA FZP-FILME. NOTE QUE EXISTEM DUAS DESCONTINUIDADES NO EIXOX, REPRESENTANDO REGIÕES ONDE O DISPOSITIVO NÃO GERA UM FOCO ÚNICO. (B) PADRÃO DE INTENSIDADE CORRESPONDENDO AOS PICOS DE $R$ EM (A) PARA TM E TE. OS RETÂNGULOS BRANCOS INDICAM A SEÇÃO TRANSVERSAL DA FZP.

FIGURA 4.9 - PADRÃO DE INTENSIDADE TRANSMITIDA PARA TM E TE EM DUAS SITUAÇÕES DIFERENTES: (A,C) FILME LOCALIZADO EM UMA POSIÇÃO CORRESPONDENTE AO PICO DE R E (B,D) FILME LOCALIZADO EM UMA POSIÇÃO ONDE O DISPOSITIVO NÃO GERA FOCO. NA SEGUNDA COLUNA ESTÃO REPRESENTADOS OS RESPECTIVOS CAMPOS (E,F) MAGNÉTICO E (G,H) ELÉTRICO, ENTRE A LENTE FZP E O FILME METÁLICO.

FIGURA 4.10 - ANÁLISE DO EFEITO DA ESPESSURA DO FILME DE OURO NA RESPOSTA DO DISPOSITIVO. VALORES CALCULADOS DE (A) R E (B) INTENSIDADE NA POSIÇÃO FOCAL, AUTONORMALIZADA, EM FUNÇÃO DA ESPESSURA DO FILME DE OURO. OS QUADRADOS PRETOS REFEREM-SE A POLARIZAÇÃO TM E OS CÍRCULOS VERMELHOS À POLARIZAÇÃO TE.

FIGURA 4.11 - SEQUÊNCIA DE FABRICAÇÃO USANDO LITOGRAFIA POR NANOIMPRESSÃO. (A) SUBSTRATO DE VIDRO COM O FILME DE OURO E POLÍMERO NO TOPO, (B) NANOIMPRESSÃO, (C) DEPOSIÇÃO DE OURO E (D) PROCESSO DE POLIMENTO.

FIGURA 4.12 - (A) CONJUNTO 5 X 7 DE MOLDES FABRICADOS USANDO DIFERENTES EBL DOSES E (B) DETALHE DE UM MOLDE DA LENTE FZP FABRICADO.

FIGURA 4.13 - (A) VISTA FRONTAL DO DISPOSITIVO FABRICADO E (B) SEÇÃO TRANSVERSAL, COM OS RESPECTIVOS MATERIAIS E DIMENSÕES.

FIGURA 4.14 - (A) PADRÃO DA INTENSIDADE TRANSMITIDA PELA FZP PROJETADA COM O FILME (D = 514 NM) PARA POLARIZAÇÃO INCIDENTE TM E TE. (B) PERFIL DA INTENSIDADE NA POSIÇÃO FOCAL AO LONGO DO EIXO X PARA POLARIZAÇÃO INCIDENTE TM E TE. LINHAS AZUL E VERMELHA REPRESENTAM OS PERFIS DE INTENSIDADE COM ( $D=514$ NM) E SEM O FILME, RESPECTIVAMENTE.

FIGURA 5.1 - (A) CÉLULA BÁSICA CONTENDO A HASTE DE OURO DE ESPESSURA T = 30 NM E (B) VISÃO FRONTAL DETALHANDO OS PARÂMETROS GEOMÉTRICOS: $\Lambda$ É O PERÍODO, L É O COMPRIMENTO DA HASTE, B É O ÂNGULO DA HASTE COM RELAÇÃO AO EIXO $X E W=30 \mathrm{NM}$. 101

FIGURA 5.2 - ESPECTRO DE TRANSMISSÃO NA POLARIZAÇÃO CRUZADA. (A) VARIANDO L, (B) $\wedge=640$ NM, CORRESPONDENTE À LINHA TRACEJADA (I) EM (A), E (C) L = 80 NM, CORRESPONDENTE À LINHA TRACEJADA (II) EM (A).

FIGURA 5.3 - $\quad$ (A) COEFICIENTE DE TRANSMISSÃO NA POLARIZAÇÃO CRUZADA EM FUNÇÃO DE B, CONSIDERANDO L = 80NM E POLARIZAÇÃO INCIDENTE NO EIXO X. (B) FASE TRANSMITIDA NA POLARIZAÇÃO CRUZADA PARA TRÊS COMPRIMENTOS DE ONDA INCIDENTE EM FUNÇÃO DE B.

FIGURA 5.4 - $\quad$ (A) GEOMETRIA DA CÉLULA USADA NA FABRICAÇÃO E (B) COEFICIENTE DE TRANSMISSÃO NA POLARIZAÇÃO CRUZADA CONSIDERANDO PARÂMETROS DADOS EM (A).

FIGURA 5.5- $\quad$ (A) HOLOGRAMA BINÁRIO CALCULADO, (B) ILUSTRAÇÃO DO HOLOGRAMA BASEADO EM METASSUPERFÍCIE A SER FABRICADO E (C) RECONSTRUÇÃO SIMULADA DA IMAGEM.

FIGURA 5.6 - PROCESSO DE FABRICAÇÃO USANDO TÉCNICA LITOGRÁFICA CONHECIDA COMO BILAYER. ..............................105

FIGURA 5.7- (A) IMAGEM MOSTRANDO A AMOSTRA COM AS DUAS CAMADAS DE ELETRORESISTE NA CÂMARA DE VÁCUO. NO DETALHE, O CANHÃO DE ELÉTRONS, A AMOSTRA E O SUPORTE COM CONTROLE (X,Y,Z). (B) IMAGEM OBTIDA DAS NANOESFERAS DE OURO PRESENTE NO SUPORTE, USADA PARA MINIMIZAR O ASTIGMATISMO DO FEIXE DE ELÉTRONS. A BARRA DE ESCALA REPRESENTADA EM (B) TEM 20 NM.

FIGURA 5.8 - ESTUDO DA DOSE LINEAR DO FEIXE DE ELÉTRONS PARA UM PADRÃO COMPOSTO POR LINHAS DE COMPRIMENTO $L \approx$ 300 NM E PERÍODO $\Lambda \approx 350$. PROCEDIMENTO REALIZADO PARA ENCONTRAR A ESPESSURA $w \approx 120$ NM. DOSES LINEARES IGUAIS A (A) $0.5 \mathrm{NC} / \mathrm{CM}$, (B) $1.1 \mathrm{NC} / \mathrm{CM}$, (C) $1.5 \mathrm{NC} / \mathrm{CM}$, (D) $2.1 \mathrm{NC} / \mathrm{CM}$, (E) $2.5 \mathrm{NC} / \mathrm{CM} \mathrm{E} \mathrm{(F)} 3.1 \mathrm{NC} / \mathrm{CM}$, ONDE NC SIGNIFICA NANOCOULUMB. IMAGENS DE MICROSCOPIA DE FORÇA ATÔMICA APÓS A REVELAÇÃO. A BARRA DE ESCALA REPRESENTADA EM (A) TEM 300 NM DE COMPRIMENTO E VALE PARA TODAS AS IMAGENS. 
FIGURA 5.9- (A) IMAGEM DE MICROSCOPIA DE FORÇA ATÔMICA DO HOLOGRAMA EXPOSTO, COM AS DIMENSÕES PRÓXIMAS À SIMULADA. A BARRA DE ESCALA REPRESENTADA TEM 300 NM DE COMPRIMENTO. (B) IMAGEM OBTIDA DURANTE MEDIDA DE MICROSCOPIA DE FORÇA ATÔMICA MOSTRANDO DIFICULDADE ENFRENTADA DURANTE A FABRICAÇÃO: BOLHAS NO RESISTE APÓS A REVELAÇÃO. (C) SUCESSIVAS EXPOSIÇÕES DO PADRÃO CALCULADO PARA O HOLOGRAMA, COM O INTUITO DE AUMENTAR O TAMANHO DO ELEMENTO E FACILITAR SUA CARACTERIZAÇÃO; IMAGEM MOSTRA ERROS DE ALINHAMENTO. 108

FIGURA 7.1 - CONFIGURAÇÃO PROPOSTA PARA A FABRICAÇÃO DA LENTE FZP INTEGRADA COM O FILME METÁLICO USANDO LITOGRAFIA POR NANOIMPRESSÃO.

FIGURA 7.2 - C CÁlCULO DO PARÂMETRO R, DEFINIDO COMO A RAZÃO ENTRE A INTENSIDADE NO FOCO E A INTENSIDADE DO MAIOR LÓBULO LATERAL, COMO FUNÇÃO DA DISTÂNCIA FZP-FILME.

Figura 7.3- PADRÃO de INTENSIDAdE SEM O FILME (A) E (B) E CORRESPONDENDO AOS PICOS DE R (C) E (D), PARA POLARIZAÇÃO TM E TE, RESPECTIVAMENTE. PERFIL DA INTENSIDADE NA POSIÇÃO FOCAL AO LONGO DO EIXO X PARA POLARIZAÇÃO INCIDENTE (E) TM E (F) TE. OS RETÂNGULOS BRANCOS EM $(A, B, C, D)$ INDICAM A SEÇÃO TRANSVERSAL DA FZP ... 


\section{LISTA DE TABELAS}

TABELA 1.1-CARACTERÍSTICAS DAS PRINCIPAIS TÉCNICAS LITOGRÁFICAS USADAS NA FABRICAÇÃO DE 36

TABELA 1.2-VANTAGENS E DESVANTAGENS DA TÉCNICA EBL EM COMPARAÇÃO COM LITOGRAFIA ÓPTICA, ADAPTADO DE [95] ......39

TABELA 2.1 - VALORES TÍPICOS DE $\Lambda_{\text {SPP }}, \Delta_{M}, \Delta_{D} E L_{\text {SPP }}$ PARA UMA INTERFACE OURO/VIDRO

TABELA 3.1 - PARÂMETROS SIMULAdOS E MEDIDOS PARA OS FILTROS AZUL, VERDE E VERMELHO. .76

TABELA 4.1- GEOMETRIA DA LENTE FZP. LARGURA DAS FENDAS, CONSTANTE DE PROPAGAÇÃO B E RESPECTIVO ÍNDICE DE REFRAÇÃO

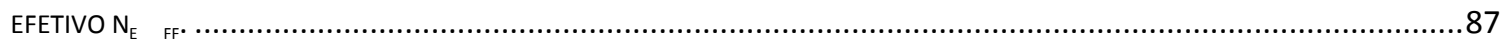

TABELA 4.2-PARÂMETROS DOS DISPOSITIVO CALCULADOS COM E SEM O FILME, PARA POLARIZAÇÃO TM E TE ..........................92

TABELA 4.3-COMPARAÇÃO ENTRE A GEOMETRIA SIMULADA E FABRICADA .................................................................96 



\section{LISTA DE SÍMbOLOS}

\begin{tabular}{|c|c|}
\hline Símbolo & Tradução \\
\hline$\lambda$ & Comprimento de onda \\
\hline$\lambda_{s p p}$ & Comprimento da onda SPP \\
\hline $\boldsymbol{E}$ & Campo elétrico \\
\hline $\mathbf{H}$ & Campo magnético \\
\hline$\omega$ & Frequência de excitação \\
\hline$\omega_{p}$ & Frequência de plasma \\
\hline$k_{0}$ & Vetor de onda \\
\hline$\varepsilon_{0}$ & Permissividade do vácuo \\
\hline$\varepsilon(\omega)$ & Permissividade relativa do meio \\
\hline$\varepsilon_{d}$ & Permissividade relativa do dielétrico \\
\hline$\varepsilon_{m}$ & Permissividade relativa do metal \\
\hline $\boldsymbol{k}_{d}$ & Vetor de onda no dielétrico \\
\hline $\boldsymbol{k}_{m}$ & Vetor de onda no metal \\
\hline$\gamma$ & Coeficiente de amortecimento \\
\hline$p$ & Fator peso \\
\hline$N$ & Número de osciladores \\
\hline$\omega_{o}$ & Frequência associada à força restauradora \\
\hline$k_{B}$ & Constante de Boltzmann \\
\hline$k_{x}$ & Componente longitudinal da excitação \\
\hline$\delta_{m}$ & Profundidade de penetração no metal \\
\hline$\delta_{d}$ & Profundidade de penetração no dielétrico \\
\hline$L_{s p p}$ & Distância de propagação da onda SPP \\
\hline$k_{x}$ & Vetor de onda longitudinal \\
\hline$e$ & Carga do elétron \\
\hline$\beta$ & Constante de propagação da onda SPP \\
\hline$\Lambda$ & Período da rede \\
\hline $\mathbf{F}$ & Fill Factor da rede \\
\hline $\mathbf{t}_{\mathrm{g}}$ & Espessura da rede \\
\hline $\mathbf{t}_{\mathbf{f}}$ & Espessura do filme \\
\hline
\end{tabular}


$\mathbf{T}_{\mathbf{0}} \quad$ Transmissão da ordem zero

I Intensidade

$f$ Distância focal

$\boldsymbol{L} \quad$ Comprimento da haste metálica 


\section{LiSTA DE ACRônimos}

\begin{tabular}{cl}
\hline Acrônimo & Definição \\
\hline SPP & Surface Plasmon Polariton \\
UV & Ultraviolet \\
PMMA & Polymethyl Methacrylate \\
EBL & Electron Beam Lithography \\
FIB & Focused Ion Beam \\
SEM & Scanning Electron Microscope \\
NPGS & Nanometer Pattern Generation \\
NIL & System \\
IL & Nanoimprint Lithography \\
FEM & Interferometric Lithography \\
TM & Finite Element Method \\
TE & Transverse Magnetic \\
OSA & Transverse Electric \\
MIM & Optical Society of America \\
RGB & Metal-Insulator-Metal \\
GMR & Red-Blue-Green \\
FWHM & Guided Mode Resonance \\
MIBK & Full Width at Half Maximum \\
FIM & Methy Isobutyl Ketone \\
ISPR & Atomic Force Microscopy \\
& Fresnel Zone Plates \\
& Perfect Matched Layers \\
& Localized Surface Plasmon \\
\hline & \\
\hline & Resonance \\
\hline
\end{tabular}





\section{INTRODUÇÃo}

\subsection{Motivação}

Uma das principais características das sociedades modernas é a demanda cada vez maior de dispositivos optoeletrônicos rápidos, compactos, integrados e de baixo custo. Durante o século XX houve um extraordinário avanço na área da eletrônica. $\mathrm{O}$ estudo de materiais semicondutores e o conhecimento de suas propriedades eletromagnéticas, aliado ao enorme avanço nos processos de fabricação, permitiram o desenvolvimento de dispositivos que fazem o processamento da informação em escala nanométrica. A miniaturização de componentes eletrônicos e o aumento da velocidade de processamento possibilitaram uma revolução no desenvolvimento de dispositivos portáteis tais como computadores, smartphones, câmeras digitais, etc, resultando em profundas mudanças políticas, econômicas, científicas e sociais. Nos dias atuais, a produção de microprocessadores comerciais contendo transistores da ordem de $30 \mathrm{~nm}$ é rotina para grandes companhias. Embora a miniaturização dos transistores contribua para o aumento de seu desempenho [1] existe um problema fundamental no que se refere ao transporte da informação digital entre os vários componentes. O "empacotamento" de unidades de processamento leva a um aumento exponencial do número de interconexões. Ao contrário dos transistores, o atraso temporal decorrente das interconexões aumenta substancialmente com a miniaturização [2], estabelecendo um limite na velocidade de processamento de circuitos digitais. Este limite fundamental impede o processamento eletrônico a velocidades superiores a $\sim 10 \mathrm{GHz}$.

$\mathrm{O}$ século XX também foi marcado pelo estabelecimento das comunicações ópticas. $\mathrm{O}$ desenvolvimento de lasers e fibras ópticas eficientes permitiu que se transmitisse um enorme volume de dados entre pontos distantes, a altas taxas, usando um dielétrico de alta transparência como meio de transmissão e a luz como portadora do sinal. Sistemas de multiplexação permitiram o envio de vários sinais usando um único canal, aumentando a largura de banda de transmissão [3]. A partir desta conjuntura, surgiram especulações de que dispositivos fotônicos poderiam substituir a eletrônica no processamento da informação, levando a uma nova geração de computadores baseados em chips ultrarrápidos. Contudo, a fotônica esbarra em uma restrição física intrínseca: a propagação da luz em meios dielétricos é limitada pela difração [4], não sendo permitido o confinamento da energia eletromagnética em dimensões menores que $\lambda / 2$, onde $\lambda$ é o comprimento de onda no meio. Em frequências 
ópticas, esse limite é da ordem de $1 \mu \mathrm{m}$. Critérios rigorosos de resolução foram estabelecidos por Abbe [5] e Rayleigh [6].

Considerando o que foi dito, tem-se a seguinte situação: a eletrônica permitiu um avanço extraordinário na miniaturização de componentes- da ordem de $\mathrm{nm}$ - porém a velocidade de processamento já se aproxima de um limite físico fundamental devido às interconexões eletrônicas, impedindo novos avanços tecnológicos. Por outro lado, a fotônica pode fornecer taxas de processamento inacessíveis à eletrônica, porém seu baixo nível de miniaturização - da ordem de $\mu \mathrm{m}$ - faz com que a combinação das duas tecnologias em um mesmo circuito seja complicada. O ideal seria ter o melhor dos dois mundos: um circuito com dimensões nanométricas que possa conduzir sinais elétricos e ópticos [7]. Além disso, a transposição da barreira representada pelo limite de difração permite o desenvolvimento de uma nova geração de dispositivos fotônicos como sensores e detectores ultrassensíveis e sistemas de imagem com resolução nanométrica, entre outros [8].

Nesse contexto, o estudo de nanoestruturas metálicas vem recebendo cada vez mais atenção devida à sua habilidade sem precedentes em gerar, manipular e detectar luz em nanoescala [9]. O avanço nos processos de fabricação e caracterização permitiu um estudo sistemático das propriedades singulares oferecidas por nanoestruturas metálicas inseridas em meio dielétrico. A esse novo ramo de estudo deu-se o nome de plasmônica.

O desenvolvimento da plasmônica pode servir como uma ponte entre a fotônica e a eletrônica, levando a uma nova classe de dispositivos. A figura 1.1a mostra diferentes domínios em termos da velocidade de operação e do tamanho do dispositivo, baseados nas propriedades dos semicondutores (eletrônica), dielétricos (fotônica) e metais (plasmônica), sendo que no passado os elementos eram relativamente grandes e lentos. As linhas pontilhadas representam limitações físicas: eletrônica é limitada pelo atraso nas interconexões $(\sim 10 \mathrm{GHz})$ e a fotônica é limitada pela difração $(\sim 1 \mu \mathrm{m})$ [10]. Na figura $1.1 \mathrm{~b}$ é mostrado o número de publicações na área de plasmônica e de cristais fotônicos a cada ano, para efeito de comparação. Verifica-se um número crescente de publicações na área de plasmônica, enquanto que o número de publicações na área de cristais fotônicos apresenta sinais de saturação. A plasmônica vem atraindo cada vez mais interesse acadêmico, e em anos recentes se tornou um dos ramos mais excitantes da fotônica [11]. 
(a)

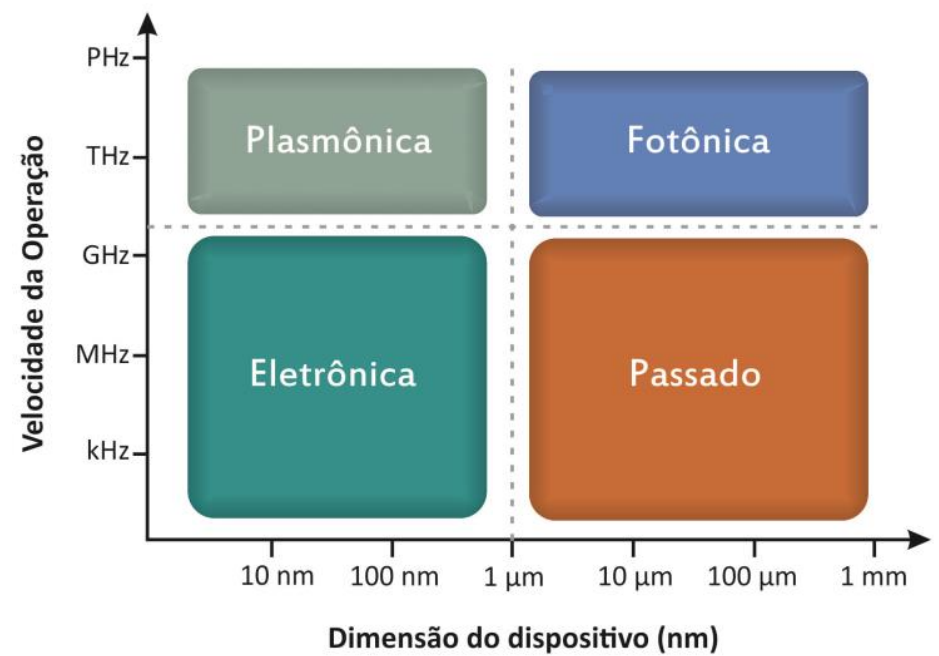

(b)

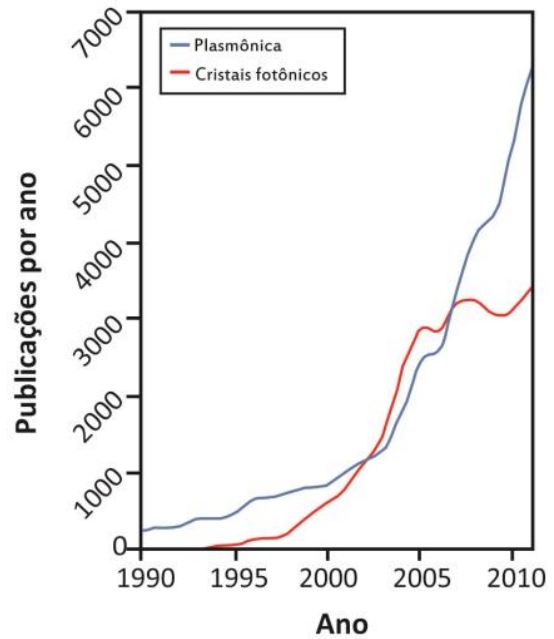

Figura 1.1 - (a) Diferentes domínios em termos de velocidade de operação e dimensão do dispositivo, adaptado de [10] e (b) número anual de publicações na área de plasmônica e de cristais fotônicos para efeito de comparação, adaptado de [11].

A seguir será feita uma introdução histórica e um levantamento bibliográfico geral das principais estruturas plasmônicas passivas, mostrando como o entendimento da óptica na interface metal-dielétrico levou ao desenvolvimento de dispositivos fotônicos mais eficientes, com aplicações em diversas áreas. Também são abordadas as técnicas litográficas mais usadas na fabricação de nanoestruturas metálicas. Como o estudo aqui compreendido trata de mais de um tipo de estrutura plasmônica, as respectivas bibliografias e motivações específicas são apresentadas no início de cada capítulo que trata dos resultados - capítulos 3 , 4 e 5.

\section{2 ÓPTICA NA INTERFACE METAL-DIELÉTRICO: PLASMÔNICA}

O termo plasmonics foi proposto em 2000 pelo grupo do professor Harry Atwater $[12,13]$ e refere-se ao estudo da geração, propagação e detecção das ondas plasmônicas, que são excitações eletrônicas acopladas a um campo eletromagnético, geralmente na interface metal-dielétrico. O acoplamento entre o campo eletromagnético e as cargas livres no metal gera uma onda que se propaga na interface metálica, chamada plasmon poláriton de superfície (surface plasmon polariton - SPP), cujos detalhes teóricos são abordados no capítulo 2. Duas características singulares distinguem as ondas SPP: (1) ela está altamente confinada à interface metal-dielétrico, sendo evanescente tanto no dielétrico como no metal e (2) seu comprimento de onda, $\lambda_{\text {spp }}$, é sempre menor que o comprimento de onda da excitação 
$\lambda$. Essas características permitem o desenvolvimento de estruturas nanométricas operando em frequências ópticas. A luz incidente é convertida em onda SPP, processada abaixo do regime de difração (propagada, focalizada, modulada, etc.) e então reconvertida em luz com propriedades difrativas, como esquematizado na figura 1.2 [14].

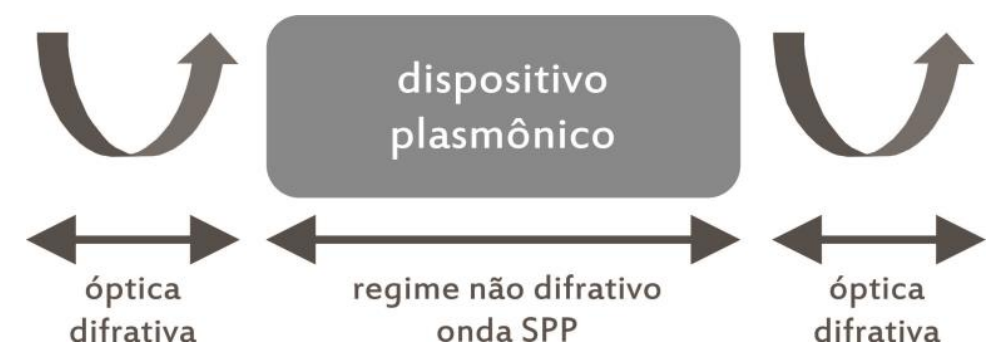

Figura 1.2 - Configuração básica de um dispositivo plasmônico, no qual o regime difrativo é usado para excitar e desacoplar a luz emitida, adaptado de [14].

A história da plasmônica remonta a pelo menos um século. Em 1902, Robert W. Wood notou que, em certos comprimentos de onda bem definidos, ocorre uma variação repentina na intensidade da luz difratada por redes metálicas [15]. Além disso, ele verificou que essas variações surgem apenas quando a onda incidente está polarizada com o campo magnético paralelo às ranhuras da rede. Este efeito ficou conhecido como anomalia de Wood, já que não podia ser explicado pela teoria padrão da difração disponível à época. A primeira interpretação física deste efeito foi proposta por Lord Rayleigh em 1907: a anomalia ocorre em um comprimento de onda no qual a onda espalhada emerge tangencialmente à superfície da rede de difração [16,17]. Porém havia algumas discrepâncias entre os dados de Wood e as previsões de Rayleigh. Em 1936, J. Strong mostrou que o formato e a localização das anomalias dependem não só do período da rede, mas também do metal [18], aspecto não considerado na conjectura de Rayleigh. Em 1941, U. Fano explicou as anomalias em termos da excitação de ondas de superfície, cujo vetor depende da geometria das ranhuras e é paralelo à superfície da rede [19]. David Pines, em 1956, atribui a perda de energia de elétrons rápidos na superfície de metais às suas oscilações coletivas, e introduziu o termo plasmon para se referir ao quantum de energia dessas oscilações [20]. Neste mesmo ano, U. Fano definiu o termo polariton para representar o acoplamento entre o plasmon e o campo eletromagnético de excitação [21]. Em 1957, Ritchie detalhou teoricamente a existência de excitações eletrônicas coletivas na superfície de um metal [22], fato demonstrado experimentalmente em 1959 por Powell e Swan [23,24]. Em 1960, a oscilação coletiva dos elétrons na superfície de um metal foi denominada surface plasmon [25]. Finalmente, em 
1968, H. Raether, E. Kretschmann e A. Otto apresentaram técnicas para a excitação de ondas SPP $[26,27]$.

Apesar de alguns efeitos da onda SPP serem conhecidos a décadas, o campo da plasmônica ressurgiu com grande interesse apenas no final do século XX, com a publicação de três trabalhos pioneiros: (1) a demonstração teórica do guiamento óptico em nanoescala no visível e infravermelho [28], (2) a descoberta que filmes metálicos com buracos nanométricos podem apresentar transmissão extraordinária [29], muito superior à esperada pela teoria de difração e (3) a proposição da lente perfeita, que tem o poder de focar todas as componentes de Fourier de uma imagem 2D, inclusive as componentes evanescentes [30]. A partir desses trabalhos o desenvolvimento de elementos baseados em plasmons de superfície ocorreu de forma acelerada, com aplicações em diversas áreas. O confinamento da luz em nanoescala permitiu o desenvolvimento de sistemas de imagem que operam abaixo do limite de difração [31-33]. Na área de células fotovoltaicas, o confinamento da luz permitiu o aumento da absorção e redução de espessura, proporcionando novas opções de projetos de painéis solares [34,35]. A indústria de biossensores vem desenvolvendo dispositivos baseados em nanopartículas metálicas ou nanoburacos, que atuam como transdutores e convertem pequenas variações no índice de refração local em deslocamento espectral [36,37]. O conhecimento das propriedades quânticas do acoplamento entre o campo eletromagnético e as cargas livres da superfície do metal abre um horizonte para o desenvolvimento de dispositivos como fontes de luz de um único fóton, transistores e circuitos ópticos ultra compactos $[38,39]$. O uso do grafeno permitiu o desenvolvimento de elementos ativos, em que o controle da densidade dos portadores de carga pode fazer a modulação da onda $S P P$ $[40,41]$.

Uma classe especial de dispositivos plasmônicos recentemente reportados são os chamados metamateriais [42-44]. Existem muitas definições e classificações, mas de maneira geral um metamaterial pode ser entendido como um material artificial composto de unidades básicas de dimensões muito menores que o comprimento de uma onda incidente. Deste modo pode-se obter um meio efetivo cuja resposta óptica pode ser sintonizada de acordo com a geometria das unidades básicas, onde ocorrem ressonâncias locais. Metamateriais exibem propriedades não observadas nos materiais constituintes [45]. O desenvolvimento dessa classe de material permitiu o acesso a novos domínios ópticos, possibilitando novas funcionalidades: índice de refração negativo [46-50], materiais com propriedade chiral mais eficientes que cristais ópticos [51,52], manto da invisibilidade (optical cloaking) [53-56], 
entre outros. O domínio desses materiais permite o desenvolvimento de dispositivos integrados que combinam diversas funcionalidades, os chamados metadevices [57].

Dentro da classe de metamateriais uma subclasse se destaca: as metassuperfícies (metasurfaces), que são estruturas planares compostas por um conjunto de ressoadores locais de dimensões e separações muito menores que o comprimento de onda incidente. Variando os parâmetros geométricos dos ressoadores pode-se sintonizar as propriedades da onda espalhada, como amplitude, fase e polarização. Deste modo, as metassuperfícies têm a capacidade de moldar uma frente de onda incidente de modo arbitrário, com resolução abaixo do comprimento de onda, utilizando o princípio de Huygens [58]. Ao contrário de componentes ópticos convencionais onde a mudança na frente de onda ocorre via propagação, nas metassuperfícies a mudança nas propriedades da luz ocorre de maneira abrupta. Vários trabalhos têm sido reportados recentemente explorando essa característica: generalização das leis da reflexão e refração [59,60], realização de lentes ópticas planas [6163], geração de vortex óptico [64], mudança no estado de polarização da luz [65,66], produção de hologramas [67-70], entre outros. Nesses casos, os ressoadores são também conhecidos como nanoantenas ou antenas ópticas [71,72], pois são projetados para eficientemente converter radiação óptica propagando no espaço livre em energia localizada, e vice-versa. Embora o conceito seja análogo às antenas convencionais em micro-ondas e ondas de rádio, nas nanoantenas as propriedades ópticas são dominadas pelas ressonâncias plasmônicas localizadas. As metassuperfícies, representadas por um conjunto de nanoantenas, oferecem uma capacidade única de controlar a luz usando componentes planares [73], facilitando a integração com processos de nanofabricação já estabelecidos.

Após a contextualização e apresentação de uma visão geral das principais estruturas plasmônicas reportadas recentemente será feita uma breve descrição dos principais processos envolvidos na fabricação de nanoestruturas metálicas.

\subsection{FABRICAÇÃo de NANOESTRUTURAS METÁliCAS}

\subsubsection{LITOGRAFIA}

A consolidação da plasmônica como um dos campos mais explorados da fotônica atualmente deve-se, em grande parte, aos avanços nos processos de fabricação e caracterização, que permitiram um estudo sistemático de estruturas metálicas com geometrias bem definidas e com dimensões cada vez mais reduzidas. Durante décadas, a necessidade da 
miniaturização dos transistores requerida pela indústria de semicondutores alavancou investimentos maciços em nanofabricação. Este processo levou ao desenvolvimento de um vasto conjunto de técnicas e equipamentos, que agora são usadas no contexto da plasmônica [74]. O principal processo associado a fabricação de nanoestruturas é a litografia. A palavra litografia vem do grego lithos (pedra) e grafién (escrita), e no contexto da nanofabricação significa um processo no qual um padrão de escala nanométrica, previamente projetado, é transferido para um substrato. Um material amplamente usado para este fim é o fotoresiste.

O fotoresiste é um material polimérico sensível à luz, que tem sua estrutura molecular modificada quando exposto à radiação eletromagnética. As regiões do fotoresiste expostas a um determinado tipo de radiação - geralmente ultravioleta (UV) - têm sua resistência química a um determinado solvente alterada. Existem dois tipos de fotoresistes: positivo, no qual as regiões expostas à radiação eletromagnética se tornam solúveis no revelador; e negativo, no qual regiões expostas se tornam insolúveis ao revelador. Materiais poliméricos a base de polimetilmetacrilato (polymethyl methacrylate - PMMA) são comumente usados. A aplicação desse material sobre um substrato é feita em um equipamento chamado spin coater, no qual o substrato é preso em uma base giratória por meio de um sistema de sucção a vácuo. Com a base giratória em repouso aplica-se uma pequena quantidade de fotoresiste no centro do substrato, e logo em seguida tem início o processo de rotação. Devido à força centrífuga produzida pela rotação da amostra, forma-se uma película de fotoresiste sobre o substrato. A espessura da película depende do tipo de fotoresiste usado e da velocidade de rotação. $\mathrm{Na}$ Fig. 1.3 é mostrado um esquema resumido do processo litográfico usando fotoresiste positivo e negativo, e na Fig. 1.4 é mostrada a relação entre a espessura do filme e a velocidade de rotação para o fotoresiste 495PMMA, tipos A2, A4 e A6 [75].

revelação

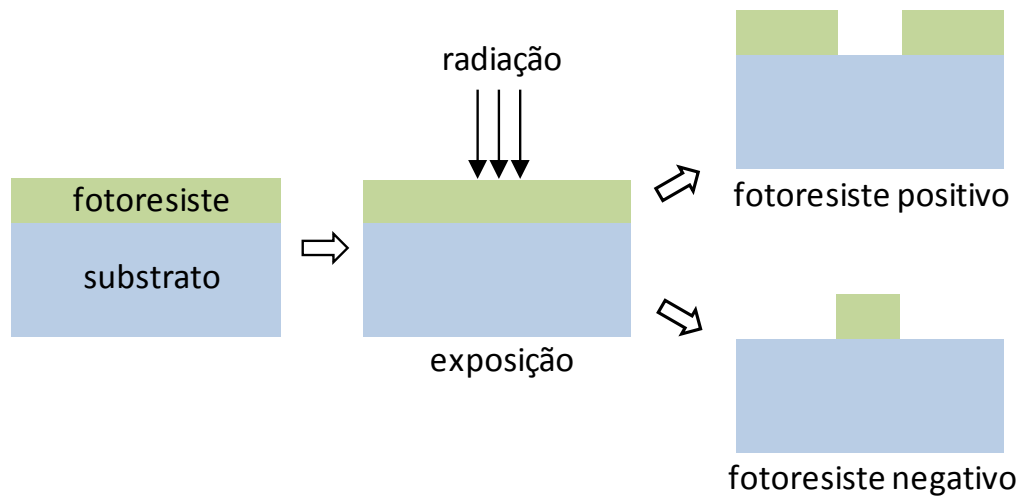

Figura 1.3 - Processo litográfico padrão usando fotoresiste positivo e negativo. Após a revelação tem-se um padrão transferido para o fotoresiste. 


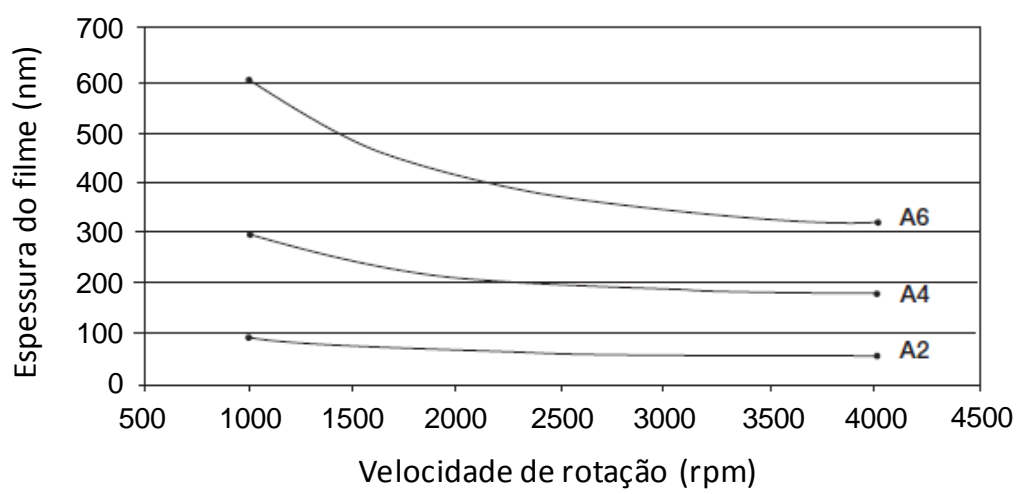

Figura 1.4 - Espessura do filme em função da velocidade de rotação para o fotoresiste comercial 495PMMA, tipos A2, A4 e A6, adaptado de [75].

\subsubsection{LIFT-OFF E ETCHING}

Uma vez obtido o padrão sobre o fotoresiste é necessário transferi-lo para o material metálico de interesse. Duas técnicas adicionais associadas à litografia são usadas na fabricação de nanoestruturas metálicas: lift-off e etching. A seguir é apresentada uma breve introdução sobre ambas as técnicas.

No processo de lift-off o padrão obtido no fotoresiste serve de molde, sobre o qual o metal é depositado. Nesse caso o filme metálico é depositado tanto sobre as áreas contendo o fotoresiste como nas áreas onde o fotoresiste foi removido- nessas regiões o metal é depositado diretamente sobre o substrato. A seguir é realizado o processo de lift-off propriamente dito, que consiste na remoção do fotoresiste, e consequentemente do filme metálico sobre ele depositado. A remoção é normalmente realizada usando banho ultrassônico em uma substância química que dissolve o fotoresiste, sendo mais comum o uso de acetona. Ao final, apenas o metal depositado diretamente sobre o substrato permanece. $\mathrm{O}$ processo de lift-off não é de fácil execução, exigindo experiência do operador. Seu sucesso depende das dimensões da estrutura, do fotoresiste e da técnica litográfica empregada. Em alguns casos, são necessárias duas camadas de fotoresiste para que o processo ocorra com sucesso [76,77]. Observações técnicas a respeito do processo de lift-off podem ser encontradas em [78,79]. Já no processo de etching ocorre a gravação da nanoestrutura diretamente no metal. Nesse caso, o padrão gravado no fotoresiste atua como máscara: nas regiões onde contém o fotoresiste o metal permanece; nas áreas onde não há fotoresiste ocorre a retirada do metal. O processo de etching pode ser químico (por dissolução) ou físico (bombardeio iônico). Detalhes técnicos podem ser encontrados em [80]. A Fig. 1.5 mostra dois caminhos para se fabricar nanoestruturas metálicas, usando (1) lift-off e (2) etching. A 
diferença fundamental é que no processo de lift-off o padrão metálico obtido é o complementar do padrão do fotoresiste, que serve apenas como uma "camada de sacrifício" e atua como máscara. Já no processo de etching o padrão obtido no fotoresiste serve de guia; o mesmo padrão é obtido no filme metálico.
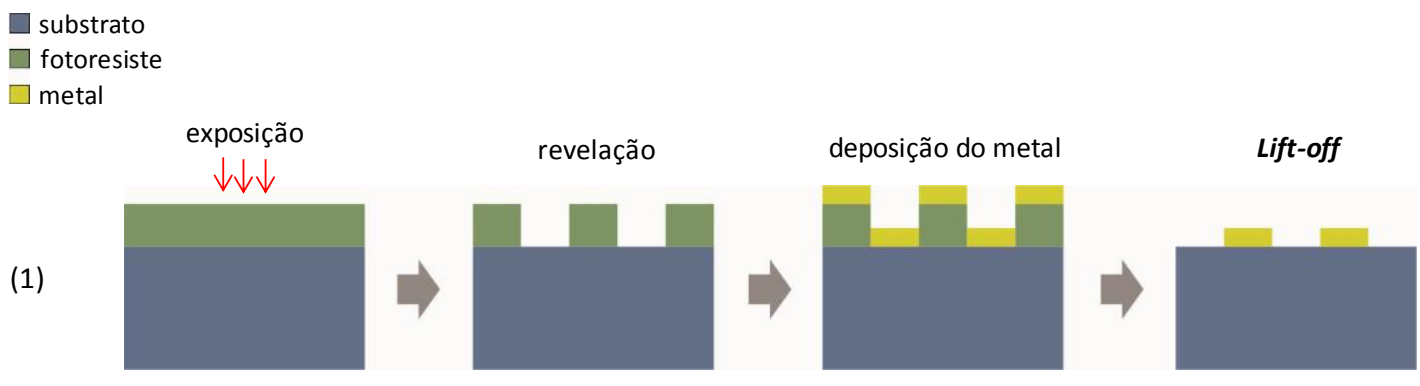

(2)
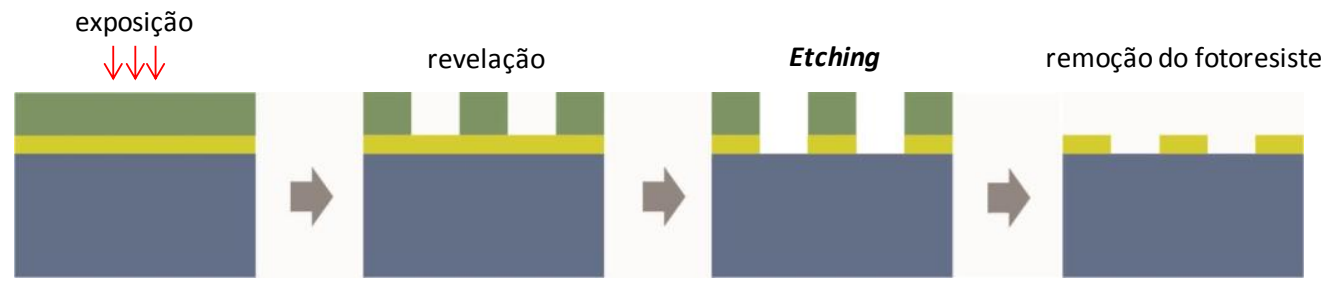

Figura 1.5 - Dois processos de fabricação de nanoestruturas metálicas: (1) usando lift-off e (2) usando etching.

Os processos de lift-off ou etching são subsequentes à gravação do padrão no fotoresiste. A seguir é apresentada uma visão geral das técnicas litográficas e uma breve descrição das técnicas usadas neste trabalho.

\subsubsection{TÉCNICAS LITOGRÁFICAS}

A transferência de um padrão para um substrato pode se dar usando diversas técnicas litográficas, entre as quais litografia interferométrica e óptica, litografia por feixe de elétrons (electron beam lithography - EBL), litografia por feixe de íons focalizados (focused ion beam - FIB), litografia por nanoimpressão, litografia por varredura de sonda, entre outras [82]. Cada uma delas possui vantagens e desvantagens, e a escolha por qual técnica usar depende do tipo de estrutura, dos materiais empregados e do tipo de aplicação. Na Tabela 1.1 é mostrado um resumo das principais técnicas litográficas, com as respectivas dimensões mínimas das estruturas, velocidade de transferência dos padrões e principais aplicações [83]. 
Tabela 1.1 - Características das principais técnicas litográficas usadas na fabricação de nanoestruturas

\begin{tabular}{|c|c|c|c|}
\hline $\begin{array}{l}\text { Técnica } \\
\text { litográfica }\end{array}$ & Tamanho mínimo & $\begin{array}{c}\text { Velocidade de } \\
\text { transferência do } \\
\text { padrão }\end{array}$ & Aplicações \\
\hline $\begin{array}{l}\text { Fotolitografia } \\
\text { (contato e } \\
\text { proximidade) }\end{array}$ & $2-3 \mu \mathrm{m}[84]$ & Muito alta & $\begin{array}{l}\text { Padrões típicos em } \\
\text { laboratório e produção de } \\
\text { dispositivos MEMS }\end{array}$ \\
\hline $\begin{array}{l}\text { Fotolitografia } \\
\text { (projeção) }\end{array}$ & $\begin{array}{l}\text { Dezenas de } \mathrm{nm} \\
(37 \mathrm{~nm}[85])\end{array}$ & $\begin{array}{l}\text { Alta - muito alta } \\
\quad(60-80 \\
\text { wafers/hora })\end{array}$ & $\begin{array}{lr}\begin{array}{l}\text { Produtos } \\
\text { eletrônica }\end{array} & \text { avançada } \\
\text { incluindo } & \text { circuitos } \\
\text { integrados e chips de } \\
\text { computador }\end{array}$ \\
\hline $\begin{array}{l}\text { Litografia por } \\
\text { feixe de } \\
\text { elétrons (EBL) }\end{array}$ & $<5 \mathrm{~nm}[86]$ & Muito baixa & $\begin{array}{l}\text { Máscaras e circuitos } \\
\text { integrados, pesquisa básica } \\
\text { (cristais fotônicos, } \\
\text { nanoantennas) }\end{array}$ \\
\hline $\begin{array}{l}\text { Litografia por } \\
\text { feixe de íons } \\
\text { (FIB) }\end{array}$ & $\begin{array}{c}\sim 20 \mathrm{~nm} \text { com } \\
\text { dimensão lateral } \\
\text { mínima de } 5 \mathrm{~nm} \\
{[85]}\end{array}$ & Muito baixa & $\begin{array}{l}\text { Pesquisa } \\
\text { (nanoburacos, } \\
\text { plasmônicas) }\end{array}$ \\
\hline $\begin{array}{l}\text { Litografia por } \\
\text { nanoimpressão }\end{array}$ & $6-40 \mathrm{~nm}$ [87] & $\begin{array}{c}\text { Alta } \\
\text { (> } 5 \text { wafers/hora) }\end{array}$ & $\begin{array}{l}\text { Biosensores, bioeletrônica, } \\
\text { nanocanais, nanofios }\end{array}$ \\
\hline
\end{tabular}

A seguir será feita uma breve descrição das técnicas usadas na fabricação dos elementos deste trabalho: litografia interferométrica, litografia por nanoimpressão e litografia por feixe de elétrons.

\subsubsection{LITOGRAFIA INTERFEROMÉTRICA}

A litografia interferométrica, também conhecida como litografia holográfica, é baseada na sobreposição de dois feixes de luz coerentes (usualmente na região UV) para gerar um padrão de interferência diretamente sobre um filme de fotoresiste. O padrão de intensidade formado pela interferência de dois feixes de amplitude E que incide sobre o filme de fotoresiste em um ângulo $\pm \theta$ é dado por $I(x)=2|E|^{2}\left[1+\sigma_{p o l} \cos (2 k x \operatorname{sen} \theta)\right]$, onde $k=$ $2 \pi n / \lambda$, sendo $\lambda$ o comprimento de onda, $n$ o índice de refração do meio e $\sigma_{\mathrm{pol}}=[1, \cos (2 \theta)]$ para polarização [TE,TM] [88]. O período do padrão de interferência, e consequentemente da grade produzida no fotoresiste, é dado por $\Lambda=\lambda /(2 n \operatorname{sen} \theta)$. O controle do período é facilmente 
ajustado pela variação do ângulo $\theta$ entre os feixes. A Fig. 1.6 mostra dois arranjos experimentais usados para gerar um padrão de interferência sobre o fotoresiste: (a) baseado na separação de feixe e (b) no espelho de Lloyd, onde o padrão é obtido pela interferência entre a parte do feixe refletida pelo espelho e a parte do feixe que incide diretamente sobre a amostra.

(a)

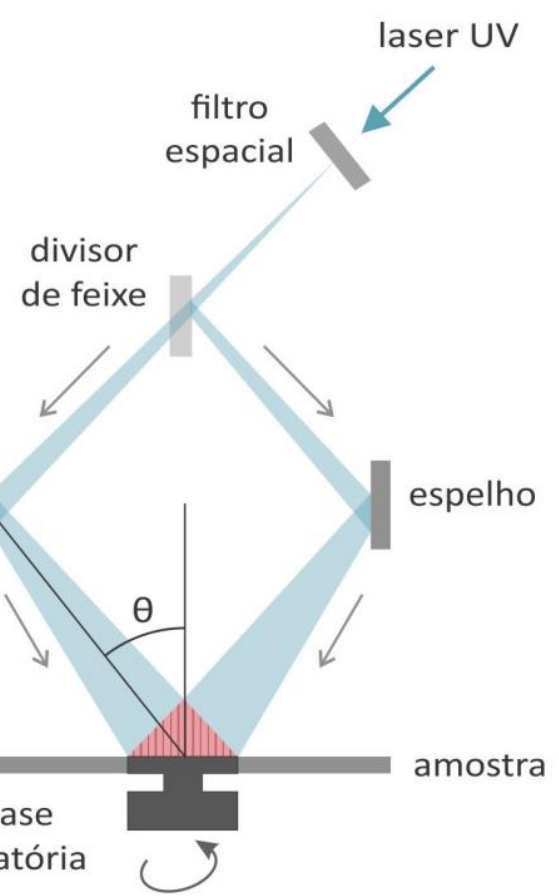

(b)

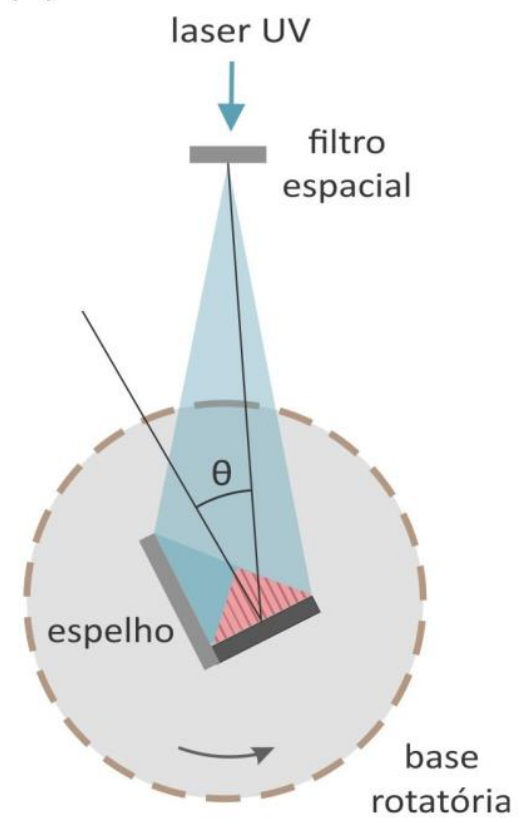

Figura 1.6 - Dois arranjos experimentais usados na fabricação de grades periódicas, adaptado de [89].

A litografia interferométrica é ideal para se produzir estruturas periódicas com resolução nanométrica. Pode-se ainda usar imersão em fluido para aumentar a resolução óptica por um fator correspondente ao seu índice de refração [90]. Para criar padrões em duas dimensões basta expor a amostra com o filme de fotoresiste, fazer uma rotação de $90^{\circ} \mathrm{e}$ expor novamente. Pode-se ainda variar o período entre as exposições, possibilitando a fabricação de dispositivos com atuação em ambas polarizações da luz incidente. Além disso, esta técnica é relativamente de baixo custo, já que não precisa de uma máscara litográfica. $\mathrm{E}$ pode ser usada para criar estruturas periódicas sobre uma área relativamente grande, da ordem de milímetros. A desvantagem é que esta técnica é restrita à estruturas periódicas, não podendo ser usada para transferência de padrões arbitrários (não-périódicos). 


\subsubsection{LITOGRAFIA POR FEIXE DE ELÉTRONS}

A litografia por feixe de elétrons é uma técnica que permite a transferência de um padrão arbitrário sobre um filme de eletroresiste, material que tem sua estrutura molecular modificada quando exposto a um feixe de elétrons. EBL apresenta duas diferenças fundamentais em relação à litografia interferométrica: (1) utiliza um feixe de elétrons altamente focado para modificar as propriedades de solubilidade de um resiste, ao contrário de radiação UV e (2) a criação do padrão é feita ponto a ponto, em vez de uma exposição única. A técnica EBL foi originalmente desenvolvida a partir do microscópio eletrônico de varredura (scanning electron microscope - SEM), ao qual foi adicionado um gerador de padrão e um sistema de controle on/off do feixe [91,92]. Deste modo se tornou possível o controle da varredura do feixe de elétrons sobre a amostra contendo o eletroresiste, possibilitando a fabricação de padrões arbitrários. Na Fig. 1.7 é mostrado um sistema EBL típico [93]. Consiste basicamente de uma câmara de vácuo, de uma fonte de elétrons e de uma coluna na qual o feixe de elétrons é acelerado, focalizado e defletido de acordo com o padrão projetado. O padrão é concebido usando um sistema computacional conhecido como sistema gerador de padrão nanométrico (nanometer pattern generation system - NPGS), que é conectado às bobinas de controle do feixe. EBL permite assim a transferência de um padrão arbitrário sobre o eletroresiste.

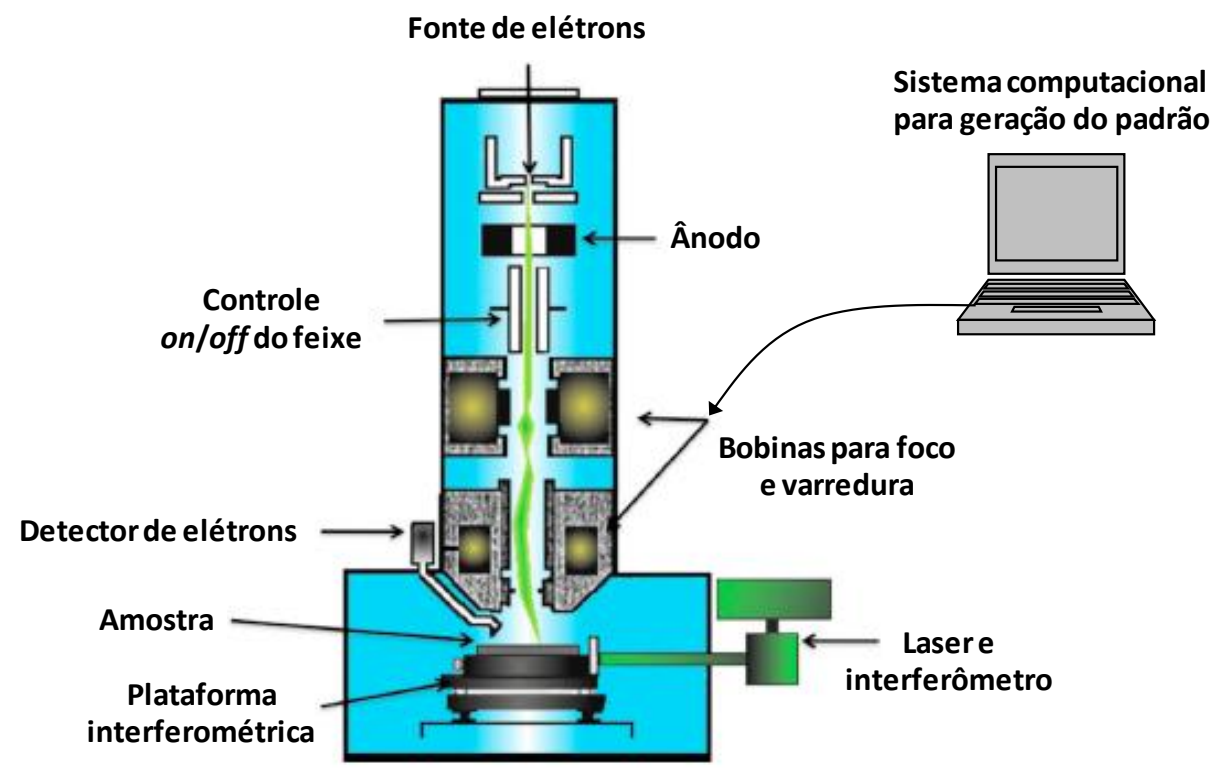

Figura 1.7 - Sistema EBL típico, composto de uma câmara de vácuo, uma fonte de elétrons e uma coluna contendo todos os elementos para o foco e varredura, além do controle on/off do feixe de elétrons. Um sistema computacional automático faz a correlação entre o desenho do padrão e a varredura do feixe. Adaptado de [93]. 
O limite de resolução da técnica EBL e a qualidade do padrão fabricado depende de muitos fatores incluindo qualidade da óptica que controla o feixe de elétrons, tipos de resiste, substrato e revelador, dose e energia do feixe, condições de revelação (tempo e temperatura), entre outros. Além disso, o espalhamento dos elétrons no resiste pode limitar ainda mais a resolução final [94]. Na tabela 1.2 são mostradas algumas vantagens e desvantagens da litografia por feixe de elétrons em comparação com a litografia óptica [95]. Detalhes da técnica EBL podem ser encontrados em [91,92].

Tabela 1.2 - Vantagens e desvantagens da técnica EBL em comparação com litografia óptica, adaptado de [95]

\begin{tabular}{ll}
\hline \multicolumn{1}{c}{ Litografia por feixe de elétrons (EBL) } \\
\hline \multicolumn{1}{c}{$\begin{array}{l}\text { Vantagens } \\
\text { poior resolução comparada à litografia }\end{array}$} & Desvantagens \\
$\begin{array}{l}\text { Padrão é escrito diretamente na amostra } \\
\text { Padrão arbitrário sem uso de máscaras }\end{array}$ & $\begin{array}{l}\text { Sistema mais complexo que fotolitografia } \\
\text { Processo de gravação lento ( horas); não é } \\
\text { eficiente para processos industriais }\end{array}$ \\
\hline
\end{tabular}

\subsubsection{LITOGRAFIA POR NANOIMPRESSÃO}

A técnica de litografia por nanoimpressão foi proposta por Chou et al em 1995 [96]. É um processo relativamente simples, baseado na deformação mecânica: um molde previamente projetado é pressionado contra um filme polimérico. Durante a pressão mecânica aplica-se radiação UV (ou algum processo térmico) para alterar as propriedades de resistência do polímero, em um processo conhecido como cura. Após a separação, o padrão do molde é transferido para o polímero. Para eliminar a camada residual entre o molde e o polímero pode-se usar plasma etching empregando oxigênio [97]. Na Fig. 1.8(a) é mostrado um resumo do processo padrão de fabricação por nanoimpressão [98], e nas Figs. 1.7(b) e 1.7(c) são mostradas exemplos de imagens obtidas por microscopia eletrônica do molde e do padrão fabricado, respectivamente [99]. 
(a)

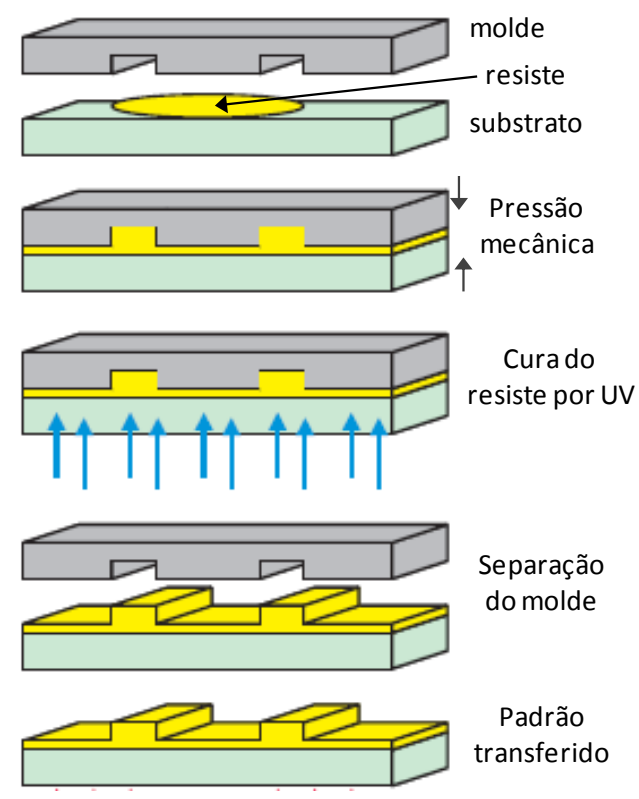

(b)

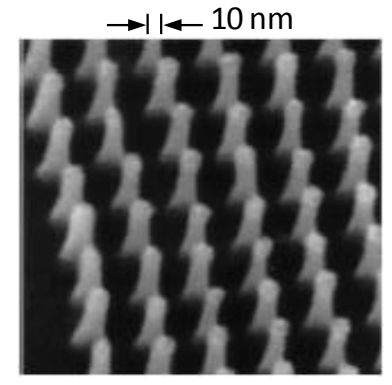

(c)

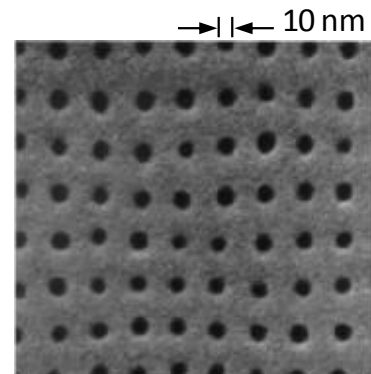

Figura 1.8 - (a) Processo padrão de fabricação litográfica por nanoimpressão. Imagens de microscopia eletrônica de varredura (b) do molde e (c) do padrão obtido no polímero. Adaptado de $[98,99]$.

Comparado com outras técnicas, a litografia por nanoimpressão possui vantagens significativas incluindo fácil execução, alta velocidade de transferência e baixo custo na fabricação de estruturas nanométricas. Por outro lado, necessita de um molde de alta qualidade, usualmente fabricado usando IL ou EBL, seguido do processo de etching. Outra característica é que o molde ou o substrato precisa ser transparente ao UV, para que ocorra a cura do resiste polimérico. Detalhes podem ser encontrados em [99,100].

\subsection{Proposta e OBJetivos da TeSE}

O estabelecimento da integração eletrônica-fotônica representada pelo campo da plasmônica requer o desenvolvimento de estruturas metálicas capazes de controlar a luz em nanoescala de modo eficiente. Nesse contexto, este trabalho tem como objetivo o projeto e a fabricação de nanoestruturas metálicas, visando aplicações em óptica difrativa. A motivação do trabalho inclui a proposta de novas estruturas e a melhora da eficiência de nanoestruturas metálicas já reportadas. A definição de quais tipos de estruturas seriam abordadas nesta tese foi estabelecida levando em conta a real possibilidade de fabricação das nanoestruturas previamente projetadas. A produção destes elementos exige infraestrutura sofisticada, tais como equipamentos litográficos e de caracterização, estrutura de suporte para preparação e manipulação das amostras, sala limpa, etc, não disponível no departamento de Engenharia 
Elétrica - USP São Carlos. Por esse motivo foram estabelecidas colaborações com outras instituições, cuja infraestrutura e técnicas de fabricação disponíveis orientaram o projeto das estruturas desenvolvidas nesse trabalho.

\subsection{Metodologia}

Inicialmente foi realizado um levantamento das principais estruturas reportadas na literatura. Este levantamento incluiu o aprendizado do software utilizado para o projeto e simulação das estruturas, e criou uma base-referência para proposição de novos dispositivos que possam apresentar melhor desempenho em comparação às estruturas previamente reportadas. A execução do objetivo é dividida em três partes: analise numérica, fabricação e caracterização.

\subsubsection{ANÁLISE NUMÉRICA}

A análise numérica foi realizada usando o software comercial Comsol 3.5a [101], baseado no método de elementos finitos (Finite Element Method, FEM). A simulação no software pode ser resumida em três passos: (1) desenho da estrutura, (2) definição dos materiais que a compõem, usando os respectivos parâmetros ópticos e (3) definição das condições de contorno na excitação, deteç̧ão e nos limites da janela computacional. Em seguida define-se a discretização espacial e inicia-se a simulação propriamente dita. Ao final, o software permite verificar parâmetros que caracterizam a resposta do dispositivo como transmissão, reflexão, perfil dos campos, etc., usando uma interface bastante amigável. Como ferramenta auxiliar para verificação da resposta e comparação entre os resultados foi também usado o software comercial High Frequency Electromagnetic Field Simulation - ANSYS HFSS [102]. A vantagem desta ferramenta é que ela permite a parametrização de alguma dimensão geométrica, facilitando a análise dos resultados.

\subsubsection{FABRICAÇÃo E CARACTERIZAÇão}

Toda a fabricação e caracterização compreendida neste trabalho foi realizada em duas instituições de pesquisa no exterior: (1) visita de 23 dias ao VTT - Technical Research Centre of Finland, na cidade de Oulu, na Finlândia e (2) doutorado sanduiche na University of Texas at Arlington (UTA), nos Estados Unidos, pelo período de 12 meses. A visita ao VTT possibilitou o contato inicial com a técnica de litografia por nanoimpressão. Mas foi 
principalmente durante o estágio na UTA que o autor teve contato mais próximo com técnicas de nanofabricação, incluindo litografia interferométrica e litografia por feixe de elétrons. Além disso, pôde participar da maior parte das etapas de fabricação, preparação das amostras, deposição de resiste, revelação e caracterização dos dispositivos fabricados. Durante sua colaboração com a instituição, além do aprendizado das técnicas de fabricação já citadas, o autor teve contato com diversos equipamentos usados na caracterização, incluindo microscópio eletrônico de varredura, microscópio de força atômica, perfilômetro, elipsômetro, entre outros.

\subsection{CONTRIBUIÇÕES DO TRABALHO}

A principal contribuição até o momento é o projeto/fabricação de filtros ópticos operando no azul, verde e vermelho, e que possuem largura de banda ( 20 nm) consideravelmente menor que os $\sim 60 \mathrm{~nm}$ previamente reportados na literatura científica considerando estrutura semelhante. Além disso, foi possível mostrar as cores puras associadas à ressonância de modo guiado. Os filtros foram fabricados usando litografia interferométrica sobre uma área relativamente grande, da ordem de $0.5 \mathrm{~cm}$.

Além da fabricação dos filtros, foi apresentada uma proposta para reduzir os lóbulos laterais de uma lente metálica do tipo zonas de Fresnel pela simples integração de um filme metálico. Os resultados numéricos permitiram identificar uma estrutura ressonante do tipo Fabry-Perot que pode reduzir os lóbulos laterais por um fator 3.0 na polarização TM e 4.8 na polarização TE, embora com considerável perda de eficiência devido à introdução do filme metálico.

Por fim, foi possível iniciar o estudo de ressoadores plasmônicos como célula para dispositivo baseado em metassuperfície. Estudos numéricos permitiram propor uma geometria a ser usada como elemento de um holograma binário no regime visível. O início da fabricação e alguns desafios envolvidos neste processo são apresentados no Capítulo 5.

\subsection{ORGANIZAÇÃO DO TEXTO}

O presente texto está organizado da seguinte forma. No capítulo 2 é feita uma introdução teórica dos processos envolvidos na plasmônica. São mostradas as principais relações matemáticas para o entendimento da propagação da onda $S P P$ na interface 
metal/dielétrico e em guias de 3 camadas do tipo metal-isolante-metal. Também são mostradas as constantes ópticas dos metais usados neste trabalho e materiais condutores alternativos aos metais tradicionais. Por fim, é apresentada uma introdução à ressonância plasmônica localizada.

O capítulo 3 é dedicado ao projeto, fabricação e caracterização de filtros ópticos no azul, verde e vermelho, baseados em ressonância de modo guiado e ressonância plasmônica.

No capítulo 4 é feito o estudo de uma lente tipo zonas de Fresnel integrada com um filme metálico. É apresentada a análise numérica da estrutura e a fabricação usando litografia por nanoimpressão.

No capítulo 5 é feita a análise numérica de uma célula projetada como elemento de um holograma plasmônico binário. É descrito o início da fabricação do elemento usando litografia por feixe de elétrons.

Por fim, o capítulo 6 é dedicado às considerações finais e sugestão de estudos para as próximas etapas.

\subsection{Trabalhos PUbLiCADOS}

Até o presente momento foram publicados três trabalhos, um em revista internacional de considerável fator de impacto (3.488) e dois em congressos internacionais organizados pela renomada Optical Society of America (OSA), destacando assim contribuições originais desta tese. Há ainda a intenção de submeter mais um trabalho que foi explorado nesta tese para um periódico internacional, cuja redação encontra-se em andamento no momento da elaboração deste texto.

- D. B. Mazulquim, K. J. Lee, J. W. Yoon, L. V. Muniz, B.-H. V. Borges, L. G. Neto, and R. Magnusson, "Efficient band-pass color filters enabled by resonant modes and plasmons near the Rayleigh anomaly,” Opt. Express 22, 30843-30851 (2014).

- D. Mazulquim, K. J. Lee, L. V. Muniz, B. V. Borges, L. G. Neto, and R. Magnusson, "High Selectivity Plasmonic Color Filter Using a Single Dielectric Film Layer", in Frontiers in Optics 2014, OSA Technical Digest (online), Optical Society of America, 2014, paper FTh3D.7. http://www.opticsinfobase.org/abstract.cfm?URI=FiO-2014FTh3D.7 
- D. Mazulquim, L. V. Muniz, B. Borges, and L. Neto, "Numerical analysis of gold nanorods as element of binary metasurface hologram for visible light", in Latin America Optics and Photonics Conference, OSA Technical Digest (online), Optical Society of America, 2014, paper LM4A.35. http://www.opticsinfobase.org/abstract.cfm?URI=LAOP-2014-LM4A.35 


\section{ASPECTOS TEÓRICOS}

Neste capítulo são abordados os principais aspectos teóricos necessários ao entendimento dos processos envolvidos na plasmônica, e em particular nas estruturas propostas nesse trabalho. Na primeira parte é discutida a resposta óptica dos metais convencionais. Em seguida é apresentada a definição da onda SPP e as principais equações necessárias para o entendimento de suas propriedades. Também são mostradas as equações para o guia metal-isolante-metal e as configurações usadas para excitar plasmons de superfície. Por fim, é apresentada uma introdução à ressonância plasmônica localizada.

\subsection{RESPOSTA ÓPTICA DOS METAIS}

A necessidade de um meio condutor para propagação da onda SPP faz com que os metais convencionais surjam como escolha natural de material plasmônico. De acordo com a Teoria de Bandas, os materiais condutores possuem as bandas de valência e de condução sobrepostas [103]. Isso faz com que os elétrons nas camadas mais externas possam acessar a banda de condução pela simples agitação térmica, ficando assim suscetíveis a campos elétricos que os fazem se deslocar pelo material. Pode-se considerar o comportamento dos metais como um plasma: um mar de elétrons livres que podem se mover sobre íons positivos quase estacionários (na aproximação de massa infinita), em um sistema com carga total nula. Se os elétrons são deslocados por um campo eletromagnético incidente ocorre separação de cargas; surge então um campo elétrico cuja direção tende a restaurar os elétrons à posição inicial de neutralidade, fazendo com que ocorra um movimento de oscilação eletrônica em torno da posição de equilíbrio. Essa oscilação eletrônica tem uma frequência característica conhecida como frequência de plasma $\omega_{p}$, dada por [104]

$$
\omega_{p}=\sqrt{\frac{n_{e} e^{2}}{m \varepsilon_{0}}}
$$

onde $n_{e}$ é a densidade eletrônica, $e$ é a carga do elétron, $m$ é sua massa efetiva e $\varepsilon_{0}$ é a constante de permissividade do vácuo. Os elétrons livres atuam como uma barreira ao campo elétrico incidente: se a frequência do campo incidente é inferior à frequência de plasma a luz 
incidente é fortemente refletida; se a frequência do campo incidente é superior à frequência de plasma a luz incidente é transmitida, pois os elétrons não conseguem responder à excitação com velocidade suficientemente alta. Nos metais convencionais, a frequência de plasma está na região do ultravioleta [104].

A resposta de um material a um campo eletromagnético incidente possui duas características: (1) depende da frequência $\omega$ do campo incidente e (2) é definida por uma função complexa. É expressada pelo índice de refração $\tilde{n}(\omega)=n(\omega)+i k(\omega)$ ou pela permissividade relativa do meio $\varepsilon(\omega)=\varepsilon_{\text {real }}(\omega)+\mathrm{i} \varepsilon_{\text {imag }}(\omega)$, onde a parte real descreve a polarização por um campo elétrico incidente e a parte imaginária está associada às perdas no material. $\mathrm{O}$ índice de refração e a permissividade são expressões equivalentes, relacionadas de acordo com as equações 2.2a-2.2d [105], e definem propriedades ópticas dos materiais como transmissão, reflexão, propagação e absorção.

$$
\begin{aligned}
& \varepsilon_{\text {real }}=n^{2}-k^{2} \\
& \varepsilon_{\text {imag }}=2 n k \\
& n^{2}=\frac{\varepsilon_{\text {real }}}{2}+\frac{1}{2} \sqrt{\varepsilon_{\text {real }}^{2}+\varepsilon_{\text {imag }}^{2}} \\
& k=\frac{\varepsilon_{\text {imag }}}{2 n}
\end{aligned}
$$

Diversos modelos foram propostos com o objetivo de obter expressões analíticas para a permissividade em função da frequência de excitação. No modelo de Drude os elétrons são considerados livres para se mover sob ação de um campo eletromagnético incidente e são amortecidos pelas sucessivas colisões. O modelo de Drude-Lorentz de multiosciladores foi além e levou em conta as transições interbandas, adicionando termos referentes aos elétrons que sofrem força restauradora. As equações 2.3a [106] e 2.3b [107] mostram a permissividade relativa em função da frequência de excitação $\omega$, obtida pelo modelo de Drude e de Drude-Lorentz, respectivamente. $\gamma$ é o coeficiente de amortecimento, $\omega_{0}$ é a frequência associada a força restauradora, $p$ é o fator peso e $N$ é o número de osciladores.

$$
\varepsilon(\omega)=1-\frac{\omega_{p}^{2}}{\omega^{2}+i \gamma \omega}
$$




$$
\varepsilon(\omega)=1-\frac{p_{0} \omega_{p}^{2}}{\omega^{2}+i \gamma_{0} \omega}+\sum_{j=1}^{N} \frac{p_{j} \omega_{p}^{2}}{\omega_{0 j}^{2}-\omega^{2}-i \gamma_{j} \omega}
$$

A permissividade dos metais empregados neste trabalho foi obtida diretamente pela interpolação dos dados experimentais, sem fazer uso do modelo de Drude-Lorentz. A Fig. 2.1 mostra a parte real e imaginária da permissividade do ouro e do alumínio em função do comprimento de onda, dados de Johnson \& Christy e Palik [108,109]. A linha preta mostra a interpolação usada na análise numérica, entre 400 e 1500 nm.
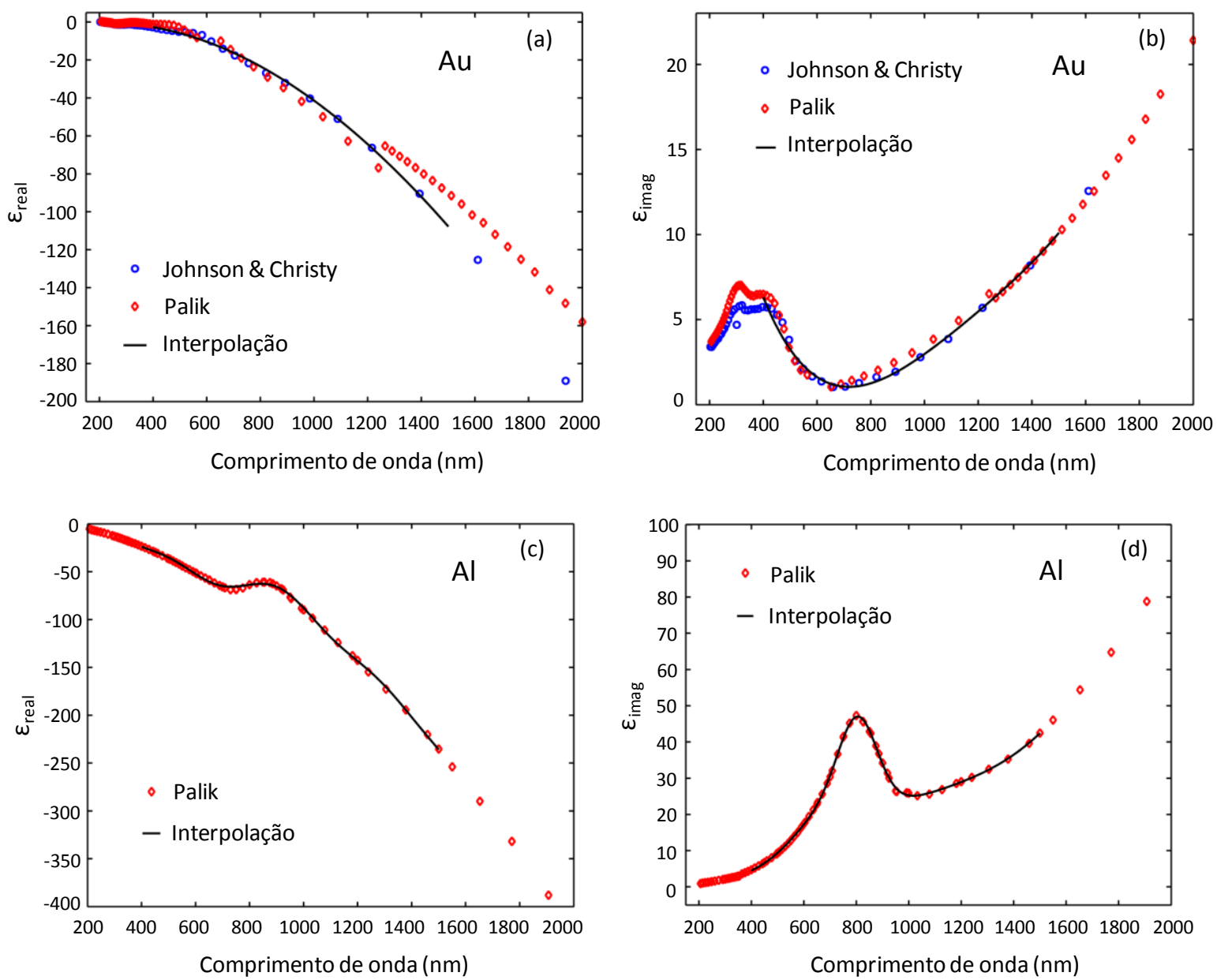

Figura 2.1 - Constantes ópticas dos metais usados neste trabalho. Parte real $(a, c)$ e imaginária $(b, d)$ da permissividade do (ouro, alumínio). Círculos azuis e vermelhos representam os dados experimentais de Johnson \& Christy [108] e Palik [109], respectivamente. As linhas pretas mostram a interpolação usada nas análises numéricas. 
Metais possuem altas perdas em frequências ópticas associadas em parte às transições eletrônicas interbandas, especialmente na região visível e ultravioleta, que podem inviabilizar dispositivos práticos. Além disso, apresentam limitações como incompatibilidade com processos CMOS (metais nobres) e degradação química em ambiente atmosférico (prata, cobre e alumínio). O desenvolvimento de novos materiais plasmônicos, portanto, representa um grande avanço tecnológico: perdas reduzidas, possibilidade de sintonizar a resposta óptica e compatibilidade com processos de fabricação já estabelecidos [110,111,112]. Recentemente vários tipos de materiais plasmônicos alternativos têm sido reportados, incluindo óxidos, nitretos [113] e cerâmicas [114].

\subsection{PLASMON POLARITON DE SUPERFÍCIE}

Conforme visto, a frequência de plasma define a frequência da oscilação natural dos elétrons livres de um metal. O quantum de energia associado a essa oscilação recebe o nome de plasmon. Quando a oscilação eletrônica acoplada a um campo eletromagnético se propaga na interface entre um condutor e um dielétrico tem-se o denominado plasmon poláriton de superfície. Uma definição particularmente interessante foi dada por Jean-Jacques Greffet [115]: "do ponto de vista da eletrodinâmica, plasmons de superfície são um caso particular de ondas de superfície; do ponto de vista da óptica, plasmons de superfície são modos em uma interface; e do ponto de vista da física do estado sólido, plasmon é uma excitação coletiva de elétrons". Na Fig. 2.2 é mostrada a relação entre a distribuição de cargas na superfície do metal e o campo elétrico, que decai exponencialmente a partir da interface. A oscilação eletrônica acoplada ao campo eletromagnético se propaga como um "pacote" na direção $x$.

A descrição das ondas SPP é feita usando eletromagnetismo clássico, apesar de o termo plasmon referir-se ao quantum de energia da oscilação eletrônica. A alta densidade de elétrons livres em um metal faz com que a separação entre os níveis de energia seja muito menor que a excitação térmica $k_{B} T$, onde $k_{B}$ é a constante de Boltzmann e $T$ é a temperatura ambiente. 


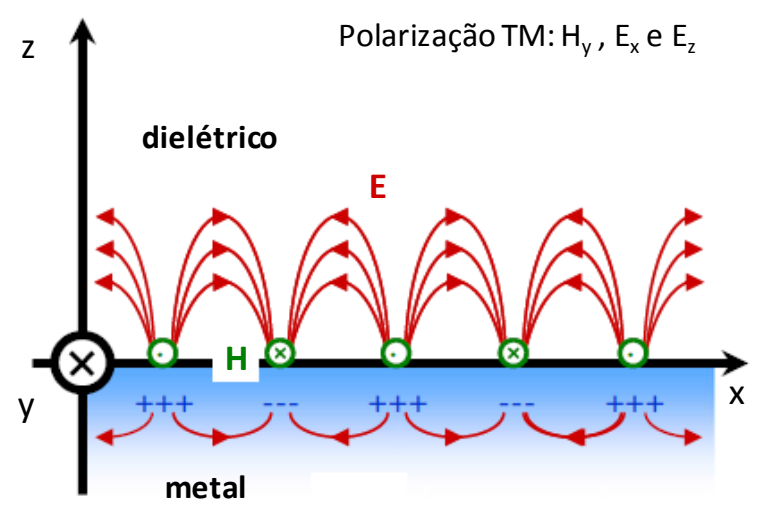

Figura 2.2 - Visualização da onda SPP, resultado do acoplamento entre o campo eletromagnético e as cargas livres na superfície do metal, adaptado de [116]. Na polarização TM tem-se as componentes de campo eletromagnético $H_{y}, E_{x}$ e $E_{z}$.

A seguir é apresentado um resumo das principais equações usadas na descrição das propriedades associadas à onda SPP, cujas derivações podem ser encontradas em $[105,115]$. A equação de onda para os campos eletromagnéticos é obtida pela combinação das equações de Maxwell, na ausência de cargas externas. Considerando campos com dependência temporal da forma $e^{-i \omega t}$ obtém-se a conhecida equação de Helmholtz:

$$
\nabla^{2} \boldsymbol{E}+k_{0}{ }^{2} \varepsilon \boldsymbol{E}=0 \quad, \quad \nabla^{2} \boldsymbol{H}+{k_{0}}^{2} \varepsilon \boldsymbol{H}=0
$$

onde $k_{0}=\omega / c$ é o vetor de onda e $\varepsilon$ a permissividade relativa do meio. A solução para os campos eletromagnéticos que se propagam na direção $x$ são da forma $\mathbf{E}(x, z)=\mathbf{E}(z) e^{i \beta x} \mathrm{e}$ $\mathbf{H}(x, z)=\mathbf{H}(z) e^{i \beta x}$, onde $\beta$ é a constante de propagação. Substituindo a expressão dos campos na equação de Helmholtz tem-se

$$
\frac{\partial^{2} E}{\partial z^{2}}+\left[{k_{0}}^{2} \varepsilon-\beta^{2}\right] \boldsymbol{E}=0 \quad, \quad \frac{\partial^{2} H}{\partial z^{2}}+\left[{k_{0}}^{2} \varepsilon-\beta^{2}\right] \boldsymbol{H}=0
$$

A onda SPP é suportada somente na polarização TM, uma vez que para ocorrer acúmulo de carga na superfície do metal é necessário uma componente de campo elétrico perpendicular à interface. De acordo com a geometria definida na Fig. 2.2 as componentes de campo eletromagnético são $H_{y}, E_{x}$ e $E_{z}$. Assim, as soluções para os campos que satisfazem as equações de Maxwell e se propagam na direção $x$, decaindo exponencialmente a partir da interface na região do dielétrico $(z>0)$ são dados por [105] 


$$
\begin{aligned}
& H_{y}(z)=A_{1} e^{-k_{d} z} e^{i \beta x} \\
& E_{x}(z)=i A_{1} \frac{k_{d}}{\omega \varepsilon_{0} \varepsilon_{d}} e^{-k_{d} z} e^{i \beta x} \\
& E_{z}(z)=-A_{1} \frac{\beta}{\omega \varepsilon_{0} \varepsilon_{d}} e^{-k_{d} z} e^{i \beta x}
\end{aligned}
$$

e os campos na região do metal $(z<0)$ são dados por [105]

$$
\begin{aligned}
& H_{y}(z)=A_{2} e^{k_{m} z} e^{i \beta x} \\
& E_{x}(z)=-i A_{2} \frac{k_{m}}{\omega \varepsilon_{0} \varepsilon_{m}} e^{k_{m} z} e^{i \beta x} \\
& E_{z}(z)=-A_{1} \frac{\beta}{\omega \varepsilon_{0} \varepsilon_{m}} e^{k_{m} z} e^{i \beta x}
\end{aligned}
$$

onde $\mathrm{A}_{1}$ e $\mathrm{A}_{2}$ são constantes, $k_{m}$ e $k_{d}$ representam a componente do vetor de onda perpendicular a interface no metal e no dielétrico, respectivamente, e $\varepsilon_{d}$ e $\varepsilon_{m}$ representam a permissividade relativa do dielétrico e do metal, respectivamente De acordo com as equações (2.6c) e (2.7c) a penetração do campo $E_{z}$ no metal $\left(\delta_{m}\right)$ e no dielétrico $\left(\delta_{d}\right)$ é dada pelo inverso de suas respectivas constantes de propagação. Na Fig. 2.3 pode-se verificar o comportamento da componente de campo $E_{z}$, evanescente tanto no metal como no dielétrico. As constantes $\delta_{m}$ e $\delta_{d}$, conhecidas como profundidade de penetração, representam a distância onde o campo elétrico é atenuado por 1/e a partir da interface, quantificando assim o confinamento da onda eletromagnética. Devido à abundância de cargas livres, o campo elétrico tem uma menor penetração no metal comparado ao dielétrico.

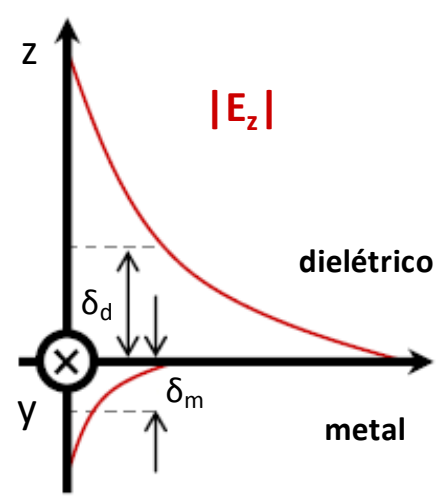

Figura 2.3 - Campo evanescente $|\mathrm{Ez}|$ da onda SPP, adaptado de [116]. 
Aplicando as condições de contorno nas componentes de campo $H_{y}$ e $E_{x}$ na interface metal/dielétrico $(z=0)$ tem-se que

$$
\frac{k_{d}}{k_{m}}=-\frac{\varepsilon_{d}}{\varepsilon_{m}}
$$

A equação 2.8 mostra que apenas haverá onda SPP se houver troca de sinal da permissividade entre dois meios. Isso ocorre justamente na interface metal/dielétrico, pois os metais apresentam $\operatorname{Re}\left[\varepsilon_{m}\right]<0$ em frequências abaixo da frequência de plasma. As expressões de $H_{y}$, equações $2.6 a$ e $2.7 a$, devem satisfazer a equação de 2.5 , portanto

$$
\begin{aligned}
& k_{d}{ }^{2}=\beta^{2}-k_{0}{ }^{2} \varepsilon_{d} \\
& k_{m}{ }^{2}=\beta^{2}-k_{0}{ }^{2} \varepsilon_{m}
\end{aligned}
$$

Substituindo as expressões de $k_{d}$ e $k_{m}$ na equação 2.8 encontra-se a relação de dispersão das ondas SPP propagando em uma interface metal/dielétrico :

$$
\beta=k_{0} \sqrt{\frac{\varepsilon_{m} \varepsilon_{d}}{\varepsilon_{m}+\varepsilon_{d}}}
$$

A constante de propagação da onda SPP é complexa, uma vez que a permissividade do metal $\varepsilon_{m}$ também é complexa. Assim, o campo eletromagnético é atenuado à medida que se propaga na interface. A distância de propagação da onda SPP $(L)$ é definida como a distância para o qual a intensidade do campo é atenuada por $1 / e$, ou seja, $L_{s p p}=1 / 2 \operatorname{Im}[\beta]$. O comprimento de onda SPP é dado por $\lambda_{s p p}=2 \pi / \operatorname{Re}[\beta]$. A tabela 2.1 mostra os valores calculados de $\lambda_{s p p}, \delta_{m}, \delta_{d}$ e $L_{s p p}$ para três comprimentos de onda de excitação $\lambda_{0}$, considerando uma interface ouro/vidro $\left(\varepsilon_{d}=2.25\right)$. A permissividade do ouro foi obtida pela interpolação dos dados experimentais [108]. Verifica-se que quanto maior o confinamento de campo (menor $\delta_{m}+\delta_{d}$ ), menor a distância propagada. 
Tabela 2.1 - Valores típicos de $\lambda_{\text {spp }}, \delta_{m}, \delta_{d}$ e $L_{\text {spp }}$ para uma interface ouro/vidro

\begin{tabular}{cccccc}
\hline$\lambda_{0}(\mathrm{~nm})$ & $\boldsymbol{\varepsilon}_{\mathrm{m}}$ & $\boldsymbol{\lambda}_{\text {spp }}(\mathrm{nm})$ & $\boldsymbol{\delta}_{\mathrm{m}}(\mathrm{nm})$ & $\boldsymbol{\delta}_{\mathrm{d}}(\mathrm{nm})$ & $\mathrm{L}_{\text {spp }}(\mu \mathrm{m})$ \\
\hline 633 & $-12.17+1.34 \mathrm{i}$ & 382 & 26 & 142 & 2.47 \\
830 & $-25.75+1.43 \mathrm{i}$ & 529 & 25 & 285 & 15.93 \\
1064 & $-48.27+3.73 \mathrm{i}$ & 693 & 24 & 512 & 29.34 \\
\hline
\end{tabular}

Para obter a dispersão em função da frequência de excitação $\omega$ pode-se considerar o modelo de Drude para a permissividade do metal, $\operatorname{com} \gamma=0$. Substituindo a equação 2.3a na equação 2.10 e considerando $\varepsilon_{d}=1$ tem-se [116]

$$
\omega=\sqrt{\frac{\omega_{p}^{2}}{2}+\left(c k_{x}\right)^{2}-\left[\frac{\omega_{p}^{4}}{4}+\left(c k_{x}\right)^{4}\right]^{1 / 2}}
$$

onde $k_{x}$ é o vetor de propagação da onda SPP. Analisando os limites, tem-se que quando $c k_{x}$ é muito menor que $\omega_{p}, \omega \approx c k_{x}$, que é a relação de dispersão de uma onda se propagando em um meio homogêneo. Quando $c k_{x}$ é muito maior que $\omega_{p}, \omega \approx \omega_{p} / \sqrt{2}$. Na figura 2.4 são mostrado as curvas de dispersão para o ar, para um meio dielétrico e para a onda SPP em uma interface metal/ar, considerando modelo de Drude com $\gamma=0$ e $\varepsilon_{d}=1$.

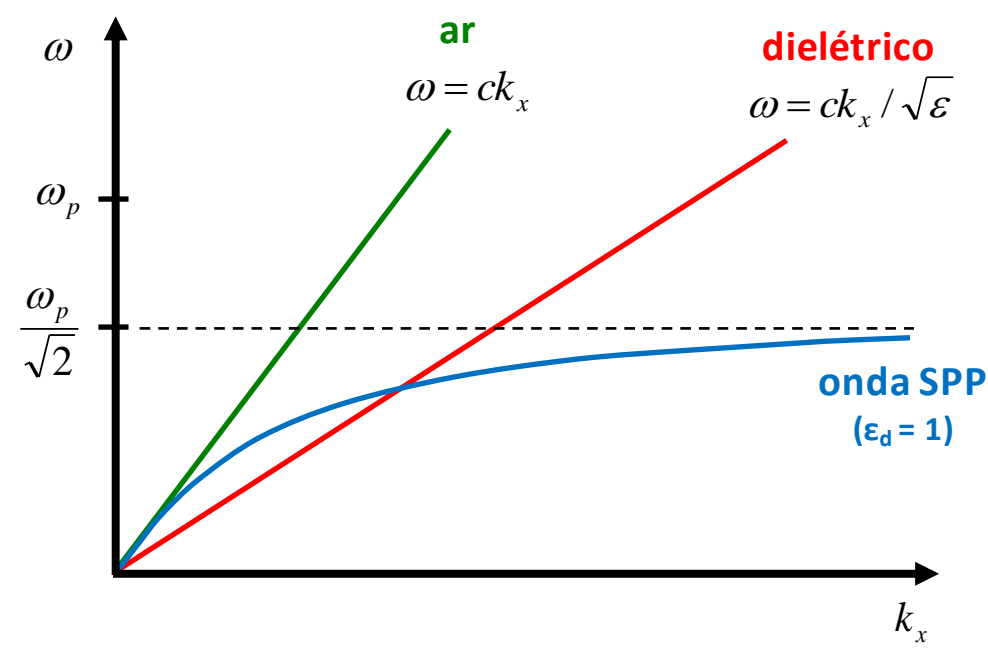

Figura 2.4 - Curvas de dispersão para o ar, meio dielétrico $\left(\varepsilon_{\mathrm{d}}>1\right)$ e onda SPP na interface metal/ar, adaptado de [116]. 
A constante de propagação da onda SPP é sempre maior que a constante de propagação no ar, fazendo com que seja impossível excitar plasmons de superfície diretamente do espaço livre. É necessário, portanto, algum método que promova um casamento vetorial entre a excitação e a constante de propagação da onda SPP.

\subsection{GUIA METAL-DIELÉTRICO-METAL}

No estudo de lentes plasmônicas é comum deparar-se com estruturas que se baseiam em um guia de três camadas do tipo metal-isolante-metal (MIM). Na Fig. 2.5 é representada a geometria básica do guia MIM. Este guia consiste em uma camada dielétrica (região I), de espessura $2 a$, entre dois metais semi-infinitos (na prática, significa que a espessura do metal é suficientemente grande comparada com a profundidade de penetração do campo eletromagnético). Quando a separação $2 a$ entre os metais é comparável com a profundidade de penetração do campo no dielétrico para uma interface simples $\left(\delta_{d}\right)$, as interações entre as ondas SPP nas duas interfaces produz um modo acoplado que se propaga no guia.

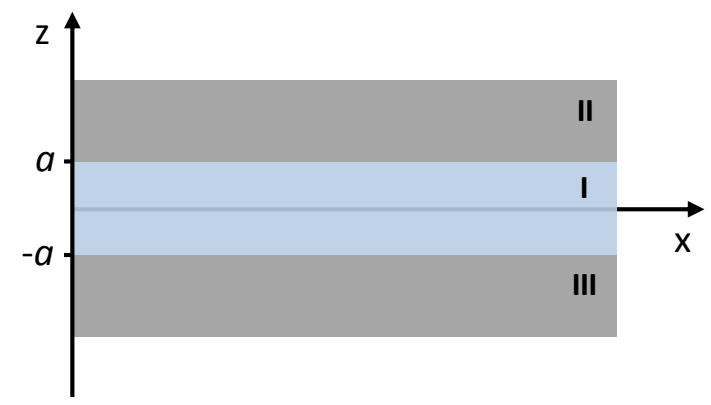

Figura 2.5 - Geometria do guia metal-isolante-metal (MIM). (I) dielétrico e (II) e (III) metal.

A análise desta estrutura é feita de maneira semelhante à interface simples metal/dielétrico. Para efeito de simplificação considera-se o mesmo metal nas regiões II e III. As soluções para os campos que satisfazem as equações de Maxwell e se propagam na direção $x$, decaindo exponencialmente no metal $(z<-a e z>a)$ são dados por [105]

$$
\begin{aligned}
& H_{y}(z)=A e^{-k_{m} z} e^{i \beta x} \\
& E_{x}(z)=i A \frac{k_{m}}{\omega \varepsilon_{0} \varepsilon_{m}} e^{-k_{m} z} e^{i \beta x} \quad(z>a) \\
& E_{z}(z)=-A \frac{\beta}{\omega \varepsilon_{0} \varepsilon_{m}} e^{-k_{m} z} e^{i \beta x}
\end{aligned}
$$




$$
\begin{aligned}
& H_{y}(z)=B e^{k_{m} z} e^{i \beta x} \\
& E_{x}(z)=-i B \frac{k_{m}}{\omega \varepsilon_{0} \varepsilon_{m}} e^{k_{m} z} e^{i \beta x} \quad(z<-a) \\
& E_{z}(z)=-B \frac{\beta}{\omega \varepsilon_{0} \varepsilon_{m}} e^{k_{m} z} e^{i \beta x}
\end{aligned}
$$

onde A e B são constantes. Na região do dielétrico (I), a solução é uma combinação linear da forma [105]

$$
\begin{gathered}
H_{y}(z)=C e^{k_{d} z} e^{i \beta x}+D e^{-k_{d} z} e^{i \beta x} \\
E_{x}(z)=-i C \frac{k_{d}}{\omega \varepsilon_{0} \varepsilon_{d}} e^{k_{d} z} e^{i \beta x}+i D \frac{k_{d}}{\omega \varepsilon_{0} \varepsilon_{d}} e^{-k_{d} z} e^{i \beta x} \quad(-a<z<a) \\
E_{z}(z)=C \frac{\beta}{\omega \varepsilon_{0} \varepsilon_{d}} e^{k_{d} z} e^{i \beta x}+D \frac{\beta}{\omega \varepsilon_{0} \varepsilon_{d}} e^{-k_{d} z} e^{i \beta x}
\end{gathered}
$$

onde $\mathrm{C}$ e D são constantes. Aplicando-se as condições de continuidade de $H_{y}$ e $E_{x}$ nas interface interfaces $z=-a$ e $z=a$ encontra-se

$$
e^{-4 k_{d} a}=\left(\frac{k_{d} \varepsilon_{m}+k_{m} \varepsilon_{d}}{k_{d} \varepsilon_{m}-k_{m} \varepsilon_{d}}\right)^{2}
$$

A equação 2.15 pode ser separada em duas equações transcendentais, que descrevem o modo simétrico e assimétrico do guia MIM, dadas por

$$
\begin{aligned}
& \tanh \left(k_{d} a\right)=-\frac{k_{m} \varepsilon_{d}}{k_{d} \varepsilon_{m}} \\
& \tanh \left(k_{d} a\right)=-\frac{k_{d} \varepsilon_{m}}{k_{m} \varepsilon_{d}}
\end{aligned}
$$

onde

$$
\begin{aligned}
& k_{d}{ }^{2}=\beta^{2}-k_{0}{ }^{2} \varepsilon_{d} \\
& k_{m}{ }^{2}=\beta^{2}-k_{0}{ }^{2} \varepsilon_{m}
\end{aligned}
$$


Como exemplo, considere um guia MIM de três camadas cuja separação $2 a$ é igual a $500 \mathrm{~nm}$. Suponha como metal a prata $(\mathrm{Ag})$ e o dielétrico a sílica $\left(\mathrm{SiO}_{2}\right)$. A prata apresenta as menores perdas na região do visível e do infravermelho, comparada aos metais convencionais como ouro, cobre e alumínio. No comprimento de onda $620 \mathrm{~nm}$ a permissividade relativa da prata é $\varepsilon_{m}=-15.037+1.02 \mathrm{i}$ e da sílica é $\varepsilon_{d}=2.12$. Aplicando esses valores ao modo simétrico, equação $2.16 \mathrm{a}$, obtém-se a constante de propagação $\beta=\left(1.5896 \times 10^{7}+8.3579 \times 10^{4}\right.$ i) $\mathrm{m}^{-1}$. Na Fig. 2.6 são apresentados os campos $H_{y}, E_{x}$ e $E_{z}$ para o guia MIM, de acordo com as equações 2.12-2.14.

(a)
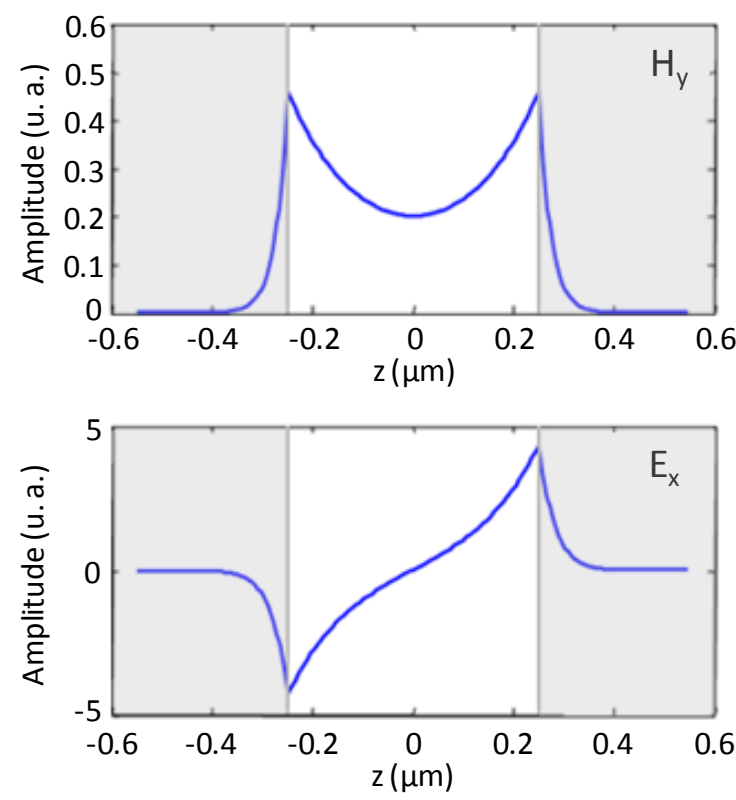

(c)

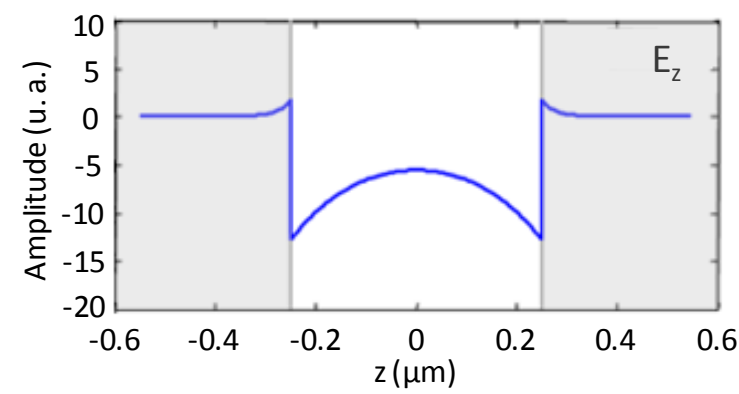

Figura 2.6 - Perfil dos campos eletromagnéticos de um guia metal-isolante-metal para o modo simétrico (a) $H_{y}$ (b) $E_{x}$ e (c) $E_{z}$.

A simetria do modo é verificada observando o campo $H_{y}$. Os gráficos dos campos eletromagnéticos permitem verificar duas propriedades: (1) a continuidade das componentes $H_{y}$ e $E_{x}$, através das interfaces metal-dielétrico, resultante das equações de Maxwell e (2) descontinuidade da componente de campo $E_{z}$ nas interfaces, resultado da concentração de cargas necessária à propagação da onda SPP. 


\subsection{EXCITAÇÃO DE ONDAS SPP}

A excitação de onda SPP ocorre quando a componente longitudinal da excitação $\left(k_{x}\right)$ é igual a constante de propagação $\beta$, dado pela equação 2.10. Para o caso de interface metal/ar, $\beta$ é sempre maior que $k_{x}$. Portanto, alguma técnica deve ser usada para promover o casamento vetorial entre as constantes de propagação. Diversas configurações foram propostas com esse objetivo, sendo usualmente divididas em dois grupos: acoplamento usando prisma e redes de difração. O acoplamento usando prisma é baseado no fenômeno da reflexão interna total [104], que envolve campos evanescentes $\operatorname{com} k_{x}>k_{0} \varepsilon$. Na configuração de Otto [26], o prisma é separado da interface metálica por uma distância da ordem da profundidade de penetração do campo no dielétrico $\left(\delta_{d}\right)$. Na configuração de Kretschmann [27] o filme metálico é depositado diretamente na base do prisma. A condição de casamento ocorre quando $k_{x}=n k_{0} \sin \theta=\operatorname{Re}[\beta]$, onde $\theta$ é o ângulo do feixe incidente com relação à normal. Um outro tipo de configuração usada para excitar ondas SPP é baseada em redes de difração, no qual uma grade (ou ranhuras) no metal é usada para adicionar uma componente vetorial e assim promover o casamento entre as constantes de propagação. $\mathrm{O}$ vetor da rede é definido como $k_{r}=2 \pi / \Lambda$, onde $\Lambda$ é o período da rede. A condição de casamento ocorre quando

$$
\operatorname{Re}(\beta)=k_{x}+m \frac{2 \pi}{\Lambda}
$$

onde $m$ é um número inteiro. Ajustando o período da grade pode-se sintonizar a excitação da onda SPP. A Fig. 2.7 mostra um esquema da excitação por prisma, nas configurações de Otto e Kretschmann, e por rede de difração.

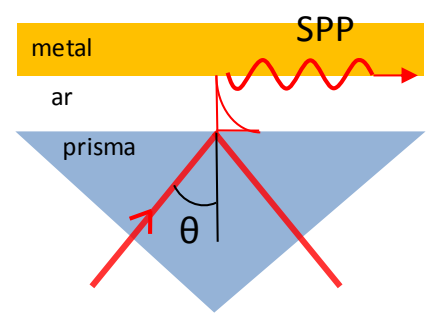

(a)

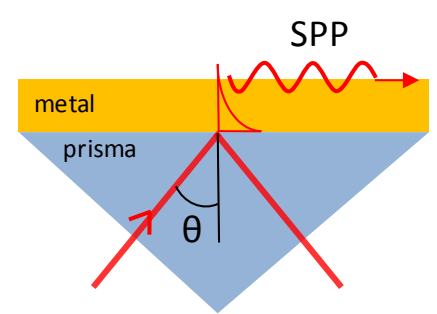

(b)

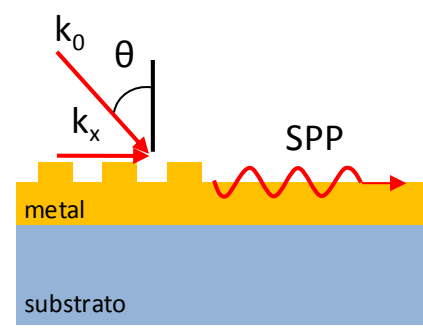

(c)

Figura 2.7 - Excitação de onda SPP usando prisma (a) configuração de Otto e (b) configuração de Kretschmann. (c) Excitação de onda SPP usando rede de difração. 


\subsection{Plasmon DE SUPERFíCiE LOCALIZADO}

A ressonância de plasmon de superfície localizado (Localized Surface Plasmon Resonance - LSPR) é similar à ressonância de plasmon de superfície. Ela ocorre quando a dimensão do objeto condutor é menor (ou comparável) à distância de propagação da onda SPP, dado por $L_{s p p}$ (seção 2.2). Nesse caso, a onda SPP está confinada na dimensão da nanoestrutura metálica: ela se propaga na interface e é refletida nas extremidades da nanoestrutura. A superposição entre ondas SPP propagando em sentidos opostos dá origem a uma onda estacionária. Assim, para um determinado comprimento de onda incidente, LSPR pode ser definido como excitações eletrônicas não propagante acopladas aos campos eletromagnéticos. Ao contrário da ressonância SPP, LSPR pode ser excitado por iluminação direta, não necessitando do auxílio das técnicas descritas na seção anterior [105]. Outra diferença, importante na área de sensoriamento, é que LSPR apresenta menor penetração de campo eletromagnético no dielétrico em comparação com ressonância SPP, sendo menos suscetível a efeitos de bulk [117].

Nas nanoantenas, a radiação óptica incidente se acopla com as excitações eletrônicas confinadas na dimensão da estrutura metálica. Na condição de ressonância, os campos eletromagnéticos estão altamente confinados na estrutura, e decaem rapidamente a partir da interface. A oscilação eletrônica localizada faz com que ocorra reirradiação de luz no espaço livre. As propriedades da luz reirradiada, como amplitude, fase e/ou polarização, podem ser sintonizadas de acordo com a geometria da nanoantena. Assim, é possível moldar uma frente de onda usando um conjunto planar de nanoantenas, previamente projetadas. Na Fig. 2.8 é mostrada a representação de uma nanoantena metálica do tipo nanorod de comprimento L e espessura 2R, e a distribuição de cargas originadas na ressonância localizada.

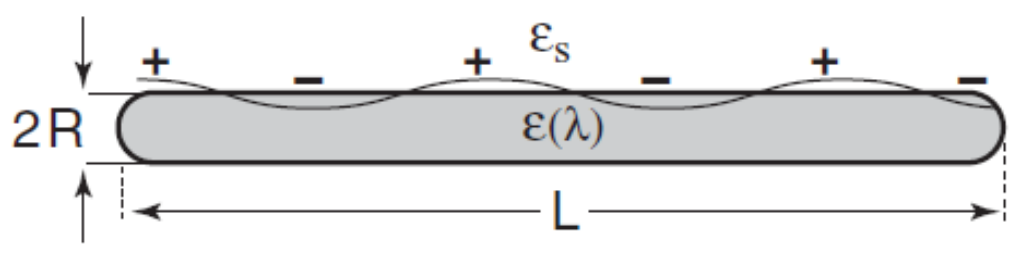

Figura 2.8 - Nanoantena metálica do tipo nanorod. A radiação óptica incidente dá origem a excitações eletrônicas não propagante. $\varepsilon_{\mathrm{s}}$ e $\varepsilon(\lambda)$ são as permissividades do meio dielétrico e do metal, respectivamente. Adaptado de [118]. 
A resposta óptica analítica de nanoantenas com geometrias arbitrárias é complexa [119]. Depende de diversos fatores incluindo geometria da estrutura (formato e tamanho) e resposta óptica do metal. O dispositivo descrito no capítulo 5 é baseado em uma célula unitária do tipo nanorod. 


\title{
3 FiLTROS ÓPTICOS BASEADOS EM MODOS RESSONANTES E PLÁSMONS DE SUPERFÍCIE
}

\begin{abstract}
Neste capítulo são descritos o projeto, a fabricação e a caracterização de um filtro óptico cujo princípio de operação é baseado em modo ressonante associado com ressonância plasmônica. Foram projetados e fabricados três filtros, com picos de transmissão no azul, verde e vermelho. São objetivos deste capítulo:
\end{abstract}

- fazer um levantamento da bibliografia da área, indicando a motivação para o estudo realizado;

- apresentar a estrutura do filtro e sua compreensão teórica mediante análise numérica;

- descrever as etapas do processo de fabricação;

- avaliar o desempenho dos filtros e comparar os resultados obtidos com os trabalhos previamente publicados na área.

Além disso, na parte final do capítulo é mostrado como o filtro óptico vermelho pode ser usado para se obter as três cores primárias Red-Blue-Green (RGB). Uma característica desse dispositivo é que, ao contrário de um prisma que gera um espectro de cores, ele consegue gerar apenas as três cores primárias, podendo encontrar aplicações em sistemas de projeção e captura de imagens.

\subsection{REVISÃo BIBLIOGRÁFICA E MOTIVAÇÃo}

Filtros ópticos são dispositivos que possuem a habilidade de selecionar cores individuais de um espectro de banda larga. Podem operar por transmissão ou reflexão, e são elementos fundamentais na produção de displays usados em câmeras, monitores, smartphones, sistemas de projeção, entre outros. A tecnologia atual dominante na produção desses elementos está baseada no uso de moléculas absorvedoras para selecionar as cores primárias RGB [120]. O fato de usar a absorção de um determinado material faz com que esses elementos sofram com algumas limitações, incluindo baixa eficiência, problemas de aquecimento intrínseco, baixa seletividade de cores e durabilidade [121]. Por outro lado, 
filtros ópticos podem ser também baseados na interação da luz com uma determinada estrutura, como ocorre em redes de difração, por exemplo. Em contraste com os filtros de absorção, os filtros que se baseiam em arranjos de estruturas possuem vantagens que incluem maior seletividade de cores, maior durabilidade e estabilidade, possibilidade de multifuncionalidade, entre outros [122]. Além disso, pode-se obter um conjunto de diferentes filtros usando um mesmo material, apenas variando parâmetros geométricos da estrutura, permitindo assim maior flexibilidade nos projetos.

Recentemente vários tipos de filtros estruturais têm sido reportados na literatura. Filtros puramente dielétricos baseados em ressonância de modos guiados (guided mode resonance - GMR) possuem largura de banda estreita e alta eficiência, já que não sofrem com a absorção metálica, porém estão restritos a filtros reflexivos no espectro visível [123-125]. Filtros metálicos baseados em ressoadores de Fabry-Perot [126-128] se utilizam da interferência das múltiplas reflexões em uma cavidade para fazer filtragem óptica, onde o comprimento de onda ressonante depende da espessura da cavidade. Uma classe especial são os filtros ópticos plasmônicos, cujo princípio de operação é baseado no conceito de transmissão extraordinária, com a excitação de plasmon de superfície. O comprimento de onda ressonante, correspondente ao pico de transmissão, pode ser sintonizado através dos parâmetros geométricos das aberturas em um filme metálico. Foram reportados filtros baseados em uma rede triangular e quadrática, com aberturas circulares [129-135], quadráticas [136], anulares [137,138], triangulares [139] e em formato de cruz [140,141]. Filtros puramente plasmônicos sofrem com a baixa eficiência resultante das perdas induzidas pelo metal. Em particular, filtros que combinam GMR com grades metálicas têm recebido cada vez mais atenção devido à possibilidade de se obter filtros eficientes operando em transmissão. Uma estrutura que combina grades metálicas com duas camadas dielétricas (guia de onda e buffer) tem mostrado resultados promissores [142-145]. Uma estrutura contendo apenas uma camada dielétrica foi abordada nesse contexto, mas sua performance é limitada pela relativa largura de banda de transmissão, maior que $\sim 60 \mathrm{~nm}[142,146]$. A Fig. 3.1 mostra exemplos de filtros ópticos, sua estrutura e respectiva resposta espectral [123,126,139,142]. 
(a)

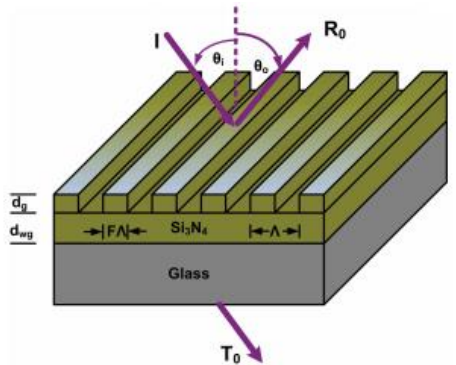

(b)

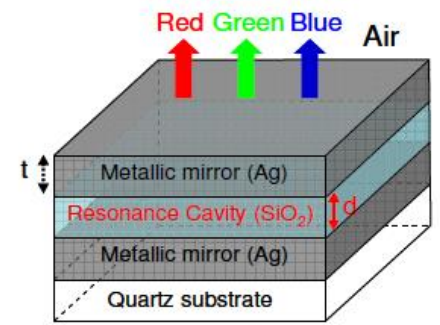

Incoming beam

(c)

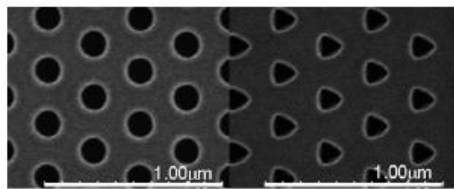

(d)

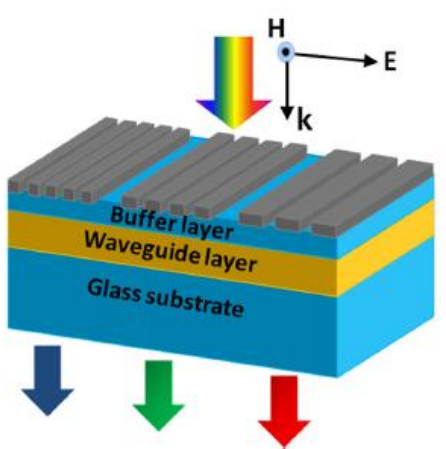

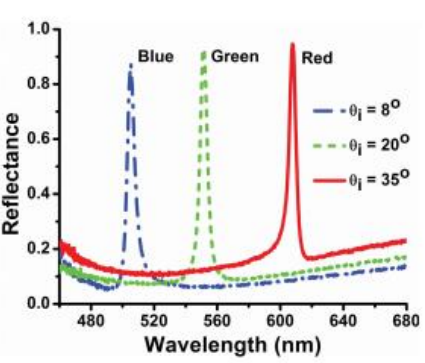
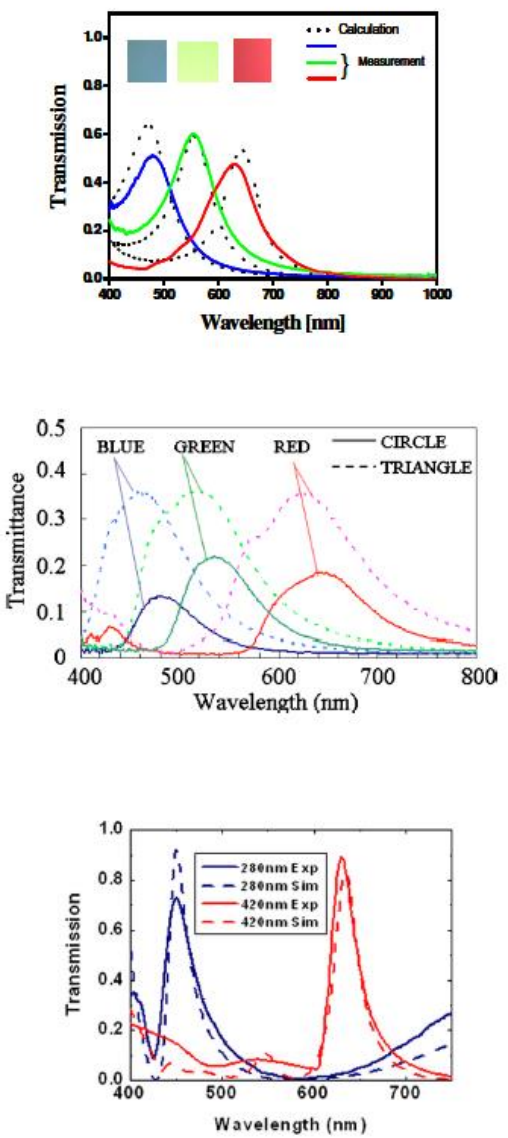

Figura 3.1 - Estrutura de diferentes filtros ópticos operando no visível, com a respectiva resposta espectral. (a) Filtro puramente dielétrico baseado em GMR, operando em reflexão [123], (b) filtro baseado em cavidade FabryPerot [126], (c) filtro plasmônico com abertura circular e triangular [139] e (d) filtro incorporando GMR e grade metálica [142].

Para aplicações práticas de filtros ópticos é altamente desejável a redução de etapas no processo de fabricação, enquanto mantém alta eficiência e reduzida largura de banda de transmissão. Deste modo, a seguir é apresentado o projeto, fabricação e caracterização de filtros ópticos operando no azul, verde e vermelho, cujas medidas experimentais mostraram eficiência ao redor de $80 \%$, com largura de banda $\sim 20 \mathrm{~nm}$. 


\subsection{ESTRUTURA DO FILTRO ÓPTICO}

A estrutura para os filtros ópticos é baseada em 3 camadas: um substrato de vidro, um filme de óxido de alumínio $\left(\mathrm{Al}_{2} \mathrm{O}_{3}\right)$ e no topo um conjunto periódico de grades lineares de alumínio $(\mathrm{Al})$. Os parâmetros geométricos que definem a resposta espectral do dispositivo são: o período da grade metálica $(\Lambda)$; o fill factor $(\mathrm{F})$, que indica a fração do período que a grade ocupa (F $\Lambda)$; a espessura da grade $\left(\mathrm{t}_{\mathrm{g}}\right)$ e a espessura do filme $\left(\mathrm{t}_{\mathrm{f}}\right)$. Além dos parâmetros geométricos, a escolha dos materiais, com seus respectivos índices de refração, também têm influência na resposta espectral do dispositivo. O metal escolhido para fabricar as grades metálicas foi o alumínio, que comparado com prata ou ouro é um material mais econômico e possui boa adesão a muitos substratos, simplificando a fabricação [130]. Por fim, o material dielétrico sobre o qual estão as grades de alumínio é o $\mathrm{Al}_{2} \mathrm{O}_{3}$. A razão pela escolha desse material se deve ao fato do seu índice de refração se aproximar do índice de refração do substrato, favorecendo uma menor largura de banda transmitida (seção 3.3.1). Além disso, o uso do óxido de alumínio favorece a adesão com a grade metálica de alumínio. A Fig. 3.2 mostra a estrutura do dispositivo, os parâmetros geométricos e os materiais usados. O dispositivo é projetado para operar com polarização TM, com o campo magnético $(\mathbf{H})$ da onda incidente oscilando paralelamente às grades metálicas.

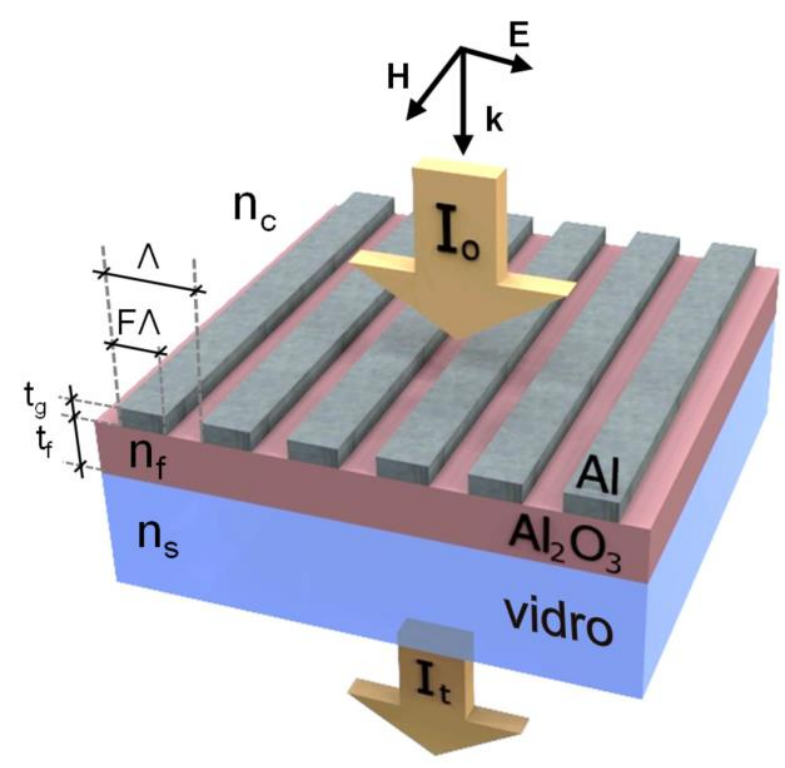

Figura 3.2 - Estrutura do filtro óptico incorporando GMR e ressonância plasmônica. Os parâmetros $\mathrm{n}_{\mathrm{s}}, \mathrm{n}_{\mathrm{f}}$ e $\mathrm{n}_{\mathrm{c}}$ denotam o índice de refração do vidro, do filme de $\mathrm{Al}_{2} \mathrm{O}_{3}$ e do ar, respectivamente. $\Lambda$ é o período, $\mathrm{F}$ é o fill factor e $\mathrm{t}_{\mathrm{g}}$ e $\mathrm{t}_{\mathrm{f}}$ são as espessuras da grade de alumínio e do filme de $\mathrm{Al}_{2} \mathrm{O}_{3}$, respectivamente. $I_{0}$ e $I_{t}$ indicam a onda incidente e transmitida, respectivamente. 


\subsection{ANÁLISE NUMÉRICA}

A análise numérica foi realizada usando o software comercial Comsol 3.5a [101], que permite uma grande discretização espacial, fato requerido quando se trata de estruturas plasmônicas, onde os campos eletromagnéticos decaem rapidamente próximos à superfície do metal. O período das grades metálicas é o fator preponderante no comprimento de onda ressonante do dispositivo. Uma busca paramétrica usando simulações teste levou aos seguintes parâmetros geométricos: $\mathrm{t}_{\mathrm{g}}=40 \mathrm{~nm}, \mathrm{~F}=0.67$ e $\Lambda=290 \mathrm{~nm}, 350 \mathrm{~nm}$ e $430 \mathrm{~nm}$ para os filtros azul, verde e vermelho, respectivamente. A Fig. 3.3 mostra o ambiente de simulação numérica, a discretização espacial de uma parte da estrutura e os parâmetros geométricos usados no projeto dos filtros ópticos.

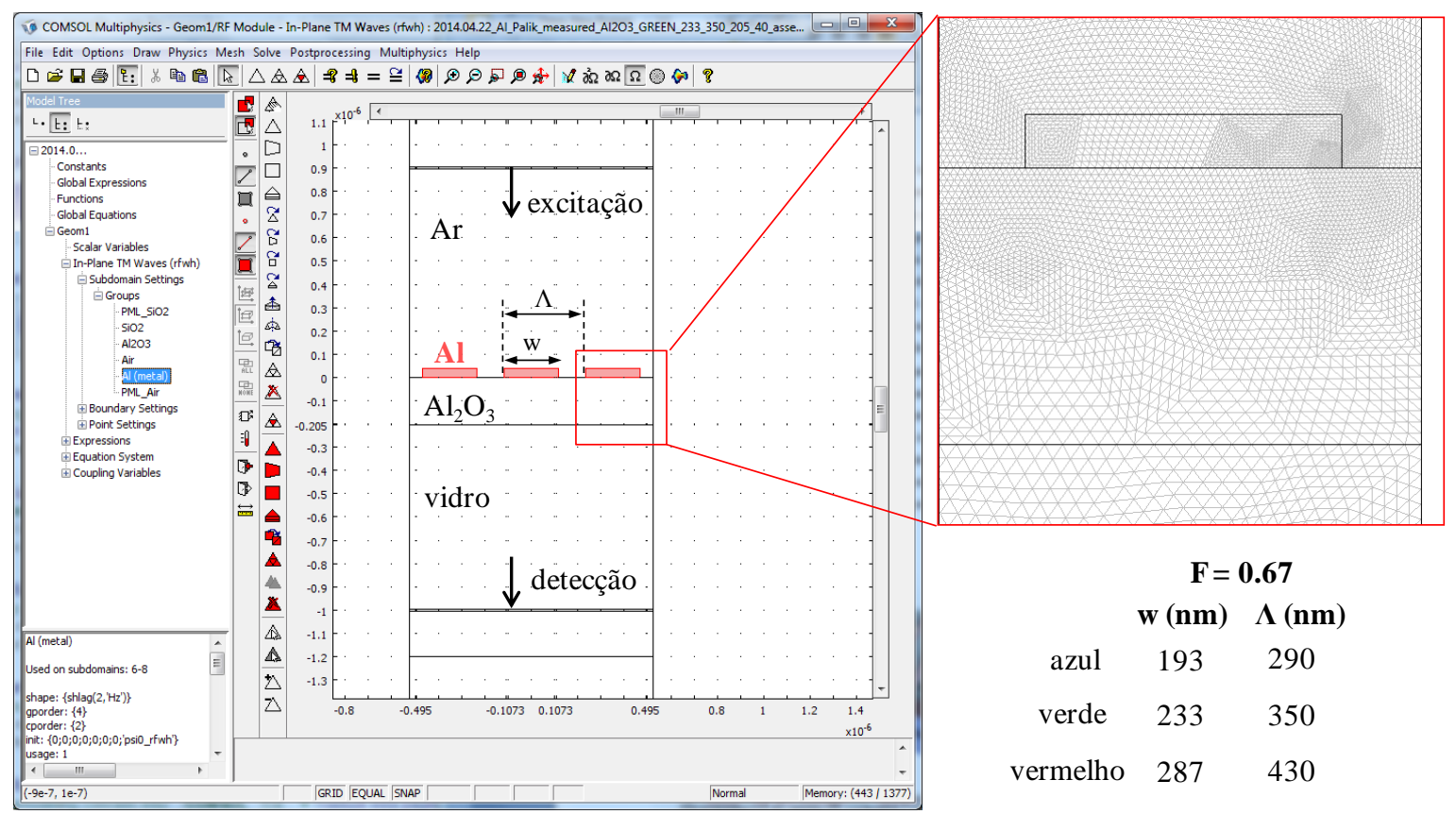

Figura 3.3 - Ambiente de simulação numérica e parâmetros geométricos dos filtros ópticos. No detalhe é mostrado a discretização espacial de uma parte da estrutura.

A resposta de cada dispositivo e sua compreensão teórica foram obtidas calculando o espectro de transmissão na região do visível, entre 400 e $750 \mathrm{~nm}$, variando a espessura do filme de $\mathrm{Al}_{2} \mathrm{O}_{3}$, de 0 a $400 \mathrm{~nm}$ com passo de $10 \mathrm{~nm}$. Os índices de refração do alumínio e do oxido de alumínio usados nas simulações provém de valores experimentais, obtidos de [109] (Fig. 2.1c e 2.1d) e medida própria (ver Fig. 3.6a), respectivamente. O índice de refração do substrato de vidro é constante $(\mathrm{n}=1.518)$ e foi assumido uma onda plana incidente com 
polarização TM. O espectro de transmissão dos filtros azul, verde e vermelho, em função da espessura do filme de $\mathrm{Al}_{2} \mathrm{O}_{3}$, são mostrados na Fig. 3.4.

(a)

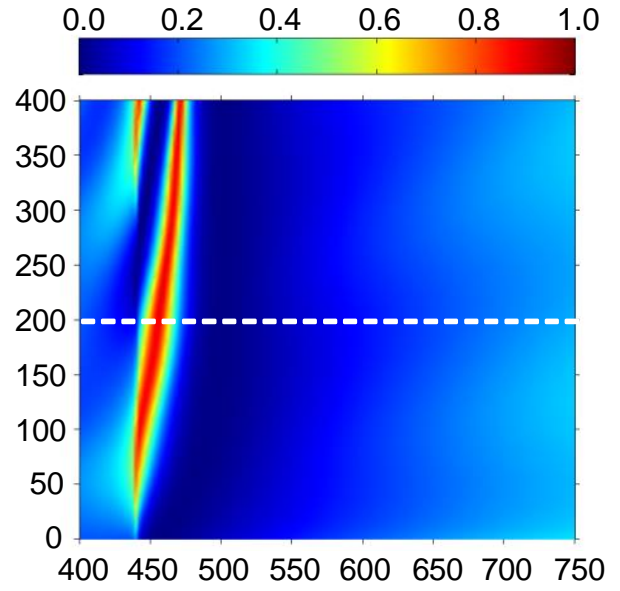

(b)

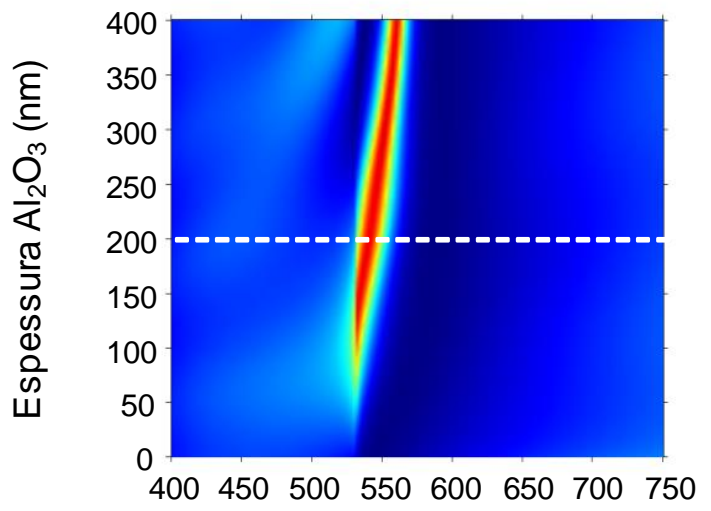

(c)

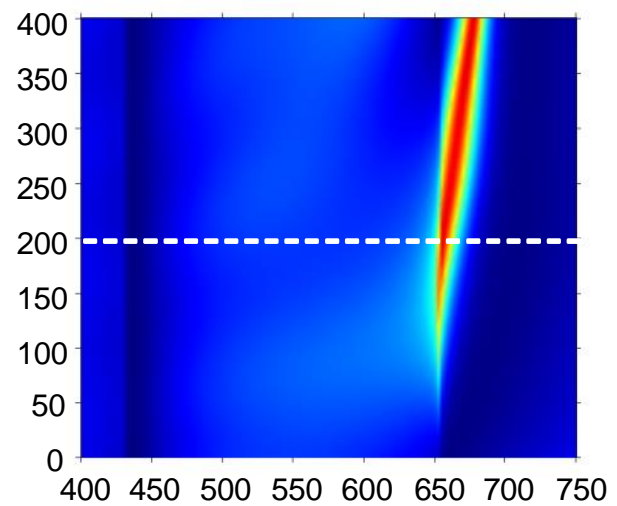

Comprimento de onda $(\mathrm{nm})$ (d)
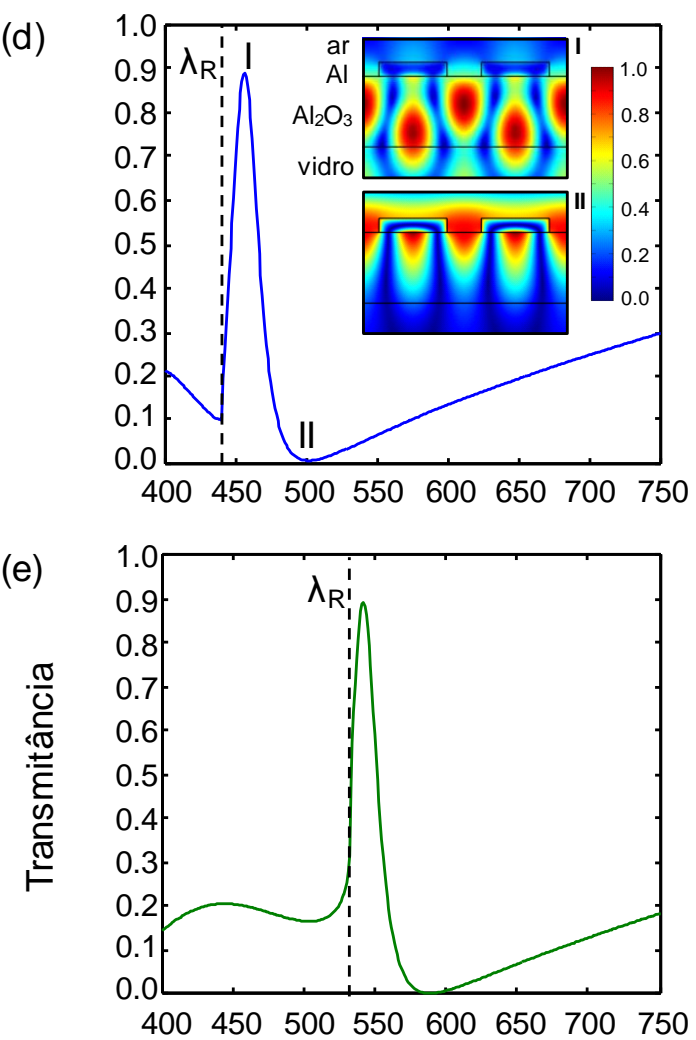

(f)

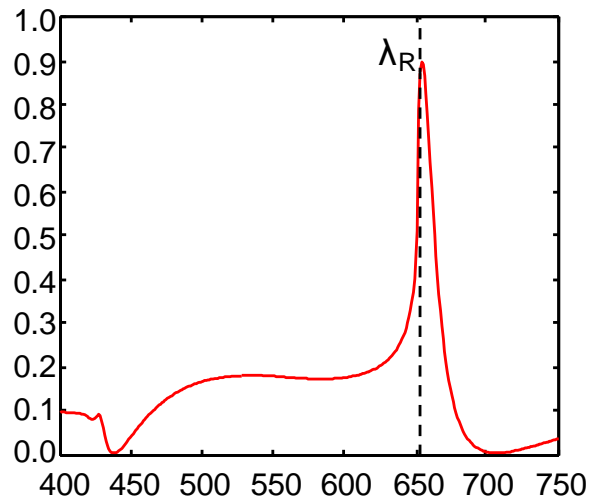

Comprimento de onda $(\mathrm{nm})$

Figura 3.4 - Resposta espectral calculada em função da espessura do filme de $\mathrm{Al}_{2} \mathrm{O}_{3}$ para os filtros (a) azul $(\Lambda=290 \mathrm{~nm})$, (b) verde $(\Lambda=350 \mathrm{~nm})$ e (c) vermelho $(\Lambda=430 \mathrm{~nm})$. Os parâmetros fixos são $t_{g}=40 \mathrm{~nm}$ e $F=0.67$. Espectro de transmissão com $t_{f}=$ $200 \mathrm{~nm}$, correspondente as linhas pontilhadas brancas em (a)-(c), para os filtros (d) azul, (e) verde e (f) vermelho. No detalhe em (d) é mostrado a amplitude auto normalizada do campo magnético $(|\mathbf{H}|)$ correspondente ao pico (I) e ao mínimo de transmissão (II). As linhas verticais pontilhadas em (d)-(f) indicam os comprimentos de onda da anomalia Rayleigh. 
Primeiramente nota-se que sem a presença do filme de $\mathrm{Al}_{2} \mathrm{O}_{3}\left(t_{\mathrm{f}}=0\right)$ não aparece pico de transmissão, ou seja, o dispositivo não atua como filtro. Conforme a espessura de $\mathrm{Al}_{2} \mathrm{O}_{3}$ vai aumentando começa a aparecer um pico de transmissão, com largura de banda estreita e bandas laterais com intensidade relativamente baixas. Isso porque o dispositivo começa a admitir o modo fundamental no guia de onda formado pelo filme. Para aplicações práticas, os três filtros devem ser integrados num painel único, portanto devem ter alta eficiência para uma mesma espessura do filme de $\mathrm{Al}_{2} \mathrm{O}_{3}$. De acordo com as simulações, os três filtros têm respostas espectrais eficientes em torno de $t_{\mathrm{f}}=200 \mathrm{~nm}$, como mostram as Figs. 3.4(d)-3.4(f). A eficiência dos três filtros se aproxima de $90 \%$ e a largura de banda transmitida (Full Width at Half Maximum - FWHM) é de $22 \mathrm{~nm}$ centrado em $456 \mathrm{~nm}$ para o filtro azul; $20 \mathrm{~nm}$ centrado em $541 \mathrm{~nm}$ para o filtro verde; e $14 \mathrm{~nm}$ centrado em $655 \mathrm{~nm}$ para o filtro vermelho.

O perfil do espectro de transmissão é gerado por uma combinação de GMR com ressonância plasmônica. A onda difratada pela grade metálica é acoplada com o modo fundamental suportado pelo guia de onda (filme de $\mathrm{Al}_{2} \mathrm{O}_{3}$ ). $\mathrm{O}$ modo no guia é do tipo leaky, sendo irradiado na cobertura e no substrato ao se propagar. A onda transmitida diretamente (ordem zero de difração) pode então interferir construtivamente com a onda irradiada, ocorrendo a transferência de energia. O modo leaky induz o pico de transmissão na condição de casamento de fase $k_{\|}=\beta \pm 2 \pi q / \Lambda$, onde $k_{\|}$é a componente longitudinal do vetor incidente, $\beta$ é a constante de propagação do modo guiado, $q$ é a ordem de difração e $\Lambda$ é o período da grade. O detalhe (I) na Fig. 3.4(d) mostra a distribuição do campo magnético correspondente ao comprimento de onda no qual ocorre o pico de transmissão. Observa-se um padrão de campo no filme de $\mathrm{Al}_{2} \mathrm{O}_{3}$ típico de um modo guiado $\left(\mathrm{TM}_{0}\right)$, no qual o formato do modo é perturbado pelos campos plasmônicos. O detalhe (II) na mesma figura exibe a distribuição do campo magnético correspondente ao comprimento de onda onde ocorre o mínimo de transmissão. Vemos uma ressonância de plasmon de superfície na interface $\mathrm{Al} / \mathrm{Al}_{2} \mathrm{O}_{3}$. Os valores das intensidades estão auto-normalizados. O comprimento de onda SPP para a interface $\mathrm{Al} / \mathrm{Al}_{2} \mathrm{O}_{3}$ considerando o comprimento de onda correspondente ao mínimo de transmissão $\left(\lambda_{0}=500 \mathrm{~nm}\right)$ é $\lambda_{s p p}=288 \mathrm{~nm}$, valor próximo ao período da estrutura $(\Lambda=290$ $\mathrm{nm})$.

Outro aspecto interessante que pode ser observado nas Figs. 3.4(a)-3.4(c) é que a banda de transmissão se torna extremamente estreita para a espessura do filme de $\mathrm{Al}_{2} \mathrm{O}_{3}$ variando de $50 \mathrm{~nm}<\mathrm{t}_{\mathrm{f}}<150 \mathrm{~nm}$ na Fig. 3.4(a), de $100 \mathrm{~nm}<\mathrm{t}_{\mathrm{f}}<200 \mathrm{~nm}$ na Fig. 3.4(b) e de $150 \mathrm{~nm}<\mathrm{t}_{\mathrm{f}}<250 \mathrm{~nm}$ na Fig. 3.4(c). Este efeito foi associado à anomalia Rayleigh. O comprimento de onda onde ocorre essa anomalia $\left(\lambda_{R}\right)$ é basicamente determinado pelo 
período da estrutura, enquanto que o comprimento de onda GMR pode ser sintonizado de forma independente por outros parâmetros como fill factor e espessura do filme dielétrico. Conforme a espessura do filme de $\mathrm{Al}_{2} \mathrm{O}_{3}$ é reduzida, o comprimento de onda GMR se aproxima do comprimento de onda Rayleigh, resultando em uma rápida queda na intensidade transmitida, de modo similar ao mostrado para filtro não metálico [147]. Para os filtros simulados, a anomalia Rayleigh está localizada nos comprimentos de onda $\lambda_{R}=n_{s} \Lambda=440$ nm na Fig. 3.4(a), $531 \mathrm{~nm}$ na Fig. 3.4(b) e 653 nm na Fig. 3.4(c), onde $\mathrm{n}_{\mathrm{s}}$ é o índice de refração do substrato (1.518). As linhas verticais nas Figs. 3.4(d)-3.4(f) indicam a localização de $\lambda_{R}$. As separações entre $\lambda_{R}$ e o pico de ressonância são $16 \mathrm{~nm}, 10 \mathrm{~nm}$, e $2 \mathrm{~nm}$, para os filtros azul, verde e vermelho, respectivamente.

Além disso, a Fig. 3.4 mostra que a resposta espectral é razoavelmente tolerante com a variação da espessura do filme de $\mathrm{Al}_{2} \mathrm{O}_{3}$ em torno de $\mathrm{t}_{\mathrm{f}} \sim 200 \mathrm{~nm}$, o que facilita a fabricação de dispositivos, já que possíveis variações na espessura não afeta de maneira significativa a resposta espectral. Filtros operando independentemente da polarização podem ser obtidos pela produção de grades em duas dimensões. Os filtros aqui apresentados foram projetados para incidência normal. A tolerância angular para o dispositivo é em torno de $\pm 2.5^{\circ}$, onde a intensidade transmitida no comprimento de onda de pico é igual ou maior a $50 \%$ da intensidade na condição de incidência normal. Portanto, os filtros possuem aceitável performance usando feixes colimados no qual a divergência está dentro da aceitação angular.

\subsubsection{EFEITO DO ÍNDICE DE REFRAÇÃO DO FILME NA LARGURA DE BANDA TRANSMITIDA}

Para estudar o efeito do índice de refração do filme dielétrico na resposta do filtro óptico foi calculado o espectro de transmissão do filtro azul considerando três diferentes índices de refração do filme: $\mathrm{n}_{\mathrm{f}}=2.5, \mathrm{n}_{\mathrm{f}}=2.0$ e $\mathrm{n}_{\mathrm{f}}=1.7$, mostrados na Fig. 3.5(a)-3.5(c). A largura de transmissão reduz consideravelmente com a diminuição do índice de refração do filme. A estreita banda de transmissão verificada nos filtros projetados é devido ao baixo contraste entre o índice de refração do guia e do substrato de vidro (1.518). Este baixo contraste leva a um maior diâmetro modal, fazendo com que uma porção menor da energia modal interaja com o metal, resultando em uma largura de banda transmitida mais estreita. Os índices de refração escolhidos podem representar materiais como $\mathrm{MgO}\left(\mathrm{n}_{\mathrm{f}} \sim 1.7\right), \mathrm{Si}_{3} \mathrm{~N}_{4}\left(\mathrm{n}_{\mathrm{f}} \sim\right.$ 2.0) e $\mathrm{TiO}_{2}\left(\mathrm{n}_{\mathrm{f}} \sim 2.5\right)$. 
(a)

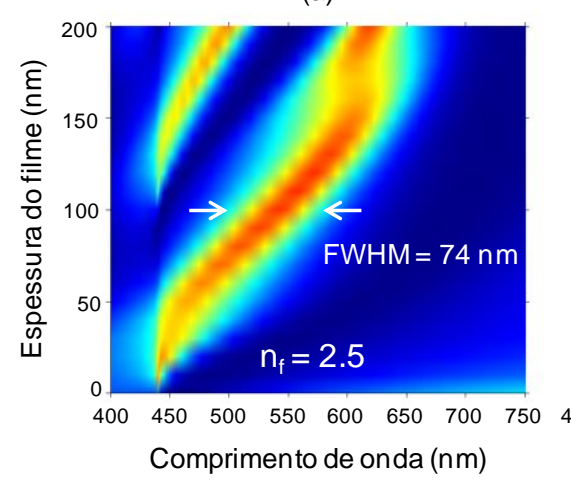

(b)

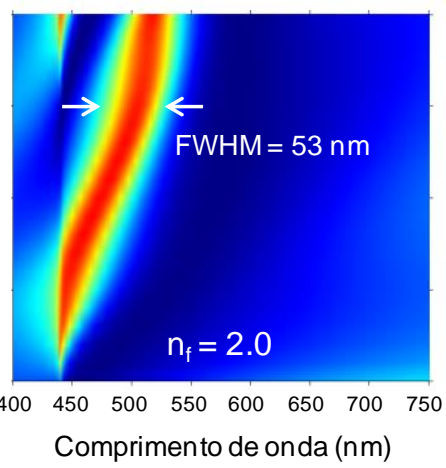

(c)

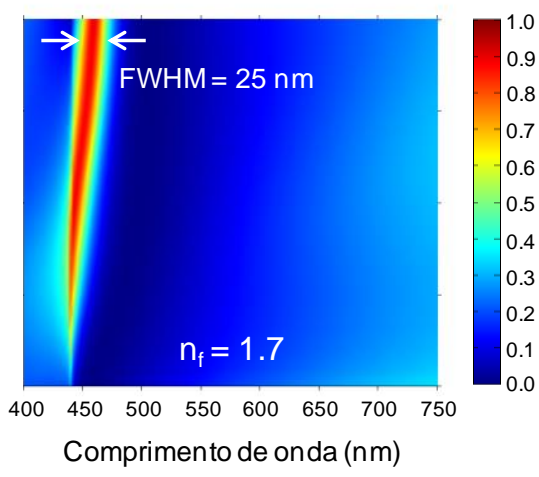

Figura 3.5 - Espectros de transmissão calculados para o filtro azul considerando três índices de refração diferentes para o filme dielétrico (a) $n_{f}=2.5$, (b) $n_{f}=2.0$, and (c) $n_{f}=$ 1.7. A largura de banda transmitida (FWHM) é mostrada nas posições (a) $t_{f}=$ $100 \mathrm{~nm},(b) t_{f}=150 \mathrm{~nm}$, and (c) $t_{f}=190 \mathrm{~nm}$. Os parâmetros fixos nas simulações são $\Lambda=290 \mathrm{~nm}, \mathrm{~F}=0.67, \mathrm{t}_{\mathrm{g}}=40 \mathrm{~nm}$, and $\mathrm{n}_{\mathrm{s}}=1.518$.

\subsection{FABRICAÇÃo E CARACTERIZAÇÃo}

Os processos de fabricação e caracterização foram realizados por meio de visita técnica à UTA (seção 1.6.1). O processo empregado na fabricação dos três filtros de cor foi a litografia interferométrica, que permite uma fabricação de baixo custo e a possibilidade de produção em série. Para a limpeza do substrato de vidro de aproximadamente 2,5 $\mathrm{cm}$ x 2,5 cm x 0,2 cm usa-se imersão em acetona, metanol e álcool isopropílico (10 minutos cada), seguido de lavagem com água deionizada e secagem com ar comprimido (nitrogênio). Em seguida é feita a deposição do filme de $\mathrm{Al}_{2} \mathrm{O}_{3}(\sim 200 \mathrm{~nm})$ usando um sistema de ultra vácuo (AJA ETC Orion series), no qual elétrons são acelerados em direção a um alvo, que é o material que se deseja depositar no substrato. Com o choque dos elétrons, o material é ejetado e se deposita no substrato. O controle da espessura do filme é feito de maneira automática, e depende do tempo de operação do sistema. Após a deposição da camada de $\mathrm{Al}_{2} \mathrm{O}_{3}$ no substrato de vidro usa-se um elipsômetro (VB-400, VASE ellipsometer system, J. A. Woollam) para medir o índice de refração e a espessura da camada depositada. A figura 3.6 mostra os valores medidos e a interpolação do índice de refração usada na análise numérica. As espessuras medidas do filme de $\mathrm{Al}_{2} \mathrm{O}_{3}$ para os filtros azul, verde e vermelho foram $\mathrm{t}_{\mathrm{f}} \approx$

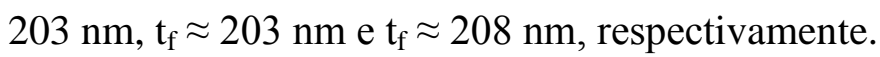


(a)

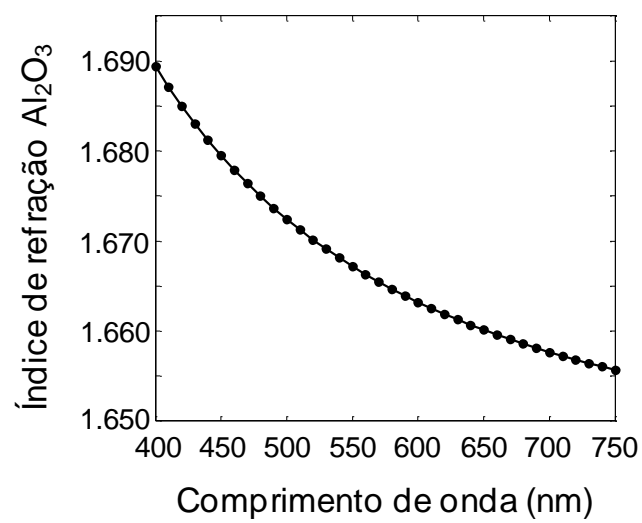

(b)

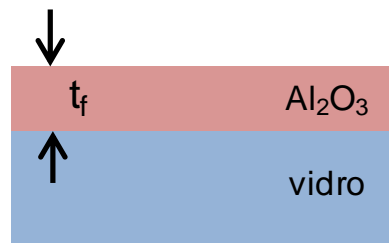

filtro azul: $\mathrm{t}_{\mathrm{f}} \approx 203 \mathrm{~nm}$

filtro verde: $\mathrm{t}_{\mathrm{f}} \approx 203 \mathrm{~nm}$

filtro vermelho: $\mathrm{t}_{\mathrm{f}} \approx 208 \mathrm{~nm}$

Figura 3.6 - Caracterização do filme de $\mathrm{Al}_{2} \mathrm{O}_{3}$ realizada por elipsometria. (a) Índice de refração e (b) espessura do filme. Os pontos em (a) representam os valores experimentais e a linha representa a interpolação polinomial usado na análise numérica.

Em seguida inicia-se o processo de fabricação das grades metálicas de alumínio. Primeiramente usa-se um spin coater para se obter uma película de fotoresiste positivo (495 PMMA, MicroChem) sobre a camada de $\mathrm{Al}_{2} \mathrm{O}_{3}$. A espessurra do fotoresiste é aproximadamente $250 \mathrm{~nm}$ usando 3000 rotações por minuto. A amostra é então levada para uma placa quente por 90 segundos a $100{ }^{\circ} \mathrm{C}$, para remoção do solvente do fotoresiste. Para a produção das grades usa-se um sistema de litografia interferométrica baseado em um espelho de Lloyd, esquematizado na Fig. 3.7(a). Um feixe laser ultravioleta operando em 266 nm é filtrado espacialmente e colimado. Este procedimento é usado para se obter um feixe coerente, expandido e com intensidade praticamente uniforme. Este feixe atinge tanto o espelho como a amostra. Parte da luz refletida pelo espelho interfere com a parte do feixe que incide na amostra, resultando em um padrão de interferência diretamente sobre o fotoresiste. Uma abertura é usada para delimitar a área exposta. O ângulo de rotação do espelho em relação ao feixe do laser define o período $(\Lambda)$, e o tempo de exposição define o fill factor $(\mathrm{F})$ da grade. A Fig. 3.7(b) mostra uma visão geral do sistema e do suporte. Uma bomba de sucção a vácuo é usada para prender a amostra, que é posicionada na abertura onde o padrão de interferência é gerado pelo espelho de Lloyd. Todo o alinhamento do ângulo da base giratória e da posição $(x, y$ e $z)$ da amostra é feito de modo automático. $\mathrm{O}$ controle liga/desliga do feixe laser (shutter) possibilita a exposição de uma matriz $3 \times 3$ com diferentes tempos de exposição. A Fig. 3.7(c) mostra uma imagem do sistema interferométrico usado [148]. 
(a)

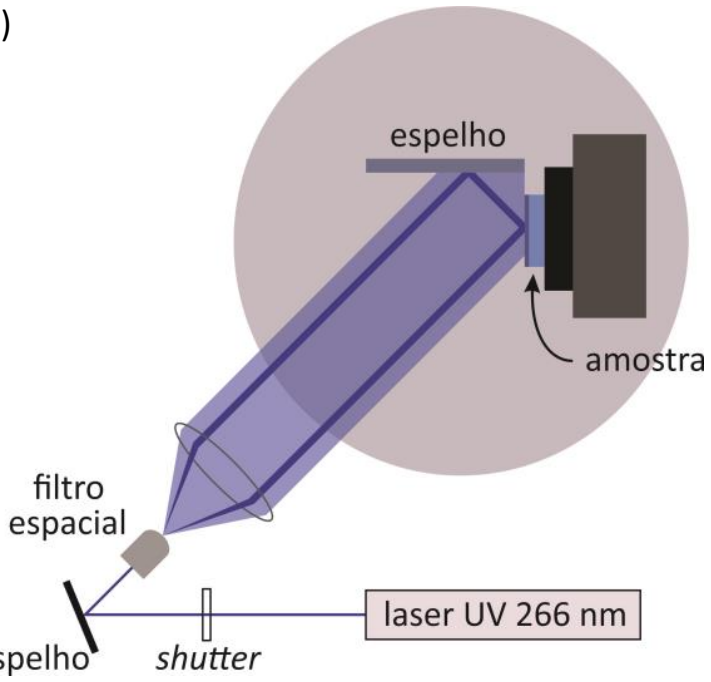

(b)

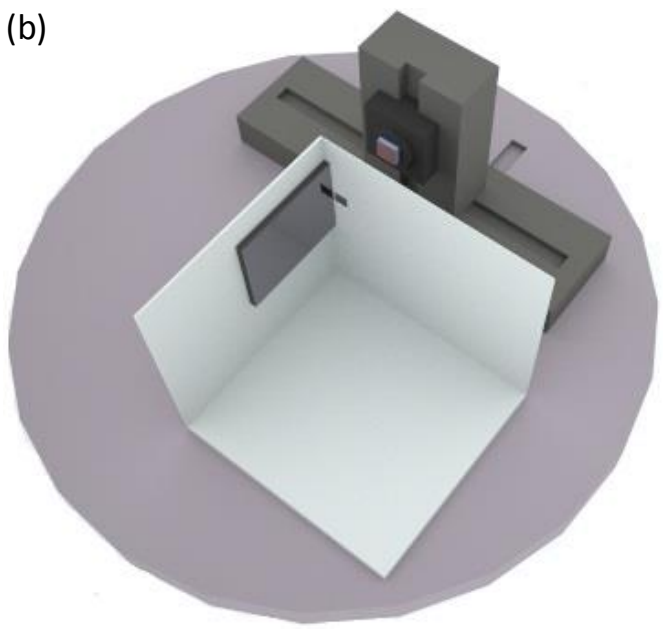

(c)

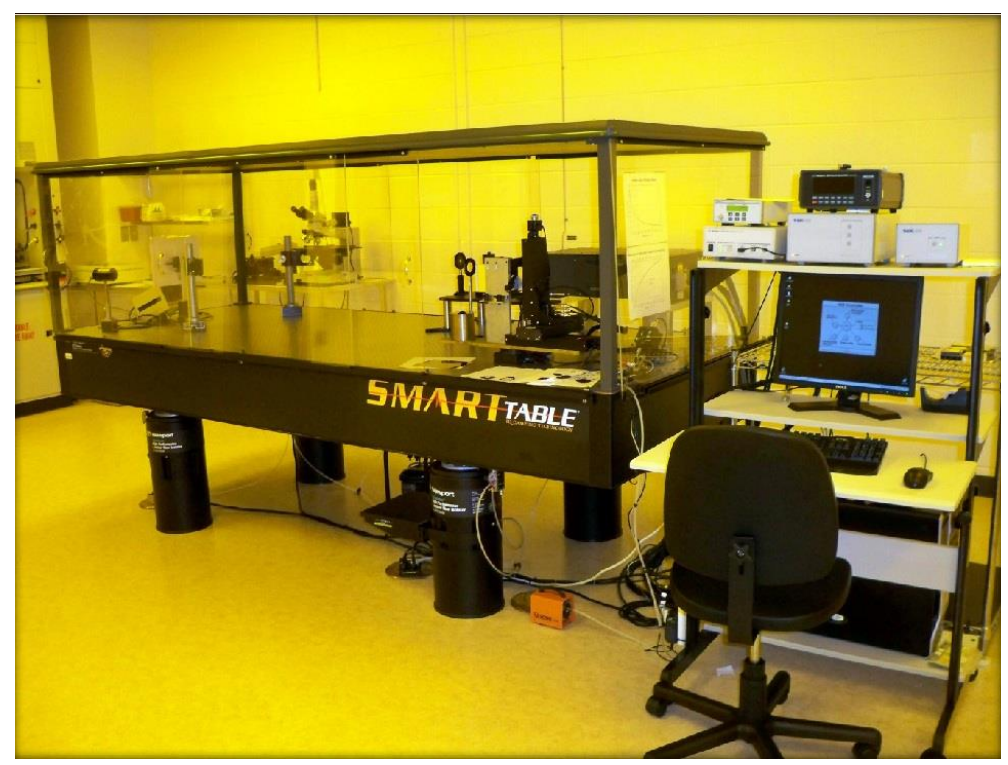

Figura 3.7 - (a) Esquema do sistema interferométrico usado na fabricação dos filtros ópticos, (b) visão geral mostrando o espelho de Lloyd, a abertura e o suporte da amostra e (c) imagem do sistema interferométrico usado [148]. 
Após a exposição, a amostra volta para a placa quente $\left(110^{\circ} \mathrm{C}, 90\right.$ segundos $)$ e então é revelada em MIBK/IPA, 3:1, durante 30 segundos. Em seguida ela é imersa em água deionizada e secada com ar comprimido. O fotoresiste positivo faz com que as zonas expostas ao UV sejam dissolvidas no revelador. Para a remoção completa do fotoresiste exposto ao laser, e possível aumento do fill factor das grades, usa-se corrosão por plasma (Oxford PlasmaLab80Plus), num processo conhecido como "descum". A figura 3.8 mostra imagens obtidas por microscópio de força atômica (Atomic Force Microscope - AFM), usadas para verificação dos parâmetros geométricos período e fill factor da grade. Quanto maior o tempo de exposição, menor o fill factor. Note que o fill factor do resiste e da grade metálica são complementares.

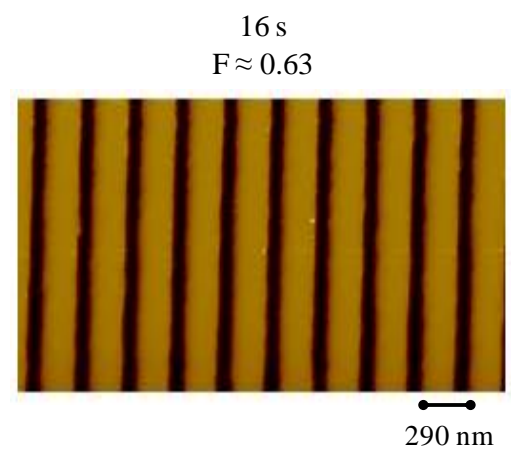

(a)

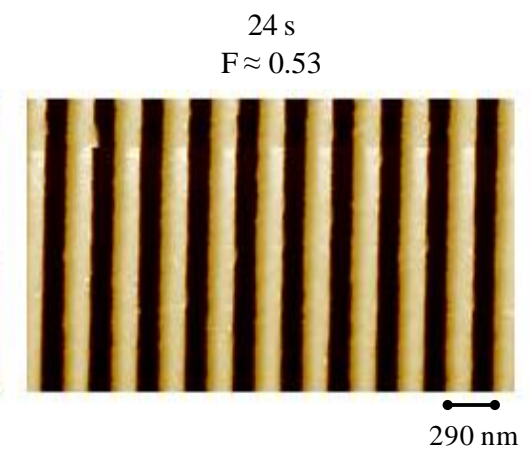

(b)

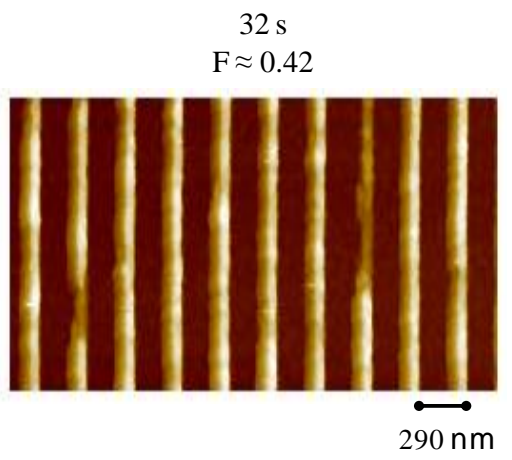

(c)

Figura 3.8 - Imagens obtidas por AFM. O período das grades é $\Lambda \approx 290 \mathrm{~nm}$, referente ao filtro azul. São mostrados as imagens referentes a três tempos de exposição no sistema interferométrico (a) 16 segundos, $\mathrm{F}_{\mathrm{a}} \approx 0.63$, (b) 24 segundos, $\mathrm{F}_{\mathrm{b}} \approx 0.53$ e (c) 32 segundos, $\mathrm{F}_{\mathrm{c}} \approx 0.42$. O fill factor do resiste $\mathrm{e}$ da grade metálica são complementares.

Somente após a verificação dos parâmetros geométricos as amostras são levadas para fazer a deposição de $40 \mathrm{~nm}$ de alumínio, usando um sistema evaporador (CHA ElectronBeam Evaporator). Após a deposição do alumínio é feito o procedimento de lift-off usando banho ultrassônico em acetona, no qual o fotoresiste- e consequentemente o alumínio depositado sobre ele - é removido, restando apenas o alumínio depositado diretamente sobre o filme de $\mathrm{Al}_{2} \mathrm{O}_{3}$. Esta etapa é crucial e de difícil execução, sendo realizada por técnico especializado. As etapas do processo de fabricação são resumidas na figura 3.9. 

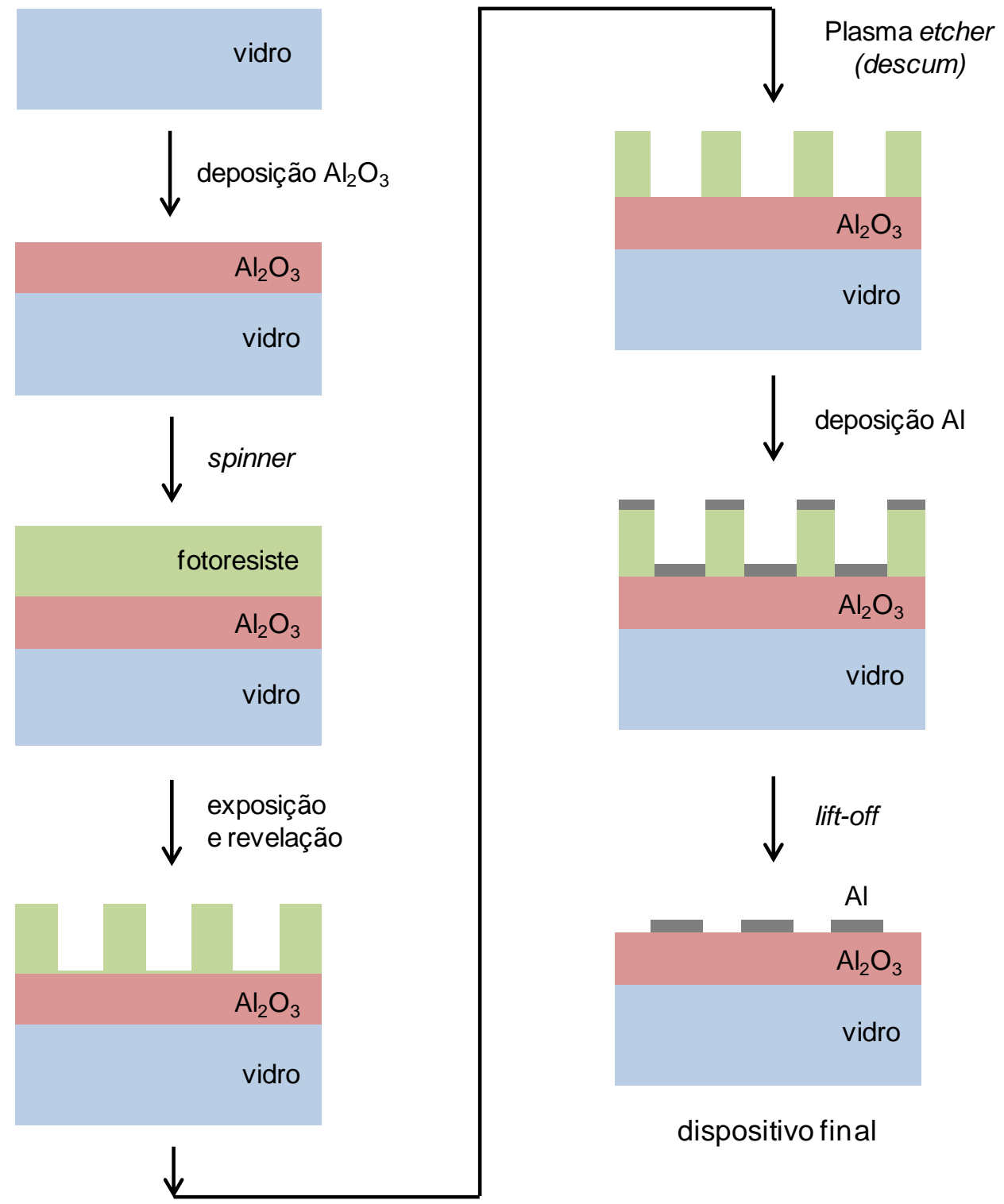

Figura 3.9 - Resumo do processo de fabricação dos filtros ópticos

Os parâmetros geométricos dos dispositivos finais foram avaliados por AFM. Os valores medidos foram os seguintes: $\Lambda \approx 291 \mathrm{~nm}, \mathrm{~F} \approx 0.656$ e tg $\approx 40 \mathrm{~nm}$, para o filtro azul; $\Lambda \approx 349 \mathrm{~nm}, \mathrm{~F} \approx 0.665$ e tg $\approx 40 \mathrm{~nm}$, para o filtro verde, e $\Lambda \approx 428 \mathrm{~nm}, \mathrm{~F} \approx 0.678$ e $\operatorname{tg} \approx 38$ $\mathrm{nm}$, para o filtro vermelho. Os valores medidos encontram-se bem próximos dos valores projetados. A Fig. 3.10 mostra as imagens obtidas, com os respectivos valores experimentais. 

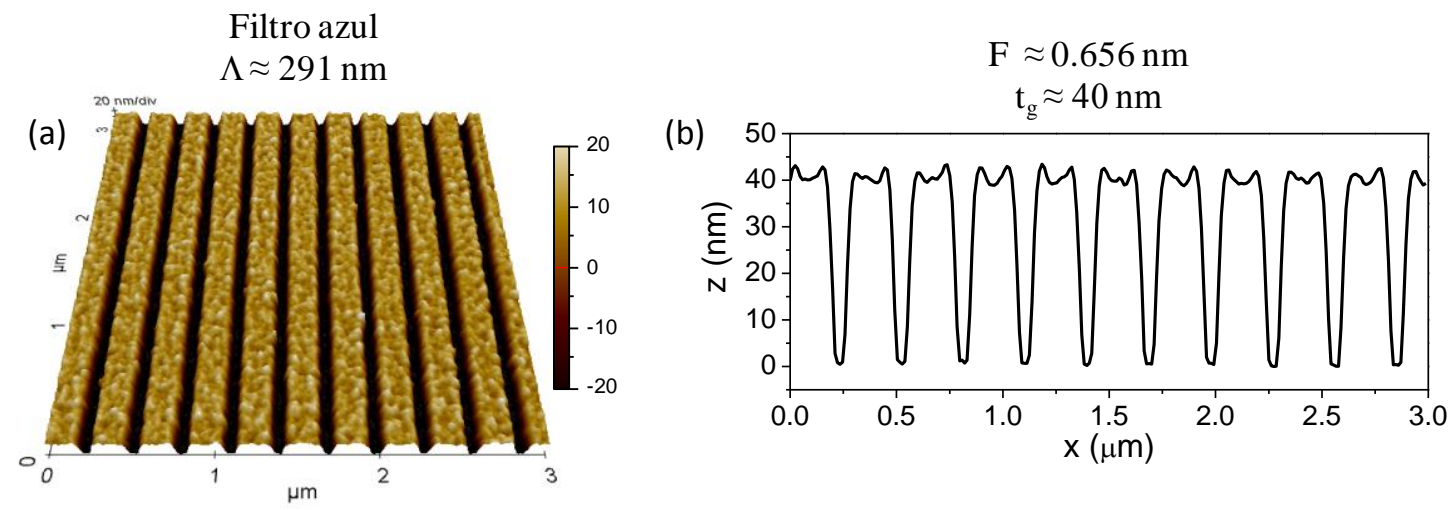

Filtro verde

$\Lambda \approx 349 \mathrm{~nm}$
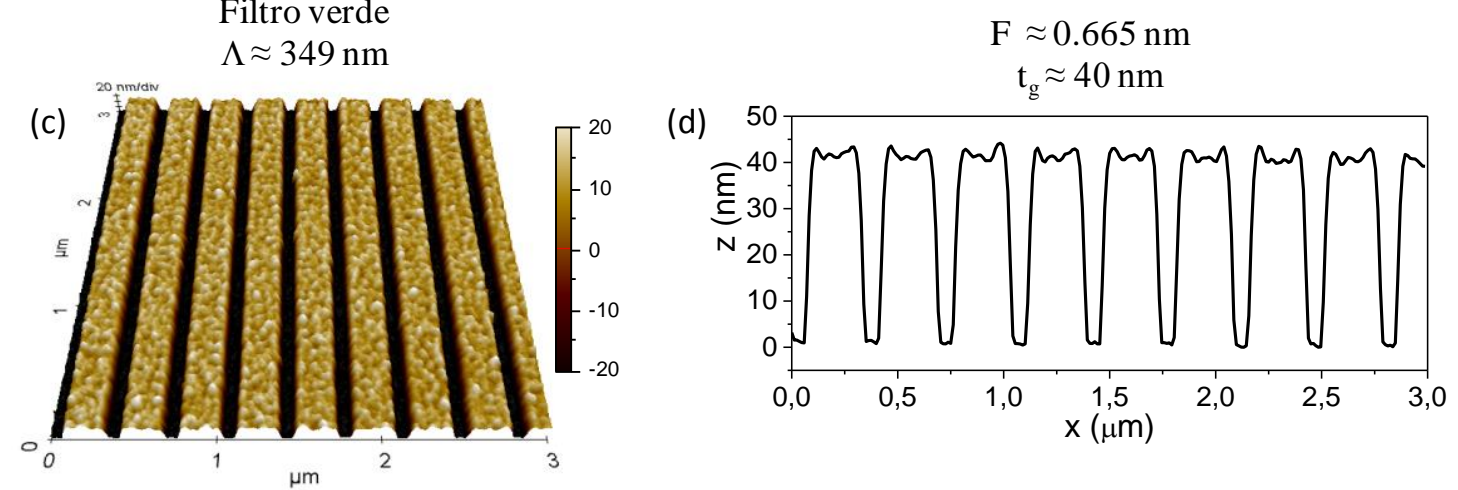

Filtro vermelho

$\Lambda \approx 428 \mathrm{~nm}$

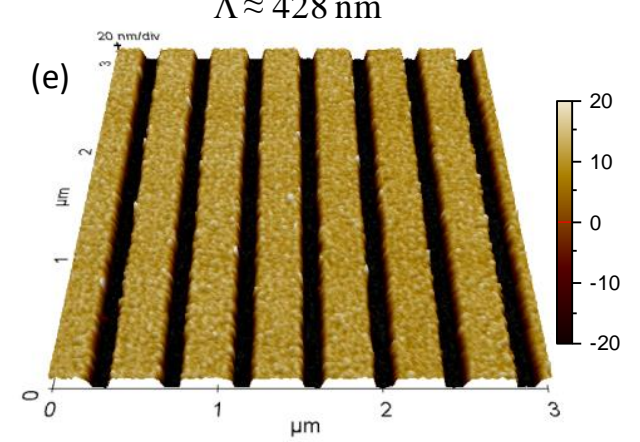

(f)

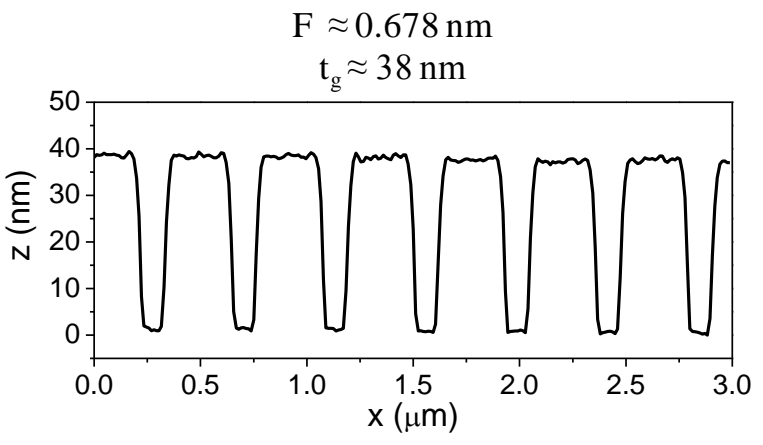

Figura 3.10-Imagens obtidas por AFM e verificação dos parâmetros geométricos dos filtros fabricados (a,b) azul, (c,d) verde e (d,e) vermelho.

\subsection{RESULTADOS E DISCUSSÃO}

A resposta espectral dos filtros azul, verde e vermelho foi obtida usando a configuração esquematizada na Fig. 3.11. A fonte de luz é uma lâmpada halógena com comprimento de onda variando entre 360 a 2000 nm (Ocean Optics HL-2000). Usando fibra óptica, lentes colimadoras e polarizador se produziu um feixe de luz branca colimado que incide no filtro fabricado com polarização TM. Novamente um conjunto colimador/fibra óptica é usado para coletar a luz transmitida pelo filtro e enviar ao analisador de espectro 
(Ocean Optics USB4000). Um diafragma óptico (íris) é usado para garantir que toda a luz incidente passe pelo filtro. A transmissão absoluta é obtida normalizando a transmissão medida pela densidade espectral da fonte de luz. Nos resultados apresentados a seguir foi considerada a reflexão que ocorre na superfície inferior do substrato de vidro ( 4.2\%).

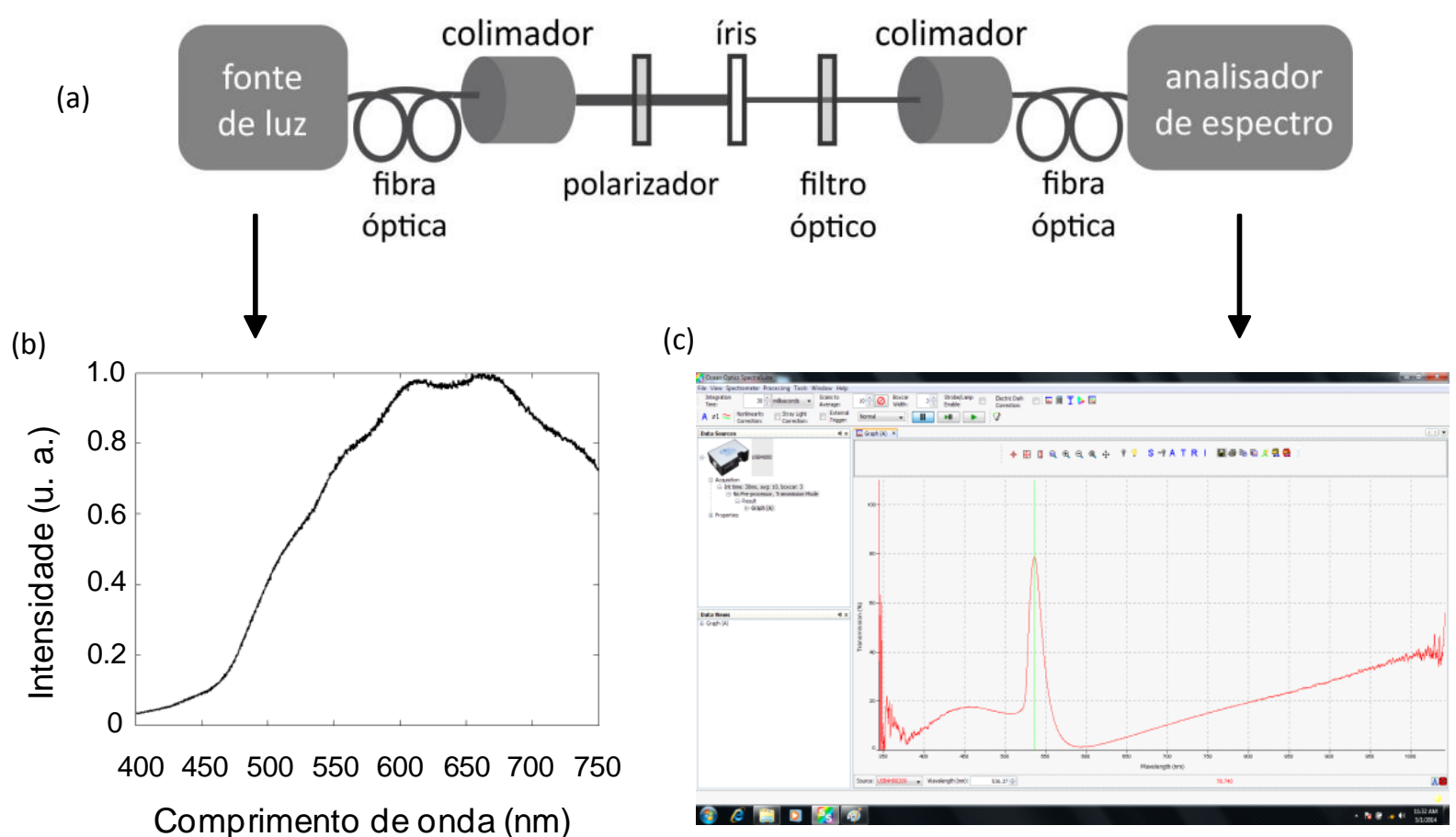

Figura 3.11 - (a) Montagem experimental para medida da resposta óptica dos filtros fabricados.

(b) Espectro da fonte de luz branca usada e (c) imagem que é gerada pelo analisador de espectro óptico.

As respostas espectrais dos filtros fabricados são mostradas na figura 3.12(a)-3-12(c). Os valores medidos estão muito próximos aos simulados de acordo com os parâmetros geométricos medidos. Os três filtros apresentam alta eficiência com relativa largura de banda estreita. A eficiência medida foi de $81 \%, 82 \%$ e $80 \%$ para os filtros azul, verde e vermelho, respectivamente. Com relação a largura de banda transmitida (FWHM) os valores medidos foram: $19 \mathrm{~nm}$ centrado em $454 \mathrm{~nm}$, para o filtro azul; $20 \mathrm{~nm}$ centrado em $536 \mathrm{~nm}$ para o filtro verde e $19 \mathrm{~nm}$ centrado em $651 \mathrm{~nm}$ para o filtro vermelho. As Figs, 3.11(d)-3.11(f) mostram as imagens das cores produzidas pela transmissão dos filtros ópticos. $\mathrm{O}$ filtro azul resultou em uma imagem com coloração roxa. Isso se deve ao fato da fonte de luz usada ter uma banda concentrada na região vermelha, onde a intensidade em $650 \mathrm{~nm}$ é em torno de 9 vezes maior que a intensidade em $450 \mathrm{~nm}$, como pode ser observado na figura 3.11(b). A cor alaranjada observada no filtro vermelho foi associada com a relativa alta banda lateral de transmissão. Convém ressaltar que a percepção das cores que os filtros geram pode ser 
modificada, uma vez que depende do espectro da fonte de luz branca. O importante é a resposta espectral de cada filtro normalizada pela incidência, como mostrado nas Figs. 3.12(a)-3.12(c). Além das cores associadas com a transmissão $\left(\mathrm{T}_{0}\right)$ foi possível também obter as cores puras associadas com os modos guiados, cujos feixes propagam pelo filme de $\mathrm{Al}_{2} \mathrm{O}_{3}$ e deixam a estrutura perpendicularmente ao feixe incidente, e perpendicularmente às grades de alumínio.

(a)

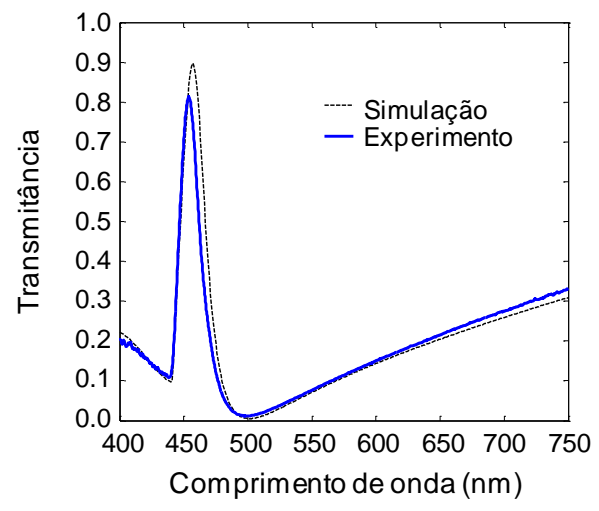

(b)

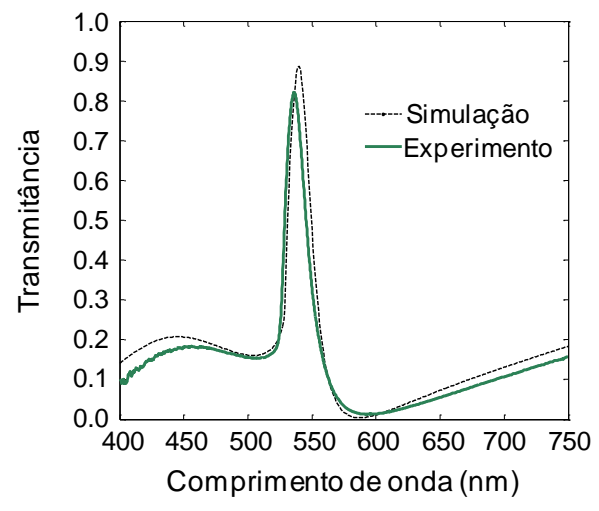

(c)

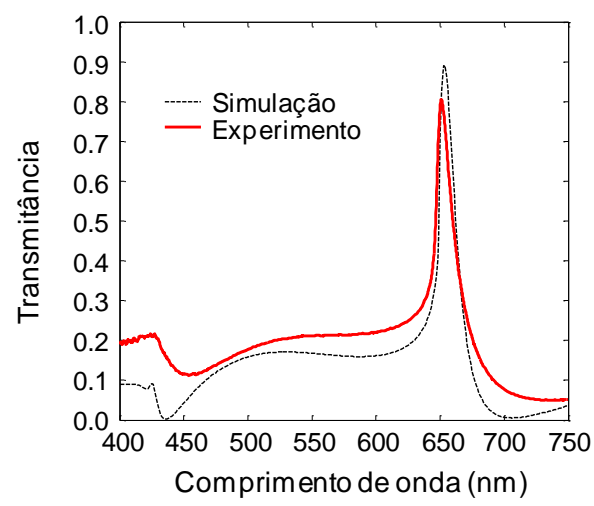

(d)

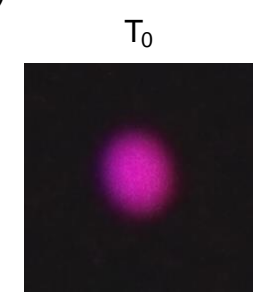

(e)

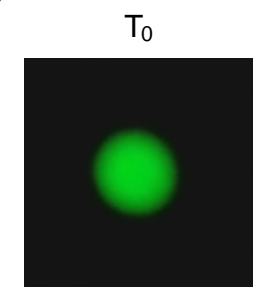

(f)

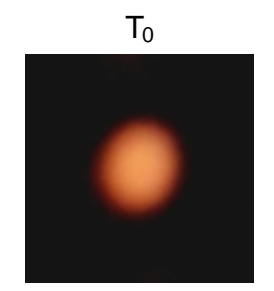

(g)

modo guiado

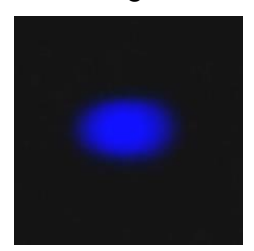

(h)

modo guiado

(i)

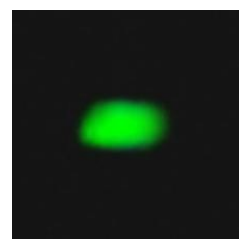

modo guiado

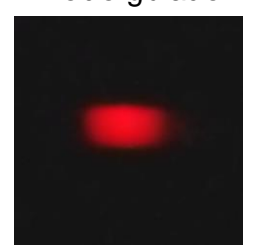

Figura 3.12 - Espectro de transmissão medido (linha contínua) dos filtros fabricados (a) azul, (b) verde e (c) vermelho em comparação com os espectros simulados usando os valores geométricos fabricados (linha pontilhada). (d)-(f) mostram as cores associadas a transmissão $\left(T_{0}\right)$ e $(g)-(i)$ mostram as cores puras associadas aos modos ressonantes. 
Na Fig. 3.13(a) são mostrados um desenho e uma foto da montagem experimental vista por cima (eixo y). Da esquerda para a direita, é possível visualizar o diafragma óptico (íris), por onde passa o feixe de luz branca polarizado que incide no filtro, o feixe azul associado ao modo propagado no filme, que deixa a estrutura perpendicularmente ao feixe incidente e às grades de alumínio (eixo y), e a cor produzida pelo filtro azul na transmissão $\left(\mathrm{T}_{0}\right)$ considerando o espectro da fonte de luz, Fig. 3.11b . O filtro óptico fabricado é mostrado na Fig. 3.13(b). É possível ver uma matriz 3 x 3, onde cada "quadrado" representa um filtro diferente, dependendo das condições de fabricação no sistema interferométrico automático (tempo de exposição).

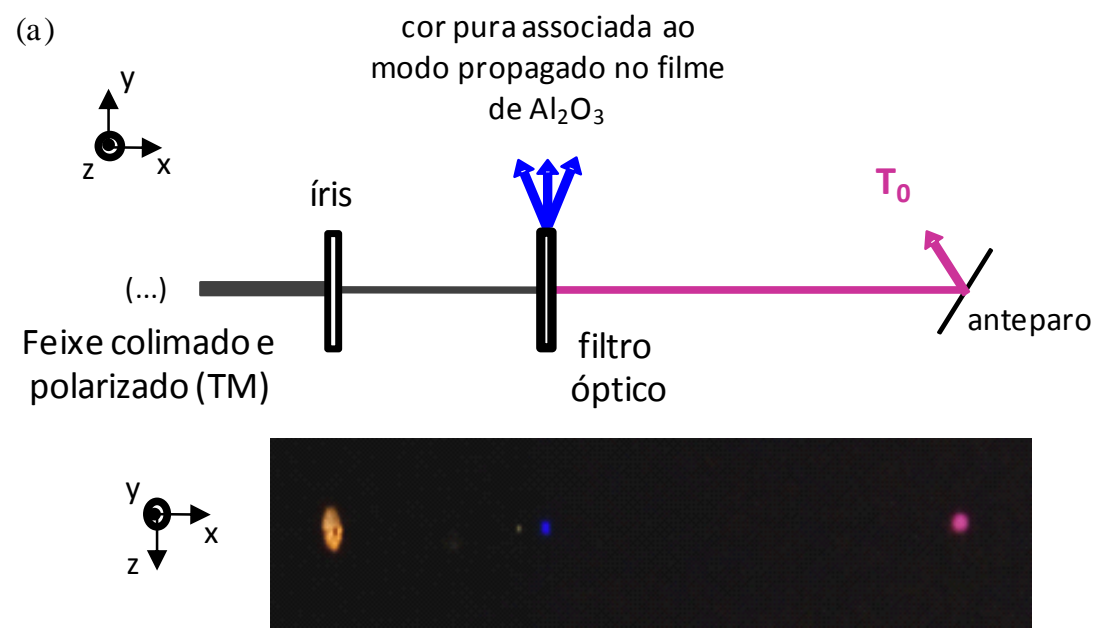

(b)

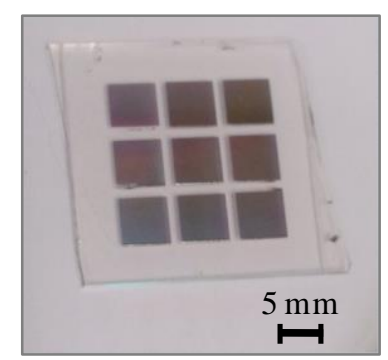

Figura 3.13-(a) Montagem experimental usando o filtro azul, com destaque para a cor associada ao modo propagante e a cor transmitida pelo filtro (TO) e (b) filtro óptico fabricado com 9 condições de fabricação diferentes.

Os resultados experimentais mostraram que é possível obter filtros ópticos de alta performance sem o uso de uma camada dielétrica adicional (buffer). A largura de banda (FWHM) medida para os três filtros foi aproximadamente $20 \mathrm{~nm}$, que é significativamente menor que os $\sim 60 \mathrm{~nm}$ previamente obtidos na literatura usando estrutura semelhante $[142,145]$. Outras larguras de banda podem ser obtidas usando diferentes materiais dielétricos, como óxido de magnésio $\left(\mathrm{n}_{\mathrm{f}} \sim 1.7\right)$, nitreto de silício $\left(\mathrm{n}_{\mathrm{f}} \sim 2.0\right)$ e óxido de titânio $\left(\mathrm{n}_{\mathrm{f}} \sim 2.5\right)$, já que a largura de banda depende do contraste entre o índice de refração do filme e do substrato, como visto na seção 3.3.1. Adicionalmente, pode-se reduzir ainda mais a largura de banda transmitida pela inclusão de uma camada dielétrica (buffer) entre a grade metálica e o guia de onda, como mostrado em [142]. A tabela 1 sumariza os parâmetros simulados e medidos para os filtros azul, verde e vermelho. 
Tabela 3.1 - Parâmetros simulados e medidos para os filtros azul, verde e vermelho

\begin{tabular}{ccccccc}
\hline Filtro & \multicolumn{2}{c}{ Azul } & \multicolumn{2}{c}{ Verde } & \multicolumn{2}{c}{ Vermelho } \\
\hline Parâmetro & Simulado & Medido & Simulado & Medido & Simulado & Medido \\
$\Lambda(\mathbf{n m})$ & 290 & 291 & 350 & 349 & 430 & 428 \\
$\mathbf{F}$ & 0.670 & 0.656 & 0.670 & 0.665 & 0.670 & 0.678 \\
$\mathbf{t}_{\mathbf{g}}(\mathbf{n m})$ & 40 & 40 & 40 & 40 & 40 & 38 \\
$\mathbf{t}_{\mathbf{f}}(\mathbf{n m})$ & 200 & 203 & 200 & 203 & 200 & 208 \\
$\lambda_{\text {pico }}(\mathbf{n m})$ & 456 & 454 & 541 & 536 & 655 & 651 \\
$\mathbf{F W H M}(\mathbf{n m})$ & 22 & 19 & 20 & 20 & 14 & 19 \\
\hline
\end{tabular}

\subsubsection{OBTENÇÃO DE RGB USANDO APENAS O FILTRO VERMELHO}

Um aspecto interessante é que a percepção da cor transmitida por cada filtro pode ser modificada de acordo com o espectro da fonte de luz usada. Na Fig. 3.14(a) é mostrada uma montagem experimental usando o filtro vermelho fabricado. Inicialmente temos um feixe de luz branca colimado e polarizado (TM), cujo espectro está concentrado na região do vermelho, Fig. 3.14(b). É a mesma fonte de luz usada na caracterização espectral dos filtros fabricados (Ocean Optics HL-2000). Usando um filtro comum (no caso um pedaço de plástico verde), o espectro inicial da fonte foi modificado para que ficasse concentrado na região verde, Fig. 3.14(c). Esse feixe espectralmente modificado é usado agora como fonte inicial a ser incidido no filtro vermelho fabricado. A fig. 3.14(d) mostra a resposta espectral após o feixe passar pelo filtro vermelho. É possível ver claramente um pico de transmissão em $651 \mathrm{~nm}$, referente à resposta espectral do filtro vermelho, Fig. 3.12(c). Como a entrada agora tem uma banda concentrada na região verde, a cor transmitida pelo filtro vermelho tem uma coloração verde. A figura 3.14(e) mostra uma fotografia tirada por cima da montagem (eixo y). É possível ver também a cor pura vermelha que deixa a estrutura perpendicularmente ao feixe incidente e às grades de alumínio, e está associada ao modo 
propagante no filme de $\mathrm{Al}_{2} \mathrm{O}_{3}$. As intensidades mostradas nas Figs. 3.14(b)-3.14(d) estão auto-normalizadas para facilitar a visualização.

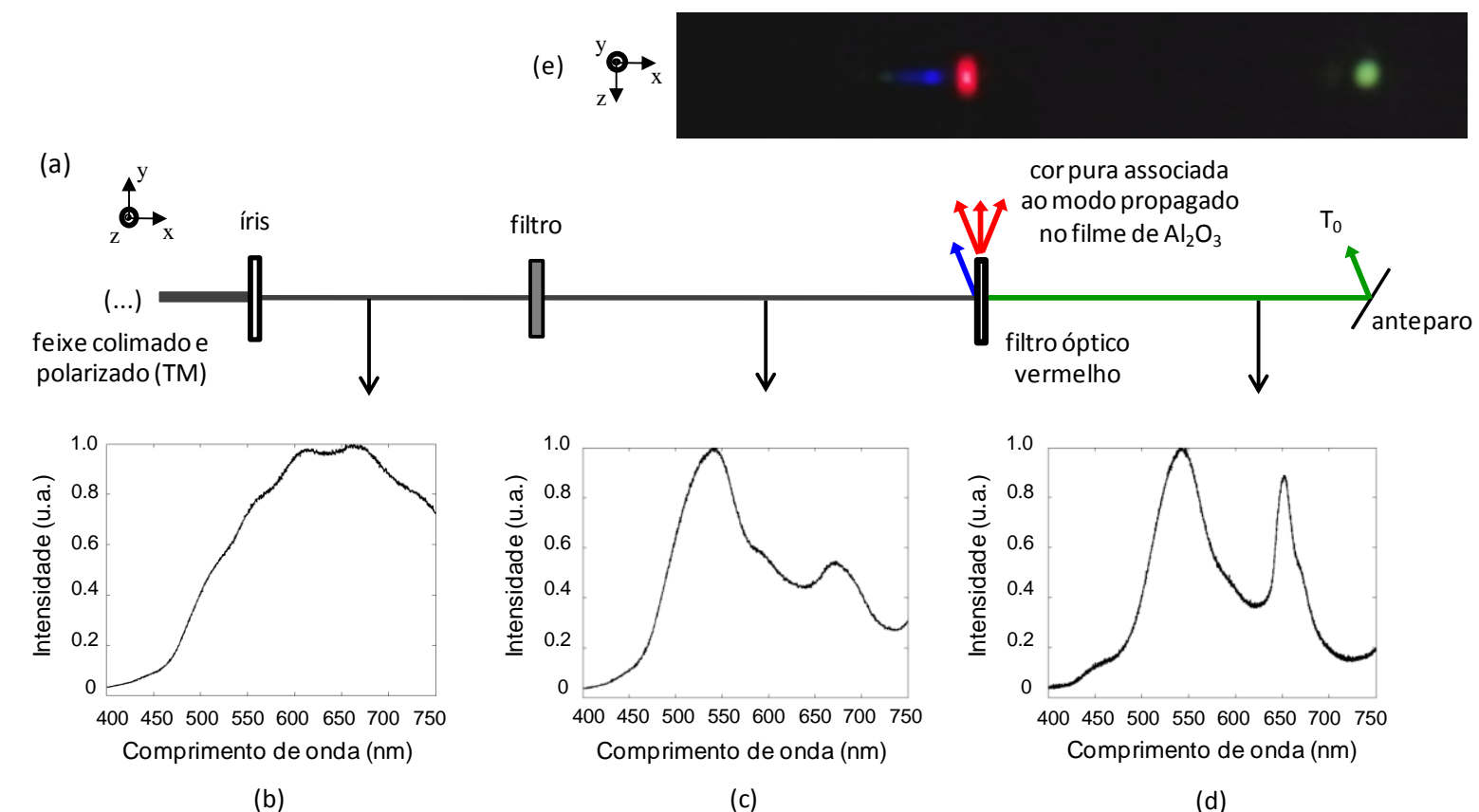

Figura 3.14 - (a) Montagem experimental para obtenção das três cores primárias RGB usando o filtro vermelho, (b) espectro inicial da fonte, (c) espectro modificado usando filtro verde qualquer, (d) espectro medido após o feixe passar pelo filtro vermelho fabricado e (e) fotografia obtida por cima da montagem experimental por cima (eixo y).

Além disso, foi possível obter também uma cor azul, aparentemente pura, que é refletida num ângulo agudo e bem definido em torno de $80^{\circ}$. Mas a cor azul não aparece apenas na reflexão, Fig. 3.15(a); aparece também na transmissão, Fig. 3.15(b). Não foi possível obter informação espectral desse feixe refletido devido à sua baixa intensidade e natureza difusa (não colimado). Sem informação espectral, a origem física do efeito fica incerta. Entretanto podemos nos permitir a tentar interpretar o fenômeno. Observando a resposta espectral calculada para o filtro vermelho, Fig. 3.4(c), vemos que além da anomalia Rayleigh na transmissão em torno de $\lambda_{\mathrm{R}}=\mathrm{n}_{\mathrm{s}} \Lambda=653 \mathrm{~nm}$, existe também uma supressão da transmissão em $\lambda \sim 436 \mathrm{~nm}$, independentemente da espessura do filme de $\mathrm{Al}_{2} \mathrm{O}_{3}$. Essa supressão da intensidade transmitida pode indicar que se trata de um efeito anômalo (o feixe emerge quase rasante à estrutura), que depende do período das grades metálicas. De fato, se calcularmos o comprimento de onda da anomalia Rayleigh para a reflexão temos que $\lambda_{R}=$ $\mathrm{n}_{\mathrm{ar}} \Lambda=430 \mathrm{~nm}\left(\mathrm{n}_{\mathrm{ar}}=1\right)$, um valor bem próximo ao verificado na Fig. 3.4(c). 
(a)

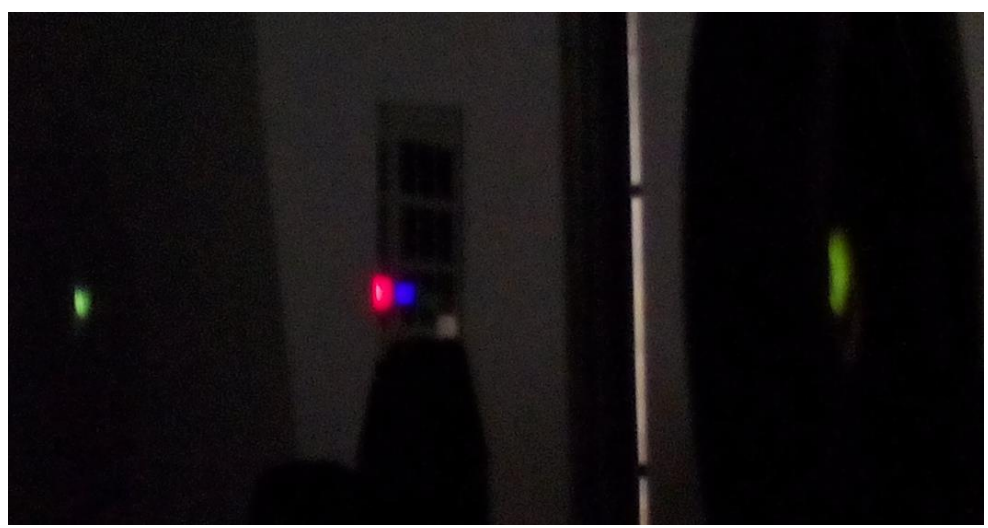

(b)

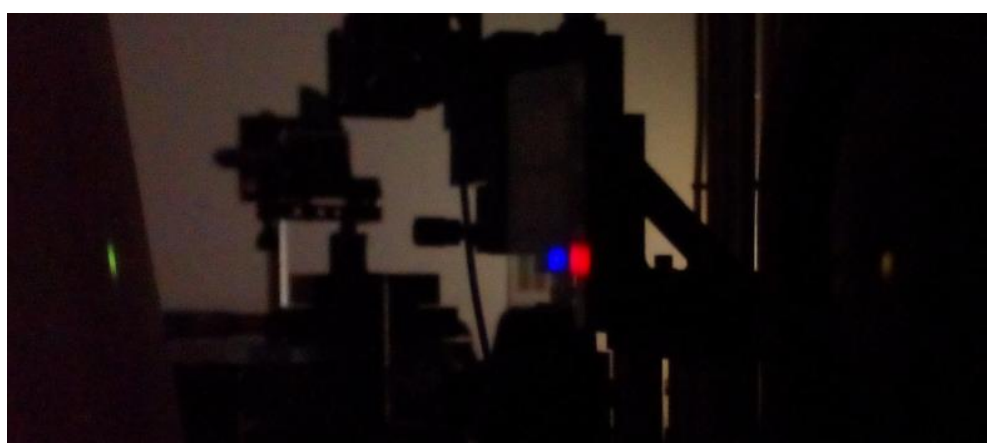

Figura 3.15 - Montagem experimental para obtenção das três cores primárias RGB usando o filtro vermelho. (a) Foto tirada mostrando a cor azul (a) na reflexão e (b) na transmissão.

Deste modo demonstramos experimentalmente a possibilidade de se obter as três cores primárias RGB ao mesmo tempo, usando um único dispositivo. Ao contrário de uma grade de difração (ou prisma) que gera um espectro de cores, este dispositivo gera apenas as três cores primárias, somente ajustando a entrada espectral. Um problema para aplicações práticas é que os feixes produzidos não estão na mesma direção, além da diferença de intensidade relativa entre eles.

\subsection{CONCLUSÃo}

Este capítulo foi dedicado à descrição do projeto, fabricação e caracterização de três filtros ópticos (azul, vermelho e verde) de alta performance. No início foi feita a revisão bibliográfica, onde se procurou estabelecer a motivação para o estudo deste tipo de dispositivo, além de mostrar como os dispositivos atuais podem ser aperfeiçoados. Usando análise numérica foi possível projetar três filtros eficientes considerando uma mesma espessura para o filme dielétrico. Além disso, as simulações forneceram base para um entendimento teórico da estrutura. A resposta espectral dos filtros é uma combinação de ressonância de modo guiado (pico de transmissão) com ressonância de plasmon de superfície 
(mínimo de transmissão), sendo fortemente influenciado pela anomalia Rayleigh quando $\lambda_{\text {pico }}$ se aproxima de $\lambda_{R}$. Verificamos que além da anomalia Rayleigh a estreita largura de banda transmitida se deve ao baixo contraste entre o índice de refração do filme de $\mathrm{Al}_{2} \mathrm{O}_{3}$ e do substrato de vidro. Os filtros foram fabricados usando litografia interferométrica, técnica que possui algumas vantagens incluindo fabricação por exposição única e geração de grades nanométricas sobre uma área extensa. Os parâmetros geométricos dos filtros foram caracterizados por elipsometria e AFM, e os valores encontrados foram bem próximos aos projetados. Experimentalmente, a resposta espectral dos três filtros estão de acordo com as previsões numéricas, apresentando eficiência ao redor de $80 \%$ com largura de banda $20 \mathrm{~nm}$. Foi possível obter alta eficiência sem a necessidade de uma camada adicional separando o guia da grade metálica. Além disso, foi possível mostrar as imagens das cores produzidas pelos filtros na transmissão $\left(\mathrm{T}_{0}\right)$ e associadas aos modos acoplados no filme. Por fim, foi mostrado como o filtro vermelho pode ser usado para se produzir as três cores primárias RGB ao mesmo tempo, ajustando o espectro da fonte luminosa. Os resultados servem também de base para a otimização de estruturas com grades em duas dimensões, operando com luz não polarizada. 


\section{LENTE ÓPTICA BASEADA EM ZONAS DE FRESNEL LINEAR INTEGRADA COM FILME METÁLICO}

Neste capítulo é feita a proposta de uma estrutura que combina placas de zonas de Fresnel (Fresnel zone plates - FZP) integrada com um filme metálico. Resultados numéricos indicam que a inserção de um filme metálico abaixo da FZP pode reduzir significativamente os lóbulos laterais produzidos pela lente. São apresentados: (1) levantamento bibliográfico das principais lentes plasmônicas e a motivação do estudo de estruturas combinando plasmônica e FZP, (2) análise numérica do dispositivo, (3) aspectos da fabricação da estrutura usando litografia por nanoimpressão e (4) avaliação dos resultados.

\subsection{REVISÃo BIBLIOGRÁFICA E MOTIVAÇÃo}

As chamadas placas de zonas de Fresnel são elementos ópticos amplamente usados para focalizar radiação eletromagnética. Consistem em uma série de zonas - lineares ou anulares - que alternam transparência e opacidade. São projetadas de modo que a luz transmitida pelas zonas transparentes interfira construtivamente em um ponto com distância focal desejada. Ao contrário de lentes refrativas convencionais, a FZP usa a difração para focalizar luz, resultando em elementos de espessura e massa reduzidas. Além disso, sua forma planar faz com que a fabricação possa ser realizada em passos únicos, reduzindo custos e possibilitando aplicações em sistemas integrados/miniaturizados. As FZP's têm sido muito usadas em aplicações como litografia e microscopia, especialmente em sistemas de raio-X e UV [149-151], onde muitas vezes representam a única forma viável de focalizar luz.

Recentemente, a plasmônica tem permitido o desenvolvimento de uma nova classe de lentes ópticas, que podem operar abaixo do limite de difração. J. B. Pendry [30] foi o primeiro a mostrar teoricamente o conceito da super lente no ano 2000, propondo o uso de uma placa de índice de refração negativo $(\varepsilon<0$ e $\mu<0)$ para focar todas as componentes de Fourier, inclusive as evanescentes. Logo depois o conceito de super lente foi comprovada experimentalmente em frequências ópticas pelo grupo do professor X. Zhang [152-155], mas seu complexo processo de fabricação ainda limita aplicações práticas. A partir daí vários tipos de estruturas metálicas têm sido reportadas para focalizar luz no espaço livre de modo mais eficiente fazendo uso das ondas SPP. Em 2005, Shi et al propôs um novo tipo de lente, 
constituída de um conjunto de nano-fendas em um filme metálico de mesma profundidade [156]. Cada fenda age como um guia do tipo metal-isolante-metal (MIM), suportando uma onda SPP cuja constante de propagação depende da largura da fenda. Quanto menor a largura da fenda, maior a constante de propagação e consequentemente maior o atraso de fase. Assim, controlando a espessura de cada fenda pode-se obter uma distribuição de fase na saída da lente tal que a luz seja focada em uma distância focal desejada. A verificação experimental dessa lente foi feita por Verslegers et al [157] em 2009, usando um filme de ouro de $400 \mathrm{~nm}$ de espessura e fendas variando de $80 \mathrm{~nm}$ a $150 \mathrm{~nm}$, fabricadas usando feixe de íons focalizados. Outro tipo de estrutura plasmônica funcionando como lente óptica foi proposta por Kim et al [158]. Consiste em uma fenda metálica central única, e uma grade dielétrica em ambos os lados da fenda, acima do metal. A onda SPP excitada na fenda se propaga na direção das grades. O período de cada grade é ajustado de modo que as ondas difratadas resultem em interferência construtiva em uma determinada distância focal. A posição focal é ajustada pelo período de cada grade dielétrica, podendo-se também mudar a direção angular do feixe propagado [159]. Uma lente plasmônica semelhante foi proposta por Jia et al [160], baseada na variação da profundidade de sulcos em um filme metálico. Essa lente tem apenas uma fenda central, e em ambos os lados existem sulcos, que podem ter variação de altura na forma côncava/convexa. A onda SPP guiada pela fenda central se propaga ao longo da superfície do metal, sendo difratada para o campo distante pelos sulcos. Controlando a geometria de cada sulco (altura e separação) pode-se fazer com que os feixes difratados interfiram construtivamente em um determinado ponto focal. Pode ser tanto unidimensional como bidimensional (sulcos em formato de anéis circulares). Além de focar luz no espaço livre, várias lentes têm sido desenvolvidas para concentrar energia na forma de plasmon de superfície. Essas lentes são baseadas em um arranjo de fendas circulares periodicamente espaçadas, cujo período está associado ao comprimento de onda de plasmon $\left(\lambda_{s p p}\right)$. Os plasmons excitados em todas as direções se propagam na interface metal/dielétrico e se interferem construtivamente no foco [161]. Nanofendas circulares têm sido também usadas para produzir dispositivos que geram feixes não-difrativos sobre uma determinada distância, conhecidos também como feixes de Bessel [162-165].

Nesse contexto, algumas estruturas têm sido reportadas unindo plasmônica e placas de zonas de Fresnel de modo a se obter a focalização da luz de maneira mais eficiente no espectro visível. Em 2007, Fu et al demonstraram que uma estrutura combinando plasmon de superfície com FZP produz um foco com propriedades além do limite de difração [166]. Kim et al investigaram a resposta de uma FZP composta por multicamadas metal/dielétrico [167]. 
Outros trabalhos mostraram a possibilidade de se obter foco eficiente usando estruturas que combinam metal com FZP [168-173]. As FZP's metálicas têm maior eficiência de transmissão e maior pico de intensidade no ponto focal que lentes metálicas baseadas em nano-fendas [174].

Assim, o estudo de lentes metálicas vem atraindo cada vez mais atenção, pois possibilita, entre outras propriedades, o foco abaixo do limite de difração. Além disso, o estudo de estruturas difrativas tem importante aplicação, pois esses elementos podem ser usados para o registro de dados em paralelo, substituindo a fibra óptica em aplicações de microscopia de campo próximo [175]. A Fig. 4.1 mostra algumas lentes metálicas e o perfil do foco gerado $[156,158,166]$.

(a)

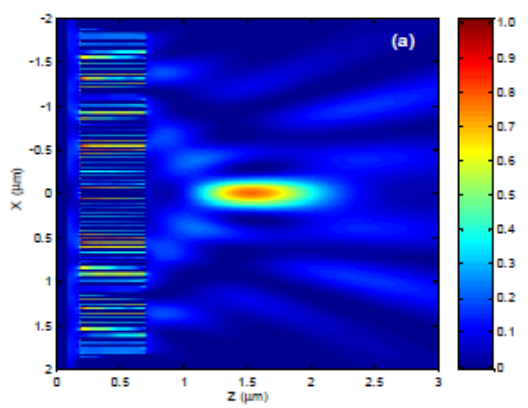

(b)

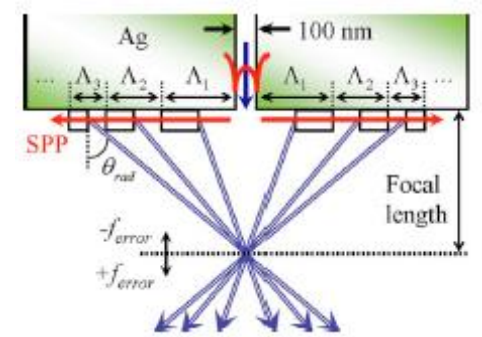

(c)

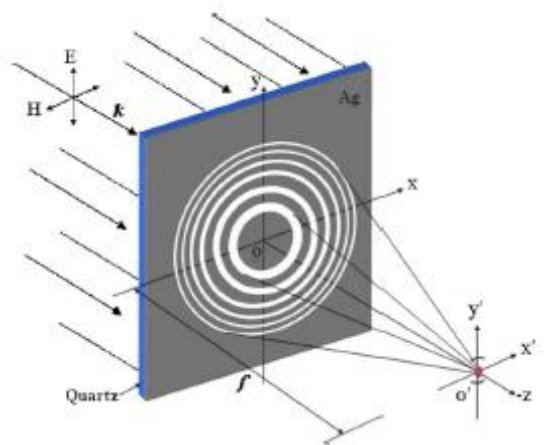

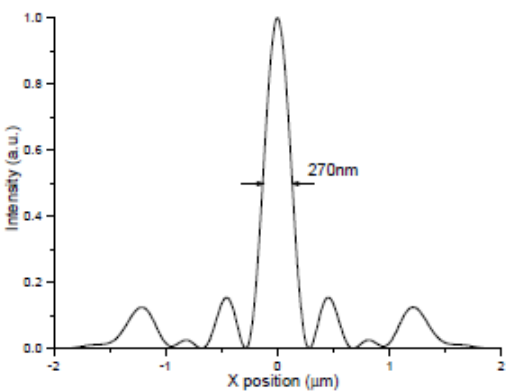
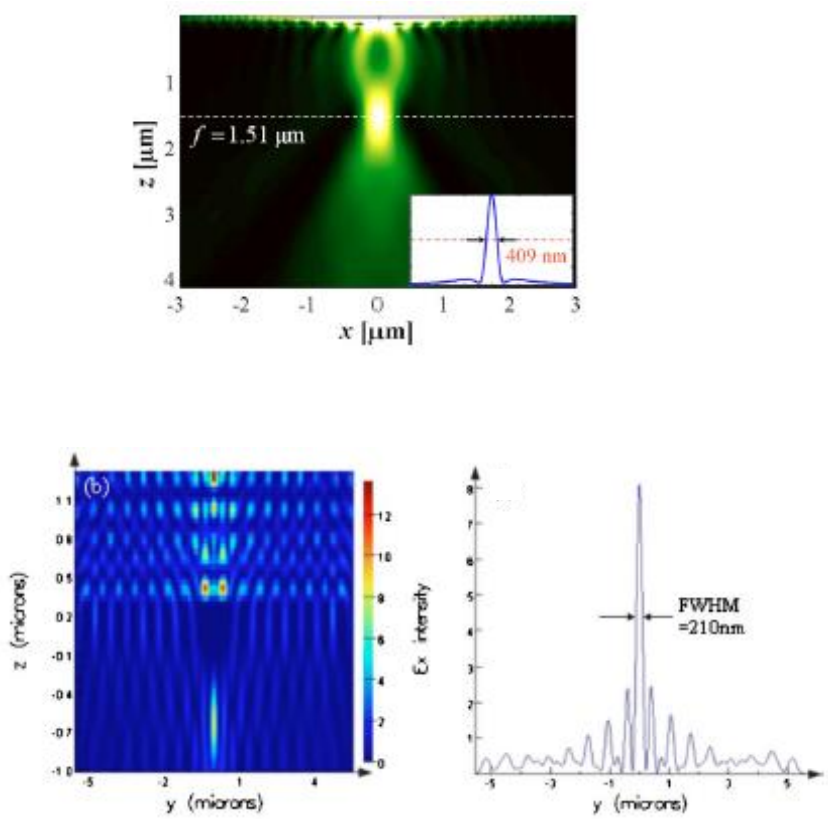

Figura 4.1 - Estrutura de diferentes lentes metálicas e o respectivo perfil do foco gerado. (a) lente baseada em nano fendas [156], (b) lente baseada em fenda única e grades dielétricas [158] e (c) lente combinando metal com FZP para geração de foco com propriedades abaixo do limite de difração [166]. 
Uma das limitações das FZP's convencionais é que a resolução no campo distante é determinada pela largura da menor zona transparente, sendo necessário um grande número de zonas para se aproximar do limite de resolução de Rayleigh [176]. Por outro lado, quando o número de zonas de Fresnel é reduzido, o primeiro lóbulo lateral formado pela lente na distância focal é significativo comparado ao lóbulo principal [177].

Nesse contexto este capítulo apresenta o estudo de uma lente de Fresnel linear integrada com um filme metálico. A análise numérica mostra que ocorre uma redução significativa dos lóbulos laterais pela inserção do filme metálico em uma posição específica. Além disso, a resposta da lente em função da distância FZP-filme mostra que a estrutura tem um comportamento tipo quasi-Fabry-Perot.

\subsection{ESTRUTURA DA LENTE FZP MODIFICADA E PARÂMETROS DAS SIMULAÇÕES}

A estrutura por nós proposta neste capítulo consiste de uma FZP linear integrada com um filme metálico, como esquematizado na Fig. 4.2. A FZP é do tipo positiva, com zona central aberta, e contém 13 zonas $(\mathrm{N}=13)$ gravadas em um filme de ouro de $200 \mathrm{~nm}$ de espessura e preenchidas com ar. $\mathrm{O}$ raio de cada zona satisfaz a equação

$$
r_{n}=\sqrt{n \lambda_{0} f+\frac{n^{2} \lambda_{0}^{2}}{4}}
$$

obtida considerando interferência construtiva na posição focal, onde $n$ é um número inteiro relativo a $n$-ésima zona, $f$ é a distância focal desejada e $\lambda_{0}$ é o comprimento de onda incidente.

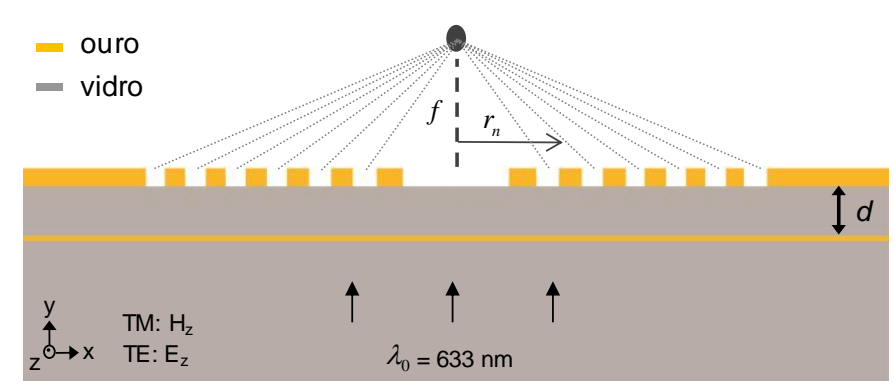

(a)

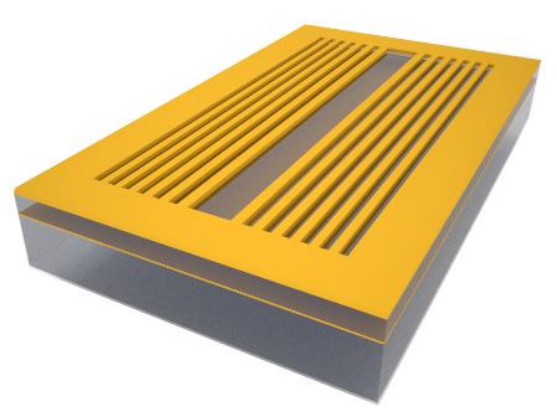

(b)

Figura 4.2 - Estrutura incorporando placas de zonas de Fresnel (FZP) com filme metálico. (a) seção transversal (plano xy) e (b) visão geral do dispositivo. O padrão de intensidade é calculado variando a distância FZP-filme, variável d em (a), para polarização incidente TM e TE. 
A análise numérica foi realizada usando o software comercial Comsol 3.5a, que permite uma profunda discretização espacial, requerida quando se trata de estruturas metálicas nas quais os campos eletromagnéticos variam rapidamente a partir da superfície. Para analisar a resposta da FZP incorporando o filme de ouro foi calculado o padrão da intensidade transmitida variando a distância FZP-filme $(d)$ de 180 a $800 \mathrm{~nm}$, com passo de 10 nm. Os parâmetros usados nas simulações foram: $f=1 \mu \mathrm{m}, \lambda_{0}=633 \mathrm{~nm}$, $\varepsilon_{\text {gold }}=-12.17+$ 1.34i. A espessura do filme foi fixada em $30 \mathrm{~nm}$ (ver seção 4.3.1) e o índice de refração do vidro é 1.457. A análise é feita para onda plana incidente com as duas polarizações, TM e TE. A condição de contorno usada nas bordas da simulação foi Perfect Matched Layers (PML), condição que previne reflexões indesejadas. As análises foram baseadas em simulações 2D, uma vez que o comprimento nas $n$-zonas abertas pode ser fixado relativamente maior que sua largura $(\sim 1.7 \mu \mathrm{m}$ para a zona central). Além disso, a análise $2 \mathrm{D}$ permite uma melhor discretização da estrutura e exige menor recurso computacional. A Fig. 4.3 mostra o ambiente da simulação numérica e a discretização espacial de uma parte da estrutura.

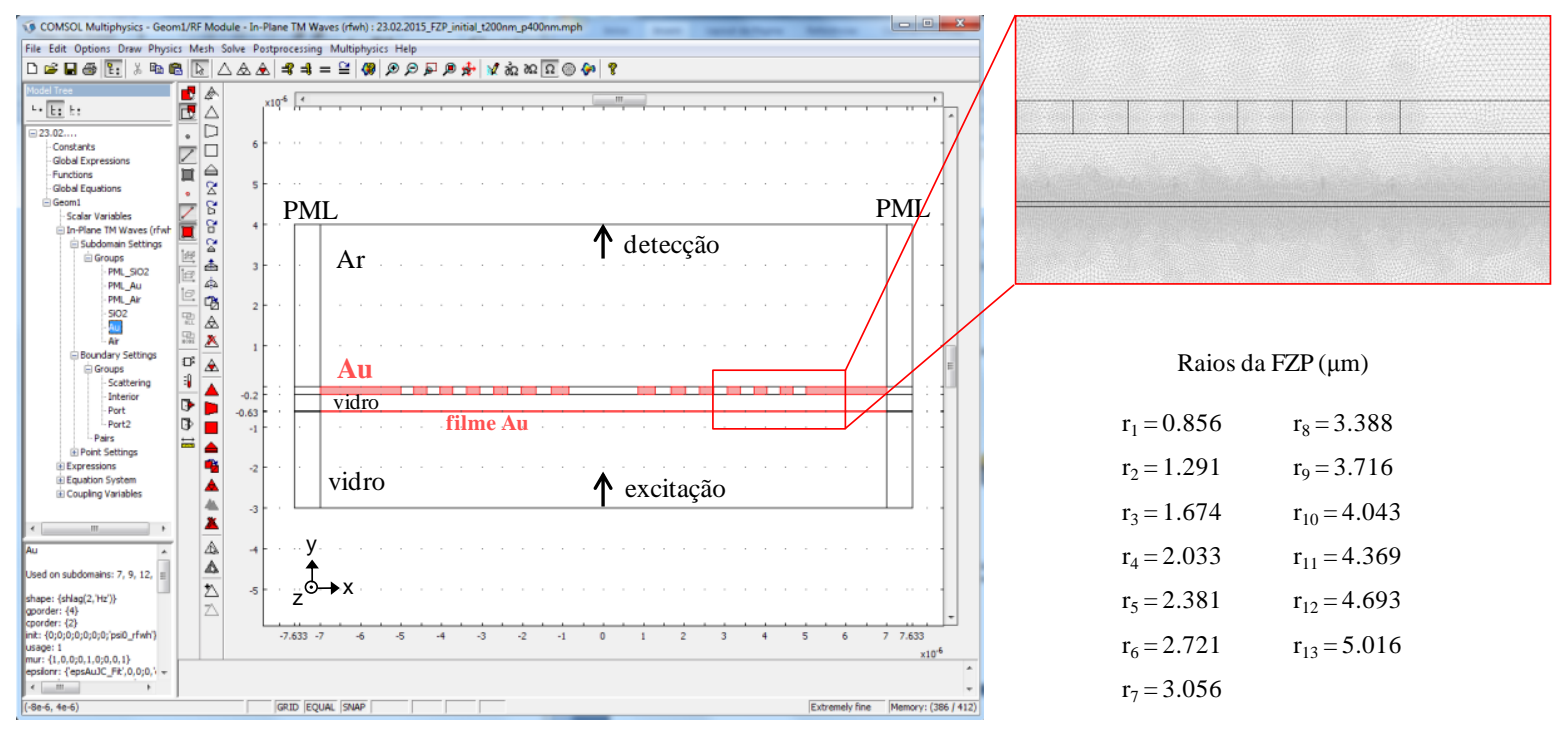

Figura 4.3 - Ambiente de simulação numérica e parâmetros geométricos da FZP. No detalhe é mostrado a discretização especial de uma parte da estrutura; abaixo são mostrados os raios da FZP calculados pela equação 4.1 , considerando $f=1 \mu \mathrm{m}$ e $\lambda_{0}=633 \mathrm{~nm}$.

Para quantificar a resposta da lente como função da distância FZP-filme foi introduzido o parâmetro $R$ (ratio), definido como a razão entre a intensidade no pico $\left(I_{p}\right)$ e a intensidade do maior lóbulo lateral $\left(I_{l}\right)$. Quanto maior o parâmetro $R$, menor são os lóbulos laterais em relação ao lóbulo central, resultando em um padrão de transmissão mais limpo. A intensidade mostrada nas análises realizadas é proporcional a $\left|\mathrm{H}_{\mathrm{z}}\right|^{2}$ para polarização TM e a $\left|\mathrm{E}_{\mathrm{z}}\right|^{2}$ para polarização TE. A Fig. 4.4 mostra a definição do parâmetro $R$. 
(a)

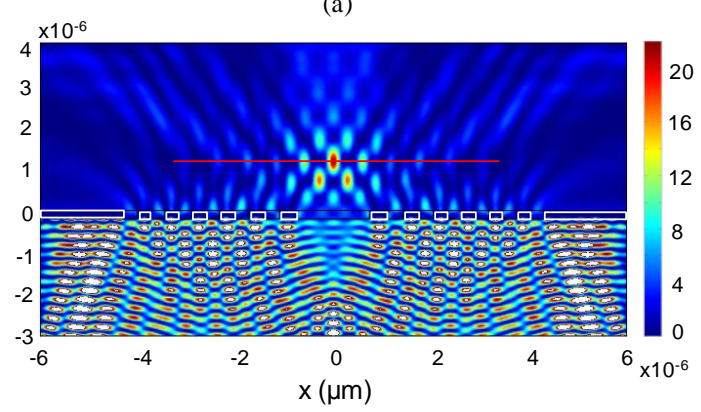

(b)

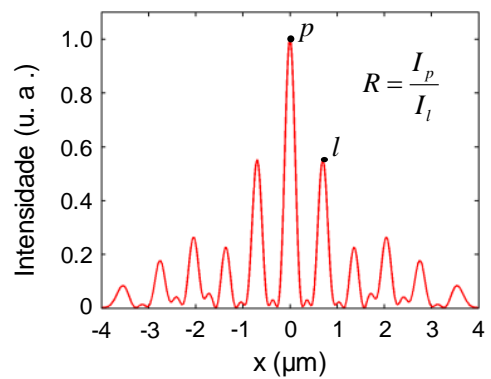

Figura 4.4 - Obtenção do parâmetro R, definido como a razão entre a intensidade no pico $\left(I_{p}\right)$ e a intensidade do maior lóbulo lateral $\left(1_{1}\right)$. (a) Padrão de intensidade transmitida e

(b) intensidade na posição focal, representada pela linha vermelha em (a).

\subsection{RESULTADOS NUMÉRICOS}

O padrão da intensidade transmitida pela FZP com e sem o filme para polarização TM e TE é mostrado na Fig. 4.5. As distâncias FZP-filme para TM e TE são $d=480 \mathrm{~nm}$ e $d=$ $490 \mathrm{~nm}$, respectivamente, correspondendo às distâncias onde a posição do filme metálico resulta num padrão mais limpo, representado pelo maior valor de $R$ encontrado (ver Fig. 4.8). A escala da intensidade foi ajustada para melhor visualização do foco, sendo mantidas as intensidades relativas referentes à mesma polarização.

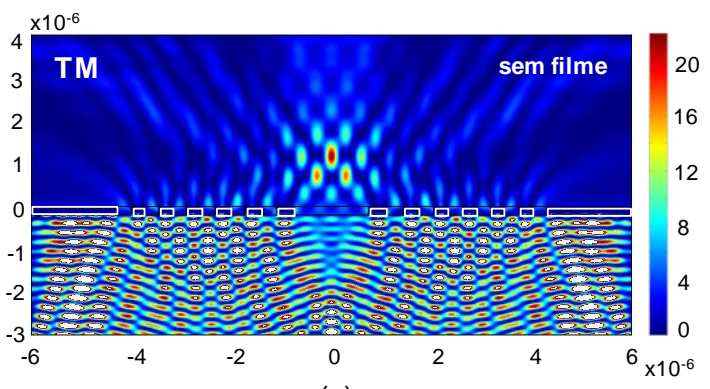

(a)

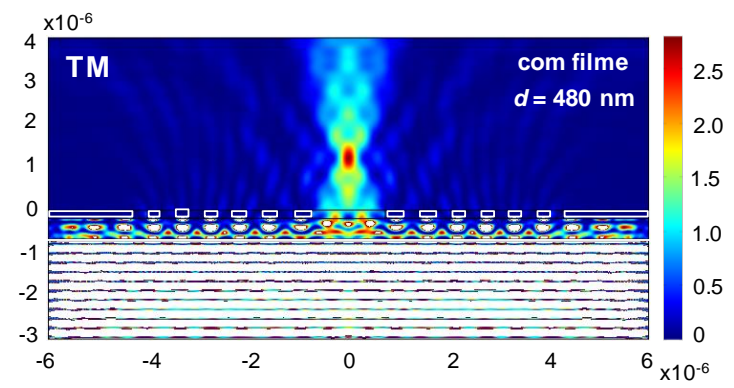

(b)

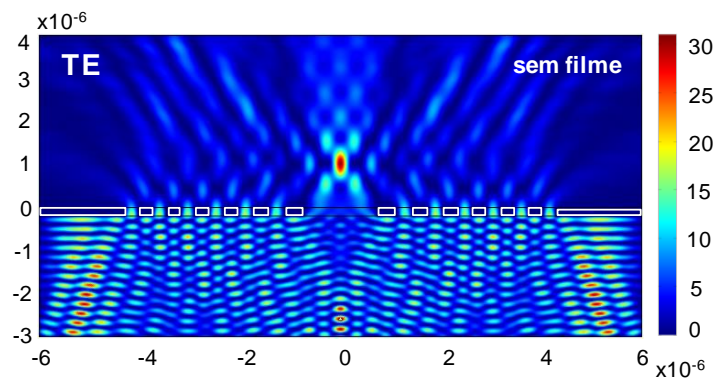

(c)

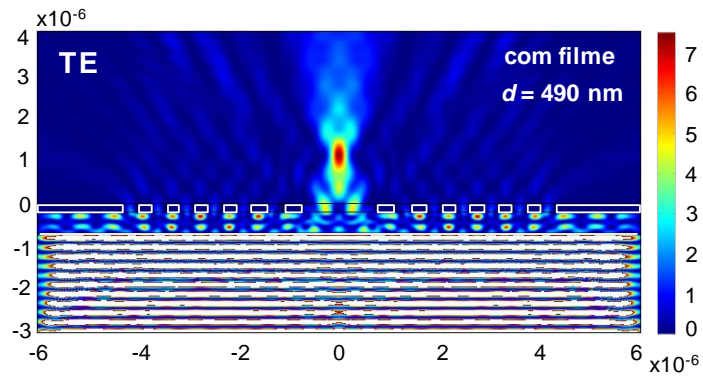

(d)

Figura 4.5 - Padrão da intensidade transmitida pela FZP com e sem o filme para polarização incidente TM e TE. Polarização TM (a) sem o filme e (b) com o filme, $d=480 \mathrm{~nm}$. Polarização TE (c) sem o filme e (d) com o filme, $d=490 \mathrm{~nm}$. A posição focal em (a), (b), (c) e (d) é $1.17 \mu \mathrm{m}, 1.20 \mu \mathrm{m}, 1.02 \mu \mathrm{m}$, and $1.12 \mu \mathrm{m}$, respectivamente. Os retângulos brancos indicam a seção transversal da FZP. 
As Figs. 4.5(a) e 4.5(c) mostram o padrão da intensidade transmitida pela FZP sem o filme para as polarizações TM e TE, respectivamente. É observado um padrão de transmissão "sujo", no qual a intensidade dos lóbulos laterais é comparável com a intensidade no foco. As distâncias focais para TM e TE são $1.17 \mu \mathrm{m}$ e $1.02 \mu \mathrm{m}$, respectivamente, sendo o foco projetado $f=1 \mu \mathrm{m}$. Observa-se então um melhor desempenho da FZP para a polarização TE. Isso se deve ao fato de que a equação usada para calcular os raios das zonas de Fresnel prevê a interferência construtiva na distância focal considerando onda plana incidente e nenhum atraso de fase entre as fendas. A equação funciona para polarização TE, mas para TM cada fenda da FZP pode ser considerada como um guia do tipo metal-isolante-metal (MIM), e desde que a constante de propagação da onda SPP depende da largura de cada fenda, existe um atraso de fase relativo. A Fig.4.6 mostra as fendas da FZP, e a tabela 4.1 mostra a largura de cada fenda, a constante de propagação $\beta$ obtida pela equação transcendental (2.16a) e o respectivo índice de refração efetivo. $\mathrm{O}$ atraso de fase relativo entre as fendas na polarização TM resultou em uma distância focal $17 \%$ maior que a projetada. A espessura da FZP (200 $\mathrm{nm}$ ) foi escolhida levando em conta a diminuição do atraso de fase relativo, mas garantindo que a lente fosse opticamente espessa.

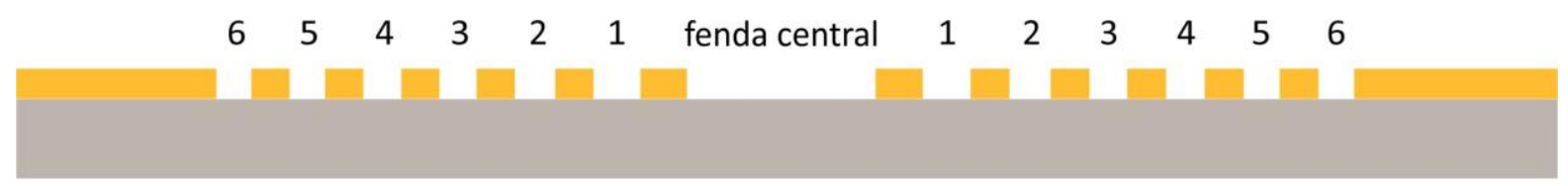

Figura 4.6 - Geometria da lente FZP.

Tabela 4.1 - Geometria da lente FZP. Largura das fendas, constante de propagação $\beta$ e respectivo índice de refração efetivo $\mathrm{n}_{\text {eff }}$.

\begin{tabular}{cccccccc}
\hline Fenda & Central & $\mathbf{1}$ & $\mathbf{2}$ & $\mathbf{3}$ & $\mathbf{4}$ & $\mathbf{5}$ & $\mathbf{6}$ \\
\hline largura (nm) & 1712.5 & 382.5 & 347.6 & 335.0 & 328.8 & 325.4 & 323.15 \\
$\boldsymbol{\beta}(\mathbf{1 0} / \mathbf{n m})$ & 10.3653 & 10.8373 & 10.9073 & 10.9363 & 10.9513 & 10.9599 & 10.9655 \\
$\mathbf{n}_{\text {eff }}$ & 1.0443 & 1.0918 & 1.0989 & 1.1018 & 1.1039 & 1.1042 & 1.1047 \\
\hline
\end{tabular}

Quando o filme metálico é integrado sob a FZP observa-se uma melhora significativa da resposta da lente, com alta supressão dos lóbulos laterais para ambas as polarizações incidentes. As Figs. 4.5(b) e 4.5(d) mostram o padrão da intensidade transmitida pela estrutura com a distância $d=480 \mathrm{~nm}$ e $d=490 \mathrm{~nm}$, para TM e TE, respectivamente. A 
posição focal da FZP com a integração do filme aumentou e está localizada em $f=1.20 \mu \mathrm{m}$ (TM) e $f=1.12 \mu \mathrm{m}$ (TE). As Figs, 4.7(a) e 4.7(b) mostram a seção transversal da intensidade na posição focal (direção $x$ ), comparando a resposta da FZP com e sem o filme para TM e TE, respectivamente. As intensidades estão auto-normalizadas para melhor visualização. Claramente nota-se uma significativa redução dos lóbulos laterais devido a inserção do filme metálico. A razão entre a intensidade no foco e a intensidade do maior lóbulo lateral (parâmetro $R$ ) aumentou de 1.81 para 5.44 para polarização TM, e de 2.94 para 14.05 para polarização TE. Os lóbulos laterais foram reduzidos por um fator 3.0 para TM e 4.8 para TE com a inserção do filme. A largura a meia altura na posição focal (FWHM) aumentou com a inserção do filme, passando de $241 \mathrm{~nm}$ para $374 \mathrm{~nm}$ para TM, e de $265 \mathrm{~nm}$ para $337 \mathrm{~nm}$ para TE. Apesar de reduzir os lóbulos laterais a inserção do filme provoca uma queda significativa da intensidade na posição focal, de aproximadamente $87 \%$ para TM e $76 \%$ para TE.
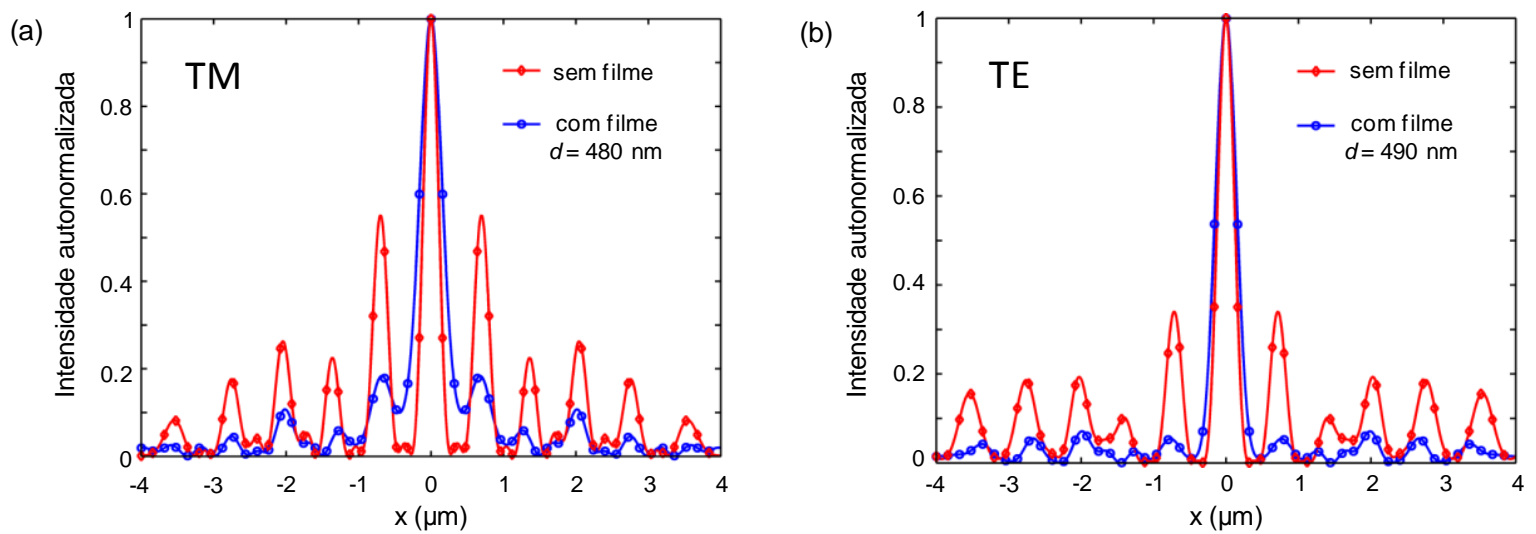

Figura 4.7 - Perfil da intensidade no posição focal ao longo do eixo x para polarização incidente (a) TM e (b) TE. Linhas azul e vermelha representam os perfis de intensidade com e sem o filme, respectivamente.

A definição da melhor posição do filme metálico sob a FZP mostrada na análise acima foi obtida da seguinte forma: (1) cálculo da intensidade transmitida variando a posição do filtro de $180 \mathrm{~nm}$ a $800 \mathrm{~nm}$, com passo de $10 \mathrm{~nm}$; (2) para cada posição do filme foi obtido o perfil da intensidade na posição focal em função do eixo $x$; (3) para cada posição do filme foi obtida a razão entre a intensidade no foco e a intensidade do maior lóbulo lateral, parâmetro $R$. A Fig. 4.6 mostra os valores de $R$ calculados para polarização TM e TE em função da distância FZP-filme. Para TE, três pontos intermediários em $d=205$, 485 e $765 \mathrm{~nm}$ foram calculados para levar em conta a rápida variação de $R$. Note que existem dois pontos descontínuos no eixo referente a distância FZP-filme. Isso se deve ao fato de que nessas regiões o dispositivo não gera um foco único, e consequentemente não é possível calcular a 
razão entre a intensidade focal e do maior lóbulo lateral. A Fig. 4.8 mostra os padrões da intensidade transmitida correspondente aos picos de $R$, para polarização incidente TM e TE.

(a)

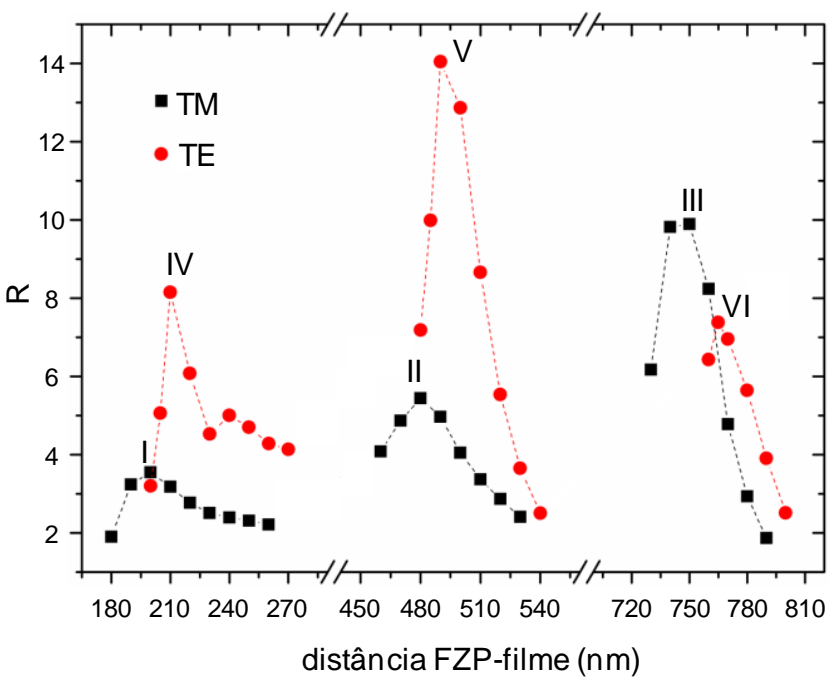

TM

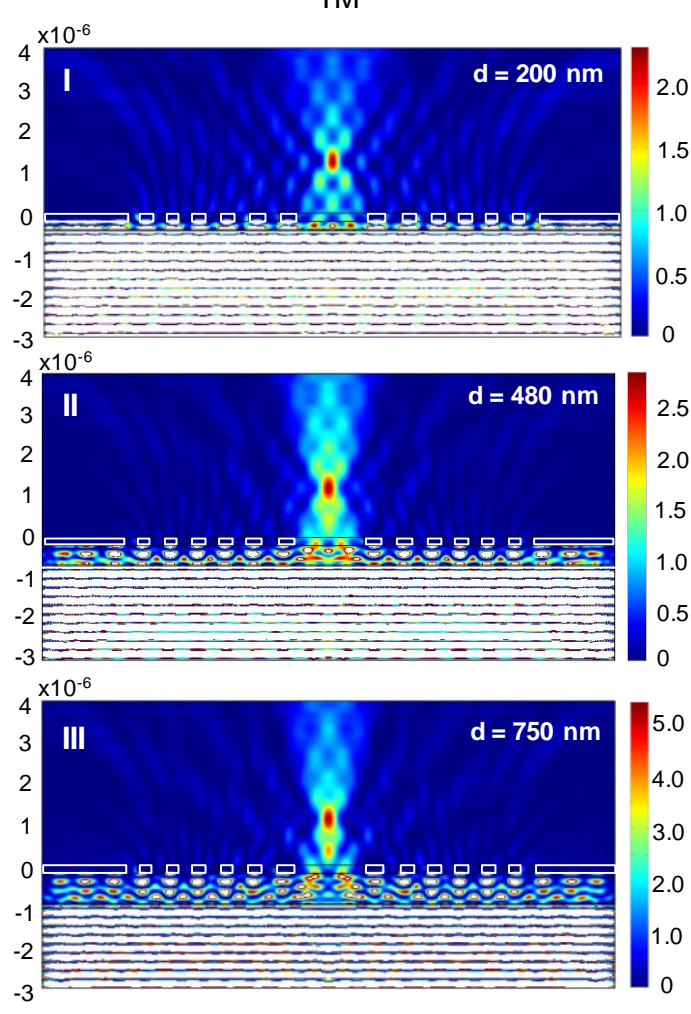

TE

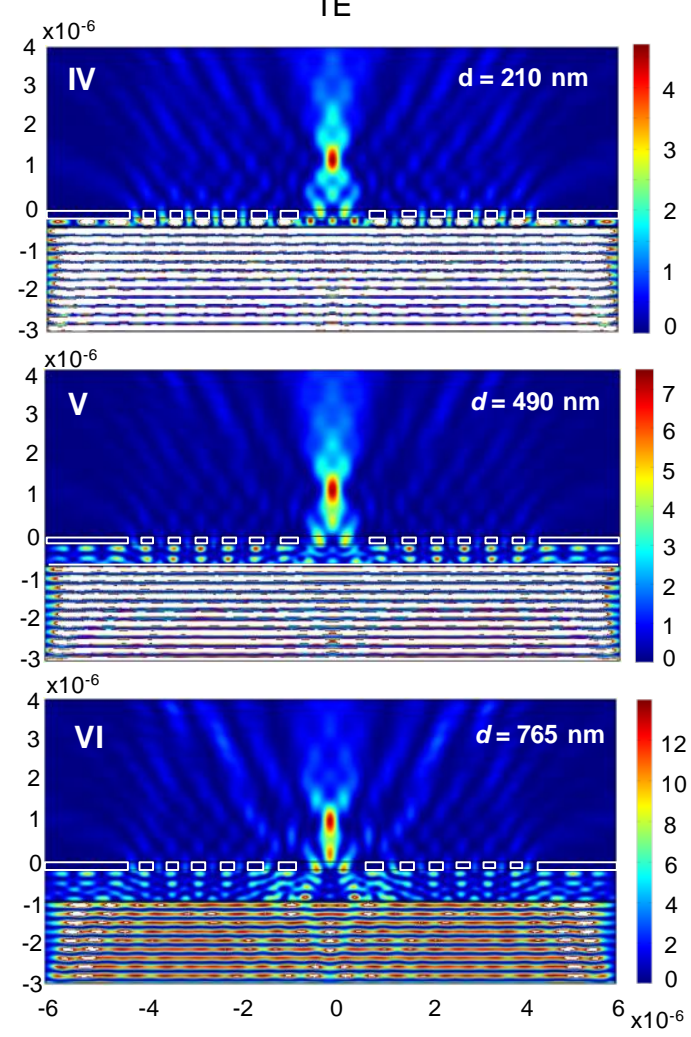

Figura 4.8 - (a) Cálculo do parâmetro $R$, definido como a razão entre a intensidade no foco e a intensidade do maior lóbulo lateral, como função da distância FZP-filme. Note que existem duas descontinuidades no eixo $x$, representando regiões onde $o$ dispositivo não gera um foco único. (b) Padrão de intensidade correspondendo aos picos de $R$ em (a) para TM e TE. Os retângulos brancos indicam a seção transversal da FZP. 
Observa-se na Fig. 4.8(a) que os picos de $R$, e consequentemente a posição do filme onde resulta um padrão de transmissão mais limpo, varia quasi-periodicamente com a distância FZP-filme. Os três picos de $R$ para TM estão localizados nas distâncias $d=200 \mathrm{~nm}$, $d=480 \mathrm{~nm}$ e $d=750 \mathrm{~nm}$. Para TE, os picos estão localizados nas distâncias $d=210 \mathrm{~nm}, d=$ $490 \mathrm{~nm}$ e $d=765 \mathrm{~nm}$. A separação entre os picos é $280 \mathrm{~nm}$ e $270 \mathrm{~nm}$ para TM, e $280 \mathrm{~nm}$ e $275 \mathrm{~nm}$ para TE. O comprimento de onda no substrato é $\lambda / n=435 \mathrm{~nm}$, portanto a separação entre dois picos de $R$, ou seja, a separação entre as distâncias FZP-filme que resultam em padrão de intensidade limpo, é um pouco maior que $\lambda_{0} / 2 n=218 \mathrm{~nm}$. A resposta da lente variando a distância FZP-filme exibe um comportamento quasi Fabry-Perot. A Fig. 4.8(b) mostra o padrão de intensidade transmitida nos picos de $R$ para TM e TE, correspondentes aos pontos I-VI na Fig. 4.8(a).

O comportamento ressonante do dispositivo incorporando FZP e filme metálico pode ser verificado observando o campo eletromagnético na região entre o filme e a lente. Figs. 4.9(a)-4.9(d) mostram o padrão de intensidade transmitida para TM e TE em duas situações diferentes: (1) o filme está localizado em uma posição que gera um padrão limpo (alto valor de $R$ ) e (2) o filme está localizado em uma posição intermediária onde o dispositivo não gera um foco único, correspondente a ponto localizado na descontinuidade do eixo $x$ na Fig. 4.8(a). Pode ser verificado nas Figs. 4.9(b) e 4.9(d) que quando o filme encontra-se numa posição intermediária entre altos valores de $R$ o dispositivo não atua como lente. Os correspondentes campos magnético e elétrico entre o filme e a FZP são mostrados nas Figs. 4.9(e)-4.9(h). Para distâncias FZP-filme que resultam em alto valor de $R$ verifica-se que os campos mostram um perfil quasi-estacionário entre o filme e as zonas da FZP, Figs. 4.9(e) e 4.9(h). Em situações onde o filme está localizado entre valores de alto $R$ (posição onde não gera foco) os campos eletromagnéticos não apresentam perfil estacionário, Figs. 4.9(f) e 4.9(h). 
(a)

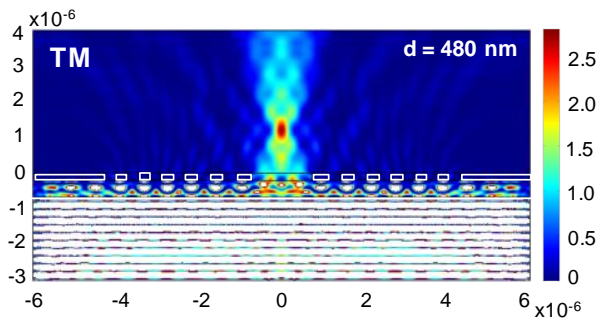

(b)

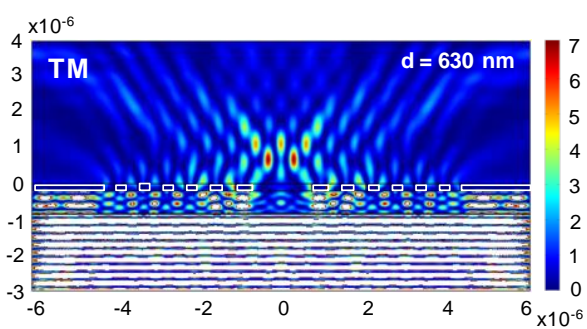

(c)

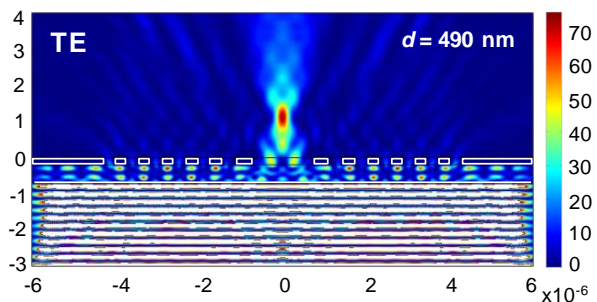

(d)

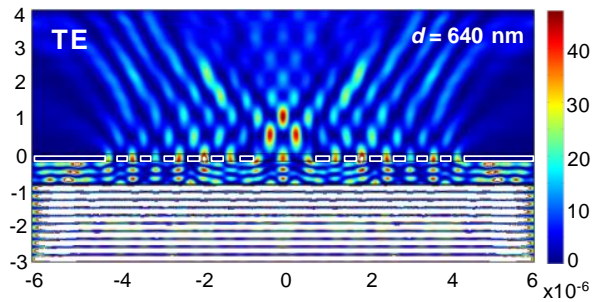

(e)

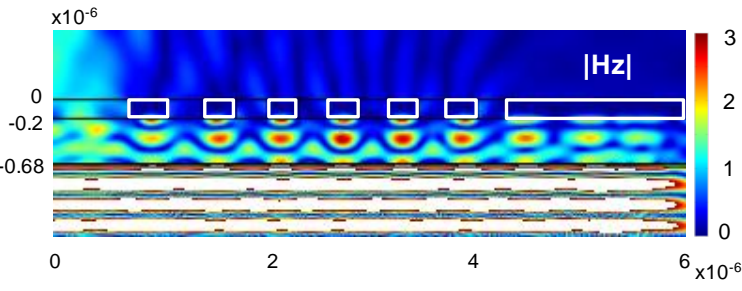

(f)

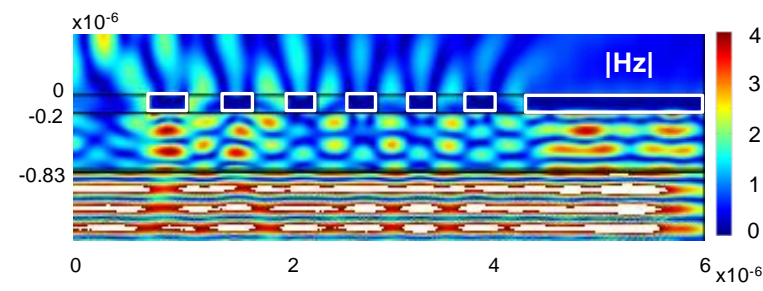

(g)

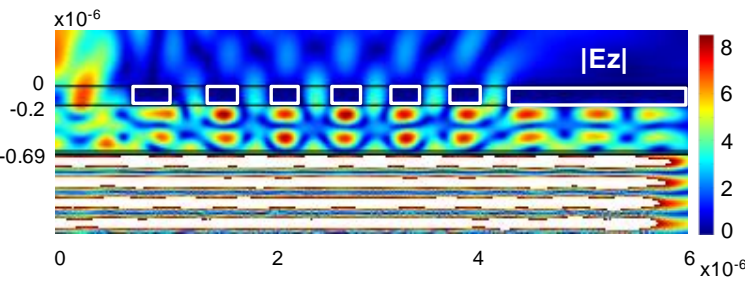

(h)

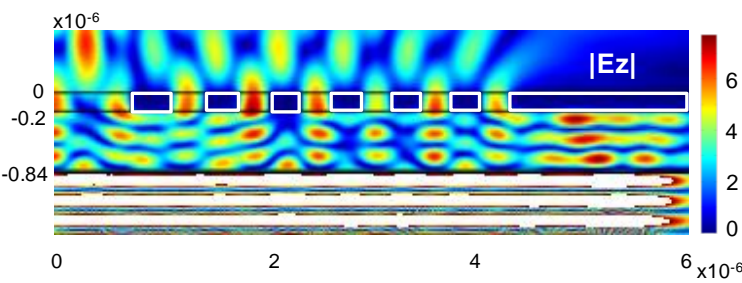

Figura 4.9 - Padrão de intensidade transmitida para TM e TE em duas situações diferentes: $(a, c)$ filme localizado em uma posição correspondente ao pico de $R$ e (b,d) filme localizado em uma posição onde o dispositivo não gera foco. Na segunda coluna estão representados os respectivos campos $(e, f)$ magnético e $(g, h)$ elétrico, entre a lente FZP e o filme metálico.

\subsubsection{ANÁlISE DA ESPESSURA DO FILME DE OURO SOB A FZP}

Para avaliar o efeito da espessura do filme de ouro sob a lente FZP na resposta do dispositivo foi calculado o padrão de intensidade transmitido variando a espessura do filme de 0 (sem filme) até $50 \mathrm{~nm}$, com passo de $5 \mathrm{~nm}$, para polarização incidente TM e TE. A distância $d$ é fixada em $480 \mathrm{~nm}$ para TM e em $490 \mathrm{~nm}$ para TE. A partir dos cálculos foi obtido a constante $R$ e a intensidade na posição focal, para as polarizações TM e TE, mostradas na Fig. 4.10. As intensidades estão autonormalizadas para melhor visualização. 
(a)

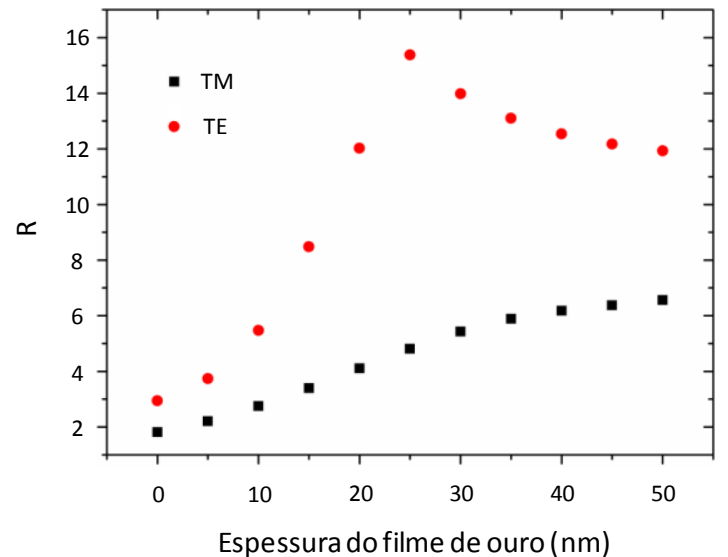

(b)

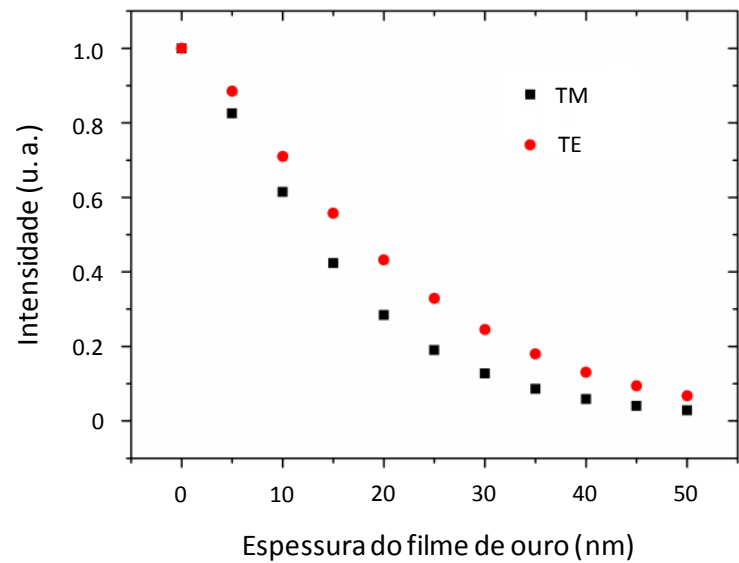

Figura 4.10 -Análise do efeito da espessura do filme de ouro na resposta do dispositivo. Valores calculados de (a) R e (b) intensidade na posição focal, autonormalizada, em função da espessura do filme de ouro. Os quadrados pretos referem-se a polarização TM e os círculos vermelhos à polarização TE.

A escolha da espessura do filme metálico igual a $30 \mathrm{~nm}$ foi feita balanceando a melhora no padrão de transmissão (dado pela diminuição da intensidade do maior lóbulo lateral em relação à intensidade na posição focal) com a intensidade na posição focal .

A tabela 4.2 faz um resumo dos parâmetros da FZP com e sem o filme, para polarização TM e TE.

Tabela 4.2 - Parâmetros dos dispositivo calculados com e sem o filme, para polarização TM e TE

\begin{tabular}{ccccc}
\hline Polarização & Distância FZP-filme $(\mathbf{n m})$ & Posição focal $(\boldsymbol{\mu m})$ & FWHM $(\mathbf{n m})$ & $\boldsymbol{R}$ \\
\hline \multirow{2}{*}{ TM } & Sem filme & 1.17 & 241 & 1.81 \\
& $\mathrm{~d}=200$ & 1.25 & 301 & 3.55 \\
& $\mathrm{~d}=480$ & 1.20 & 374 & 5.44 \\
& $\mathrm{~d}=750$ & 1.12 & 346 & 9.89 \\
\hline \multirow{2}{*}{ TE } & Sem filme & 1.02 & 265 & 2.94 \\
& $\mathrm{~d}=210$ & 1.23 & 315 & 8.16 \\
& $\mathrm{~d}=490$ & 1.12 & 337 & 14.05 \\
& $\mathrm{~d}=765$ & 1.00 & 327 & 7.39 \\
\hline
\end{tabular}




\subsection{FABRICAÇÃo E CARACTERIZAÇÃo}

Inicialmente a fabricação da lente foi esquematizada para ocorrer nas seguintes etapas: (1) deposição do filme de ouro ( 30 nm) sobre um substrato de vidro, (2) deposição do filme de $\mathrm{SiO}_{2}(\sim 480 \mathrm{~nm})$, (3) deposição do filme de ouro ( 200 nm) e (4) uso do equipamento FIB para "esculpir" a lente FZP no filme de ouro situado no topo da amostra. Ao final do processo o dispositivo teria a estrutura esquematizada na Fig. 4.2. Porém, durante as visitas técnicas realizadas pelo autor, não foi possível o acesso ao equipamento FIB. Deste modo, outro método foi sugerido na fabricação do dispositivo: litografia por nanoimpressão, a ser realizada por meio de visita técnica ao VTT - Finlândia (seção 1.6.2). O esquema de fabricação baseado na transferência de um padrão previamente fabricado para um filme de polímero está esquematizado na Fig. 4.11.

polímero $\quad$ ouro vidro molde

(a)
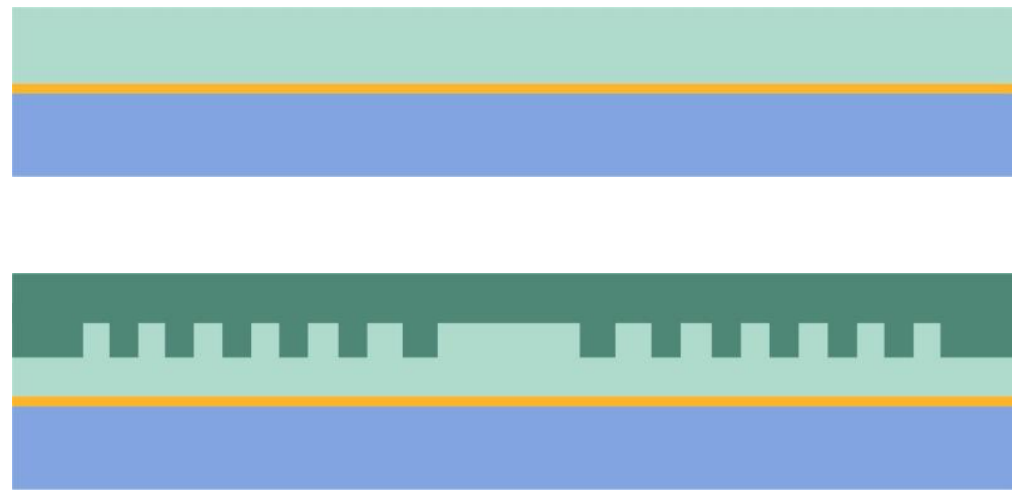

(b)

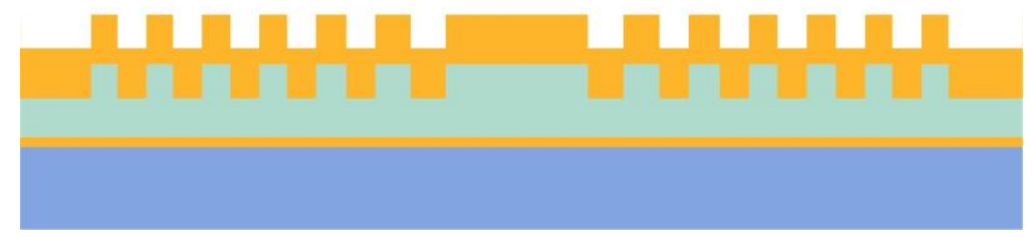

(d)

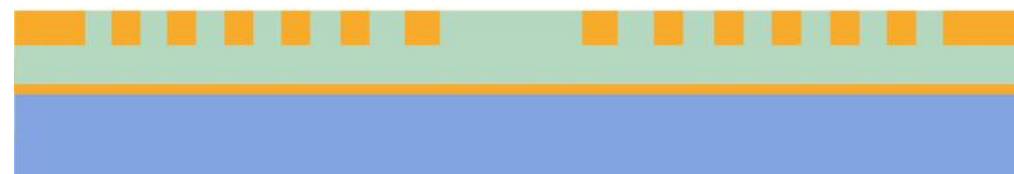

Figura 4.11 - Sequência de fabricação usando litografia por nanoimpressão. (a) substrato de vidro com o filme de ouro e polímero no topo, (b) nanoimpressão, (c) deposição de ouro e (d) processo de polimento. 
Inicialmente temos um substrato de vidro no qual foi depositado uma camada de 30 $\mathrm{nm}$ de ouro. Para melhor adesão do ouro, uma fina camada de cromo ( $\sim \mathrm{nm})$ é depositada sobre o substrato. Em seguida usa-se um spin coater para se obter uma película de polímero (Ormocore Micro Resist Technology, [178]) sobre o filme de ouro, Fig. 4.11(a). Tem-se então o início do processo de nanoimpressão, onde o molde é pressionado contra o filme de polímero, Fig. 4.11(b). Após a cura e separação do molde, é depositado 200 nm de ouro sobre o polímero, Fig. 4.11(c). Por fim, um processo de polimento do metal finaliza a fabricação do dispositivo, Fig. 4.11(d). A estrutura fabricada por nanoimpressão possui duas diferenças com relação a estrutura projetada usando FIB: (1) no lugar da camada de vidro entre o filme e a lente FZP tem-se agora um material de polímero, ou seja, muda-se o índice de refração, e (2) as fendas da FZP estão preenchidas do mesmo material polimérico, ao contrário da fabricação usando FIB. Essas diferenças na estrutura básica não altera o comportamento tipo Fabry-Perot do dispositivo, porém ocorrem mudanças nos valores numéricos referente às distâncias FZP-filme que geram um padrão de transmissão com lóbulos laterais reduzidos. No apêndice A são mostrados os resultados numéricos considerando esta nova configuração. Considerando estrutura fabricada por nanoimpressão, a distância FZP-filme que resulta em um pico de $R$ está em torno de $420 \mathrm{~nm}$ para polarização TM e $440 \mathrm{~nm}$ para polarização TE.

O molde foi previamente fabricado na University of Eastern Finland, e já estava disponível no período da visita técnica. Foi fabricado em silício usando procedimento padrão: (1) deposição de fotoresiste [179], (2) exposição por feixe de elétrons (EBL), (3) revelação, (4) processo de etching (2 minutos, PLasmaLab 100) e (5) remoção do resiste. A Fig. 4.12(a) mostra uma imagem de microscopia eletrônica de um conjunto de moldes 5 x 7 fabricados usando diferentes EBL doses, e a Fig. 4.12(b) mostra o detalhe de um molde correspondente à lente FZP. A altura do padrão medida usando perfilômetro foi $\approx 245 \mathrm{~nm}$. Note que o molde em Si é o complementar da lente FZP. A partir desse molde foi feito um negativo, pressionando-o contra uma película de polímero espessa. Durante a compressão faz-se a cura do polímero usando radiação UV ( 2 minutos). Em seguida o negativo do molde é usado para imprimir a lente no polímero. 
(a)

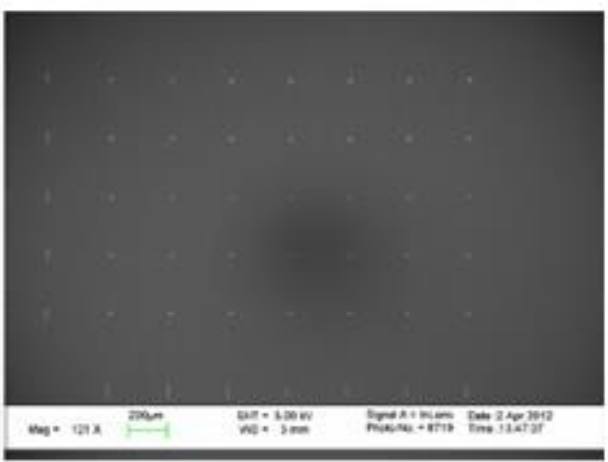

(b)

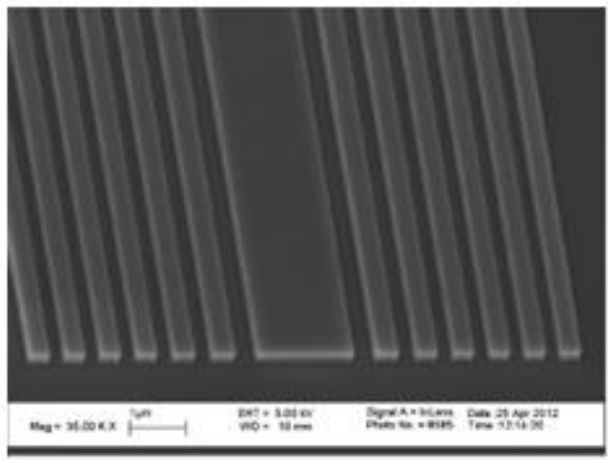

Figura 4.12 - (a) Conjunto $5 \times 7$ de moldes fabricados usando diferentes EBL doses e (b) detalhe de um molde da lente FZP fabricado.

Após a fabricação descrita na Fig. 4.11, os pesquisadores do VTT usaram microscopia eletrônica para verificar a geometria da estrutura. As Figs. 4.13(a) e 4.13(b) mostram uma vista frontal da lente e a seção transversal do dispositivo fabricado, respectivamente.

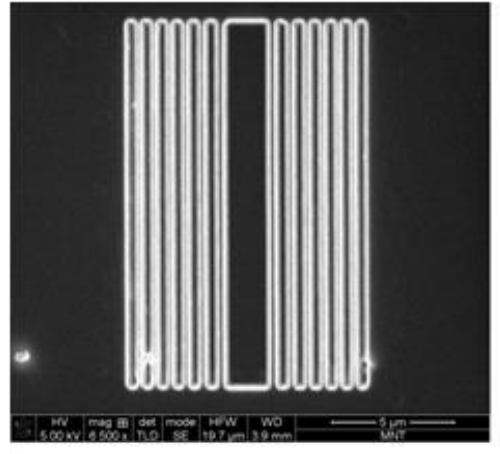

(a)
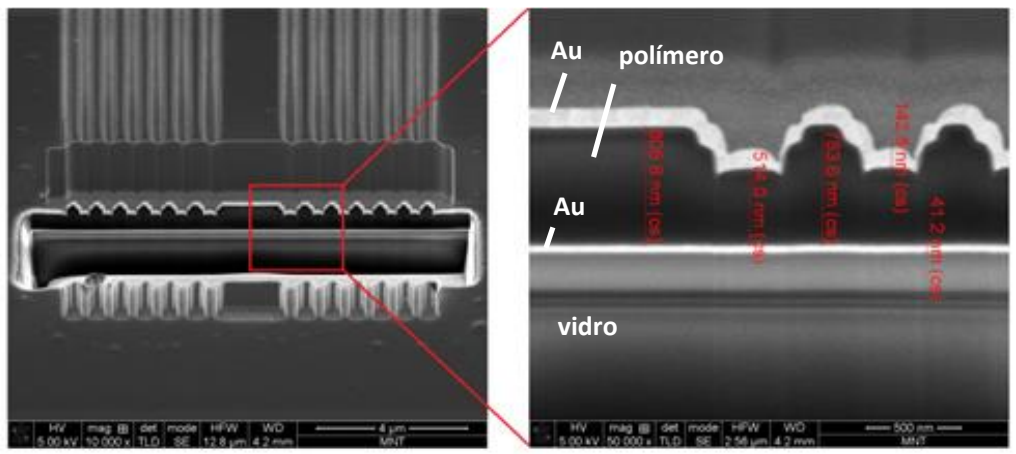

(b)

Figura 4.13 - (a) Vista frontal do dispositivo fabricado e (b) seção transversal, com os respectivos materiais e dimensões.

Embora a vista frontal do dispositivo fabricado se assemelhe ao projetado, a seção transversal mostra que o padrão representado pela lente FZP está com um formato inusitado. Ao invés de um formato de quinas observou-se uma geometria ondulada, um formato não retangular. Além disso, a imagem da seção transversal sugere que o ouro, referente à camada superior, não foi totalmente removido. O polimento referente a etapa final de fabricação foi realizado usando abrasivo comum, manualmente, e de modo rudimentar; não permitindo um controle apurado da remoção do ouro. A Tabela 4.2 mostra a comparação entre a geometria simulada e medida. 
Tabela 4.3 - Comparação entre a geometria simulada e fabricada

\begin{tabular}{ccc}
\hline Geometria & Simulada & Fabricada \\
\hline Espessura filme de ouro & $30 \mathrm{~nm}$ & $41.2 \mathrm{~nm}$ \\
Distância FZP-filme & $420 \mathrm{~nm}$ & $514,0 \mathrm{~nm}$ \\
Altura da FZP & $200 \mathrm{~nm}$ & $291,8 \mathrm{~nm}$ \\
\hline
\end{tabular}

O aspecto inusitado do formato da lente FZP pode advir de diversos fatores incluindo: defeito no molde original, defeito no molde usado na impressão, problemas mecânicos na pressão do molde, problemas no polimento, entre outros. Considerando a qualidade do molde produzido e ausência de defeitos na fabricação de outros tipos de estruturas usando moldes replicados, foi a etapa final do polimento o provável responsável pelo aspecto não esperado da lente FZP. Mas mesmo se formato e a geometria da lente FZP fabricada estivesse de acordo com o esperado, a diferença entre a distância FZP-filme projetada e fabricada não permitiria justificar a melhora do padrão de intensidade pela inserção do filme metálico. A Fig. 4.14(a) mostra o padrão de intensidade transmitido da geometria inicialmente projetada com a distância FZP-filme igual a 514 nm, para polarização TM e TE. A Fig. 4.14(b) mostra o padrão da intensidade na posição focal ao longo do eixo $x$, com $(d=514 \mathrm{~nm})$ e sem o filme, para polarização TM e TE.

Verificando as diferenças entre a geometria simulada e fabricada e o formato não esperado para o padrão da lente FZP, decidiu-se não continuar com a caracterização óptica, pois a lente fabricada não forneceria resultados úteis que permitiriam verificar a melhora do padrão da FZP linear pelo uso do filme metálico. 
(a)
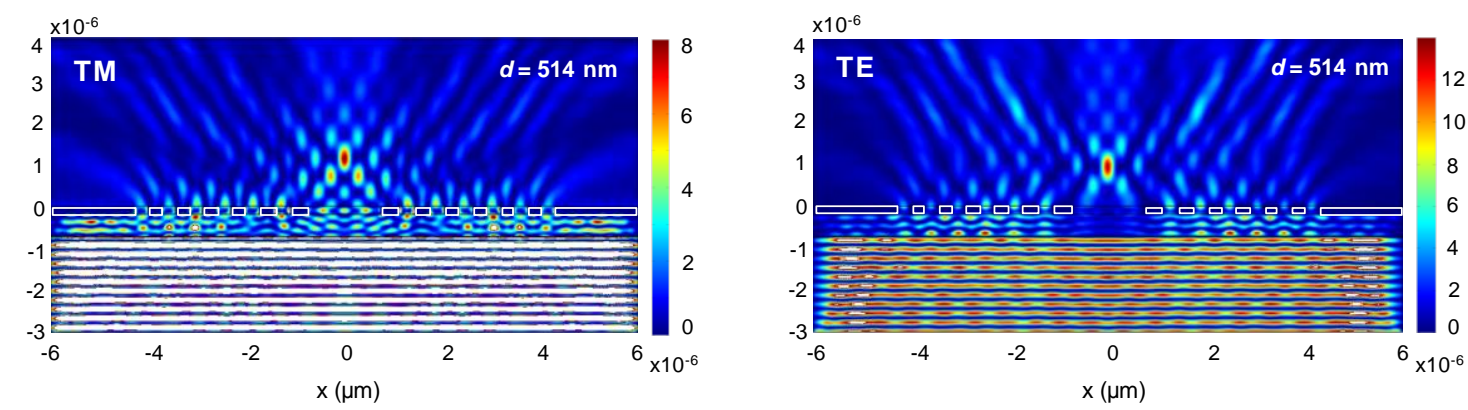

(b)
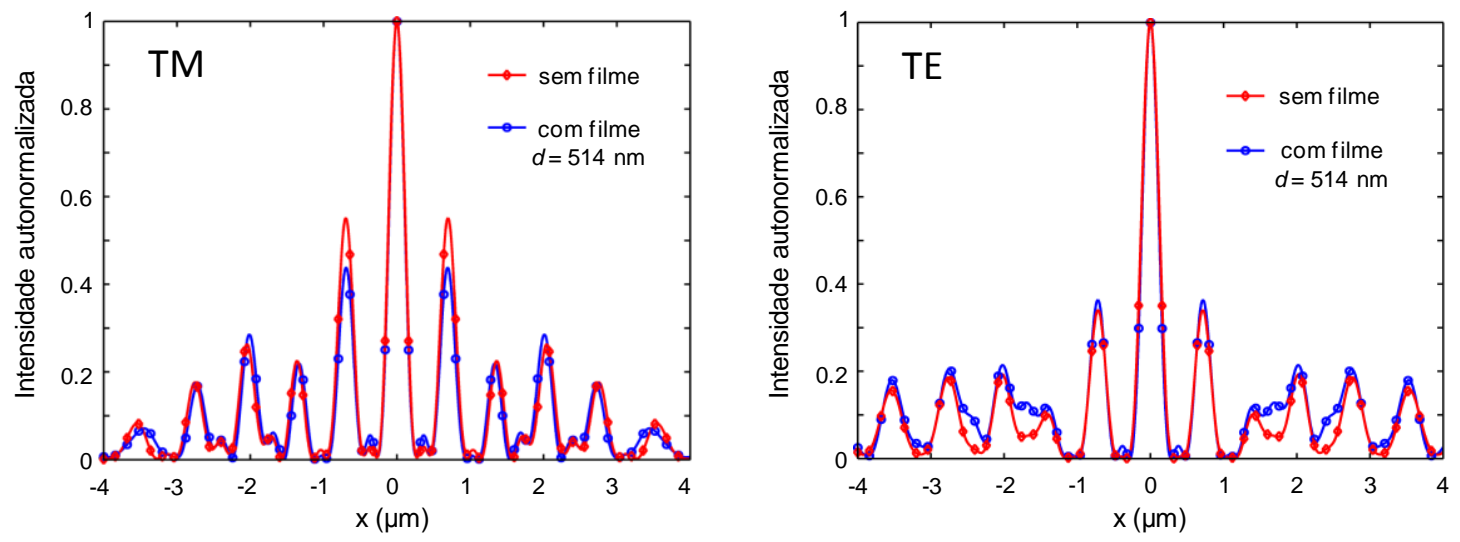

Figura 4.14 - (a) Padrão da intensidade transmitida pela FZP projetada com o filme $(\mathrm{d}=514 \mathrm{~nm}$ ) para polarização incidente TM e TE. (b) Perfil da intensidade na posição focal ao longo do eixo x para polarização incidente TM e TE. Linhas azul e vermelha representam os perfis de intensidade com $(d=514 \mathrm{~nm})$ e sem o filme, respectivamente.

\subsection{CONCLUSÃo}

Neste capítulo foi feita a proposta de uma estrutura que consiste em uma lente FZP integrada com um filme metálico. A análise numérica mostrou que os lóbulos laterais produzidos pela lente podem ser significativamente reduzidos pela inserção de um filme metálico, em uma distância específica. A redução do maior lóbulo lateral foi por um fator 3.0 na polarização TM e 4.8 na polarização TE. Além disso, verificou-se que a resposta da estrutura tem um comportamento quasi-Fabry-Perot com a distância FZP-filme. A desvantagem desta estrutura é a perda de eficiência na posição focal provocada pela inserção do filme metálico: uma queda de aproximadamente $87 \%$ para TM e $76 \%$ para TE. A fabricação do dispositivo não permitiu sua caracterização óptica, pois houve uma diferença significativa entre a estrutura projetada e obtida. Embora a litografia por nanoimpressão possibilite transferir padrões de modo simples, ela pode não ser a técnica mais adequada para fabricar esta estrutura. Observa-se dois entraves para a fabricação usando nanoimpressão: (1) 
como observado na análise numérica, a espessura do filme de polímero (distância FZP-filme) é um fator crucial na resposta da estrutura, porém o uso de spin coating não permite um controle apurado da espessura, como ocorre, por exemplo, com processos de deposição por sputtering; e (2) a etapa final de polimento do metal da camada superior, Fig. 4.11(c) e 4.11(d), precisa ser repensada, pois o uso de abrasivo não permite um controle da retirada do metal. Considera-se que a fabricação inicialmente sugerida, usando FIB, representa uma possibilidade de superar essas dificuldades relacionadas ao processo de nanoimpressão. 


\section{TRABALHO FUTURO - HOLOGRAMA BINÁRIO BASEADO EM RESSOADOR METÁLICO TIPO} NANOROD

Neste capítulo é descrito o início do estudo de um holograma binário baseado em metassuperfície. Inicialmente foi feita a análise numérica de um ressoador metálico tipo nanorod, que permitiu verificar a resposta óptica em função de sua geometria. Em seguida foi analisada uma geometria na qual a antena pudesse ressoar no regime visível, com a máxima eficiência possível, e ao mesmo tempo apresentasse dimensões que mitigasse o desafio experimental, uma vez que a fabricação se torna dificultosa para dimensões em torno de 50 $\mathrm{nm}$. Definida a geometria da célula que compõe o holograma binário foi iniciada sua fabricação usando litografia por feixe de elétrons (EBL). Por fim, são mostradas algumas imagens relativas à fabricação em andamento e às dificuldades ainda por superar.

\subsection{REVISÃo BIBLIOGRÁFICA E MOTIVAÇÃo}

Elementos ópticos convencionais são baseados nas leis da reflexão, refração e difração para modificar uma frente de onda incidente. A lei de Snell, conhecida desde o século XVI, é a lei da óptica que define o ângulo de refração de um feixe que atravessa a interface entre dois meios.

Recentemente o avanço nos processos de fabricação permitiu esculpir nanoestruturas diretamente na superfície de um material. Essa superfície estruturada, chamada de metassuperfície (metasurface), é percebida pela luz incidente como um novo meio, uma vez que a separação entre as nanoestruturas é muito menor que o comprimento de onda da luz. $\mathrm{O}$ desvio angular de um feixe que atravessa a metassuperfície pode ser ajustado de acordo com a geometria planar das nanoestruturas. Esta propriedade abre novas possibilidades no projeto de dispositivos ópticos. A equação da lei de Snell generalizada foi obtida pelo grupo do professor Federico Capasso em 2011 [59], derivada do princípio de Fermat [104]. Posteriormente, em 2012, foi demonstrada no infravermelho [60]. Um efeito interessante em três dimensões é que a refração e reflexão anômala podem estar em um plano diferente do plano de incidência da luz [180]. 
Uma vantagem representada pelas metassuperfícies é que a mudança nas propriedades de uma frente de onda (amplitude, fase e/ou polarização) ocorre abruptamente na interface, em uma distância muito menor que o comprimento de onda da luz $(\sim \lambda / 30)$. Ao contrário, elementos convencionais necessitam de uma distância comparável ou maior que o comprimento de onda, uma vez que as mudanças nas propriedades ocorrem via propagação da luz no meio. Metassuperfícies permitem também uma maior flexibilidade nos projetos, pois suas propriedades podem ser sintonizadas pela geometria das nanoestruturas $[181,182]$ ao invés das propriedades ópticas dos materiais. Além disso, sua fabricação se utiliza de toda uma tecnologia planar de fabricação já estabelecida, desenvolvida na indústria de semicondutores.

Os elementos básicos das metassuperfícies são chamados de ressoadores ópticos ou nanoantenas [118, 183-188]. Quando um campo eletromagnético interage com um ressoador metálico, seus elétrons de condução são guiados não só pelo campo incidente, mas também pela força de Coulomb retardada; isso faz com que a solução analítica da resposta dos ressoadores seja um problema extremamente complexo [183]. Para uma antena clássica, a ressonância de primeira ordem é obtida quando $L=\lambda / 2$ [189]. Entretanto, em frequências ópticas ocorre a penetração do campo no metal e assim a antena não responde mais ao comprimento de onda de excitação, mas a um comprimento de onda efetivo $\lambda_{\text {eff }}$ que depende da geometria e do metal usado. Quando o comprimento da antena se torna comparável à penetração de campo no metal, sua resposta óptica é controlada pela excitação eletrônica coletiva. Considerando ressoadores do tipo nanorod, o comprimento de onda efetivo aproximado é dado por $\lambda_{e f f},=\mathrm{n}_{1}+\mathrm{n}_{2}\left(\lambda / \lambda_{s p p}\right)$, onde $\lambda_{s p p}$ é o comprimento de onda SPP e $\mathrm{n}_{1}, \mathrm{n}_{2}$ são coeficientes que dependem da geometria [118].

Neste contexto, uma superfície composta por ressoadores ópticos tem uma propriedade peculiar: a luz que a atinge não atravessa o meio simplesmente; o campo eletromagnético incidente excita ressonâncias plasmônicas, provocando a re-emissão da luz. Assim, as propriedades da luz espalhada - amplitude, fase e polarização - podem ser sintonizadas de acordo com a geometria planar dos ressoadores. A possibilidade de controlar localmente a amplitude, fase e/ou polarização da onda espalhada permite moldar uma frente de onda incidente de modo arbitrário, de acordo com o princípio de Huygens [58,190].

Diversos dispositivos baseados em metassuperfície têm sido reportados recentemente, incluindo elementos que curvam a luz (light bending) [59,60,191], lentes ópticas planares [61-63,191] sem aberração esférica [61] e cromática [192], e polarizadores de luz [65,66, 
193]. Uma aplicação que tem chamado a atenção é a produção de hologramas [67-70, 194199].

Neste contexto, é apresentada neste capítulo a análise numérica de um ressoador metálico do tipo nanorod (haste), para ser usado como elemento de um holograma binário no regime visível. A vantagem deste holograma é que ele pode operar em vários comprimentos de onda. Em seguida também é mostrado o início da fabricação usando litografia por feixe de elétrons.

\subsection{ESTRUTURA E ANÁLISE NUMÉRICA}

A unidade básica da metassuperfície consiste de um ressoador tipo nanorod. Usando duas células cujas hastes metálicas estão em direções $\pm 45^{\circ}$ com relação a polarização incidente é possível obter uma diferença de fase igual a $\pi$ na polarização cruzada. Deste modo, pode-se projetar um holograma de fase binário de acordo com o princípio de Huygens, usando codificação implementada anteriormente [200]. Desde que a diferença de fase seja igual a $\pi$ para qualquer comprimento de onda incidente, a faixa espectral do holograma depende da largura de banda transmitida na polarização cruzada. A Fig. 5.1 mostra a estrutura da célula básica. Ela consiste em uma haste de ouro de espessura $t=30 \mathrm{~nm}$ e largura $w=30$ nm. O período da célula $(\Lambda)$ cresce linearmente com o comprimento da haste $(\Lambda=$ $L / \sqrt{2}+2 w$ ), e representa o tamanho do pixel. O período foi definido de modo a acomodar uma célula individual e minimizar a interação com a célula vizinha.

(a)

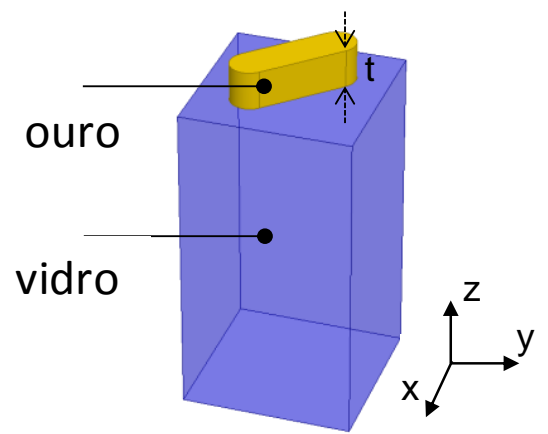

(b)

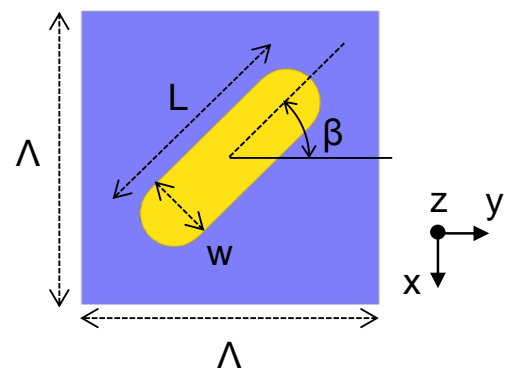

Figura 5.1 - (a) Célula básica contendo a haste de ouro de espessura t $=30 \mathrm{~nm}$ e (b) visão frontal detalhando os parâmetros geométricos: $\Lambda$ é o período, $L$ é o comprimento da haste, $\beta$ é o ângulo da haste com relação ao eixo $x$ e $w=30 \mathrm{~nm}$.

A análise numérica foi realizada usando o software comercial HFSS [102], que permite uma parametrização do comprimento da haste metálica $(L)$. O índice de refração do vidro é dado pela equação de Sellmeier $(\sim 1.5)$ e do ouro é dado por [108]. O cálculo da 
transmissão na polarização cruzada (eixo y) é feito considerando um conjunto periódico de células. A haste metálica é orientada $\beta=45^{\circ}$ com a polarização incidente (direção $x$ ). A Fig. 5.2 mostra o espectro de transmissão na polarização cruzada variando o comprimento da haste $L$ de $50 \mathrm{~nm}$ a $300 \mathrm{~nm}$. A intensidade é dada por $\left|S_{21}\right|^{2}$, onde $S_{21}$ é o coeficiente de transmissão.

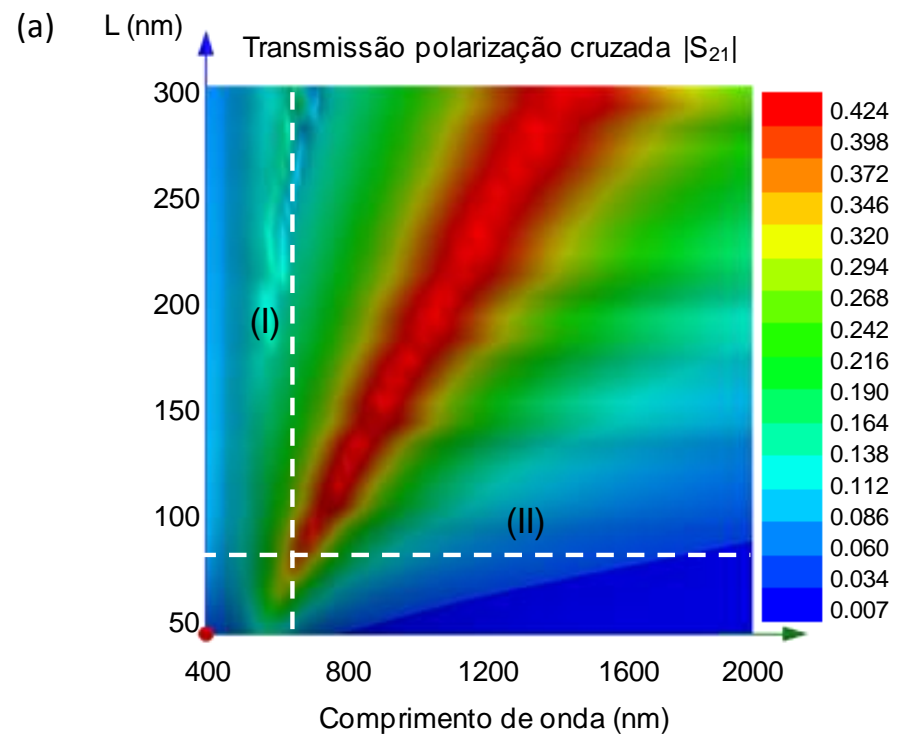

(b)

Transmissão polarização cruzada

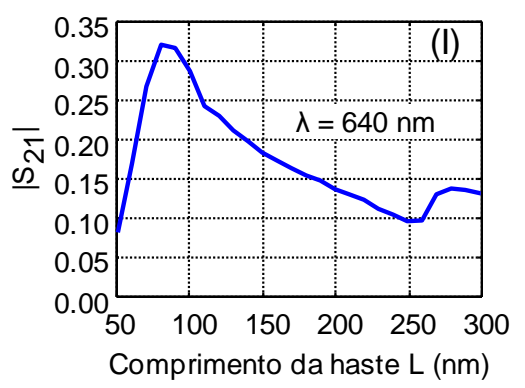

Transmissão polarização cruzada

(c)

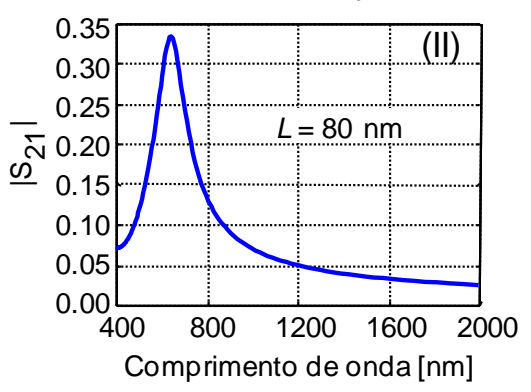

Figura 5.2 - Espectro de transmissão na polarização cruzada. (a) Variando L, (b) $\lambda=640 \mathrm{~nm}$, correspondente à linha tracejada (I) em (a), e (c) $\mathrm{L}=80 \mathrm{~nm}$, correspondente à linha tracejada (II) em (a).

A Fig. 5.2(a) mostra que o comprimento de onda de ressonância e a largura de banda transmitida na polarização cruzada variam de maneira quase linear com o comprimento da haste metálica. Além disso, é possível observar a ressonância de segunda ordem com eficiência reduzida, no canto superior esquerdo. A ressonância de primeira ordem em $\lambda=640$ $\mathrm{nm}$ ocorre quando o comprimento da haste $L=80 \mathrm{~nm}$. Fig. 5.2(b) mostra o coeficiente de transmissão da polarização cruzada em função do comprimento da haste, referente à linha tracejada (I). Fig. 5.2(c) mostra o espectro de transmissão na polarização cruzada para $L=80$ nm. O coeficiente de transmissão máximo é 0.33 , resultando em uma eficiência de $11 \%$. A largura de banda transmitida (FWHM) é igual a $130 \mathrm{~nm}$. A orientação da haste é $\beta=45^{\circ}$, onde ocorre a máxima eficiência transmitida na polarização cruzada. A Fig. 5.3(a) mostra o coeficiente de transmissão na polarização cruzada (eixo $y$ ) em função de $\beta$ considerando $L=$ $80 \mathrm{~nm}$ e polarização incidente no eixo $x$. A Fig. 5.3(b) mostra a fase transmitida na 
polarização cruzada para três comprimentos de onda incidente em função de $\beta$. Verifica-se que a diferença de fase é sempre $\pi$ considerando células $\operatorname{com} \beta \pm 45^{\circ}$, como esperado.

(a)
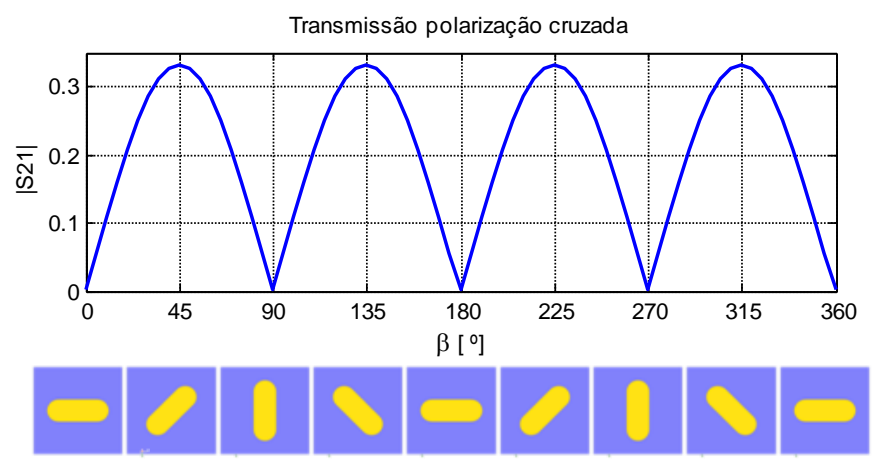

(b)
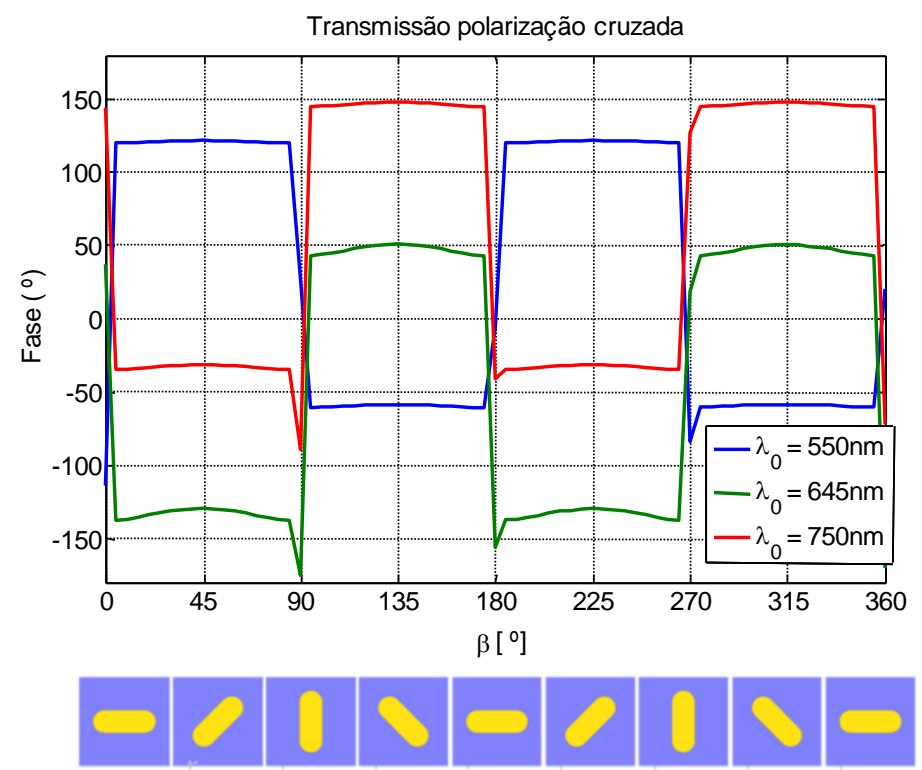

Figura 5.3 - (a) Coeficiente de transmissão na polarização cruzada em função de $\beta$, considerando $L=80 \mathrm{~nm}$ e polarização incidente no eixo $\mathrm{x}$. (b) Fase transmitida na polarização cruzada para três comprimentos de onda incidente em função de $\beta$.

A fabricação de uma estrutura metálica de dimensões $L=80 \mathrm{~nm}$ e $w=30 \mathrm{~nm}$ (para ressoar em $\lambda=640 \mathrm{~nm}$ ) representa um enorme desafio experimental. Com o intuito de mitigar o processo de fabricação foi simulada uma nova geometria com dimensões maiores, que ressoasse na região do vermelho e mantivesse o coeficiente de transmissão em torno de 0.35 . A Fig. 5.4(a) mostra a geometria usada na fabricação e a Fig. 5.4(b) mostra a resposta espectral na polarização cruzada. $O$ coeficiente de transmissão $\left|S_{21}\right|$ em $\lambda=650 \mathrm{~nm}$ é igual a 0.39 , resultando em uma eficiência de $15 \%$. Os parâmetros geométricos são: $L=300 \mathrm{~nm}, w=$ $120 \mathrm{~nm}, \Lambda=350 \mathrm{~nm}$ e $t=30 \mathrm{~nm}(\lambda / 22)$. Vários testes foram realizados para se definir essa geometria e certificar que com esse período não haveria crosstalk entre duas células adjacentes. Além disso, cada pixel do holograma binário pode ser considerado como um 
grupo de células básicas, por exemplo, $2 \times 2$ ou $5 \times 5$, aproximando ainda mais da condição periódica usada nas simulações. O software Comsol [101] também foi usado para efeito de comparação.

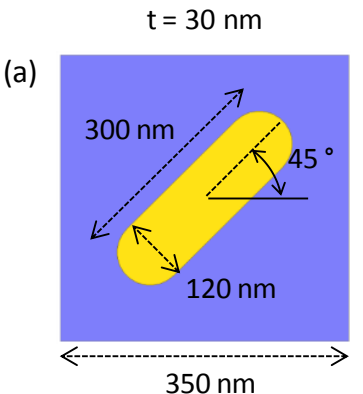

(b)

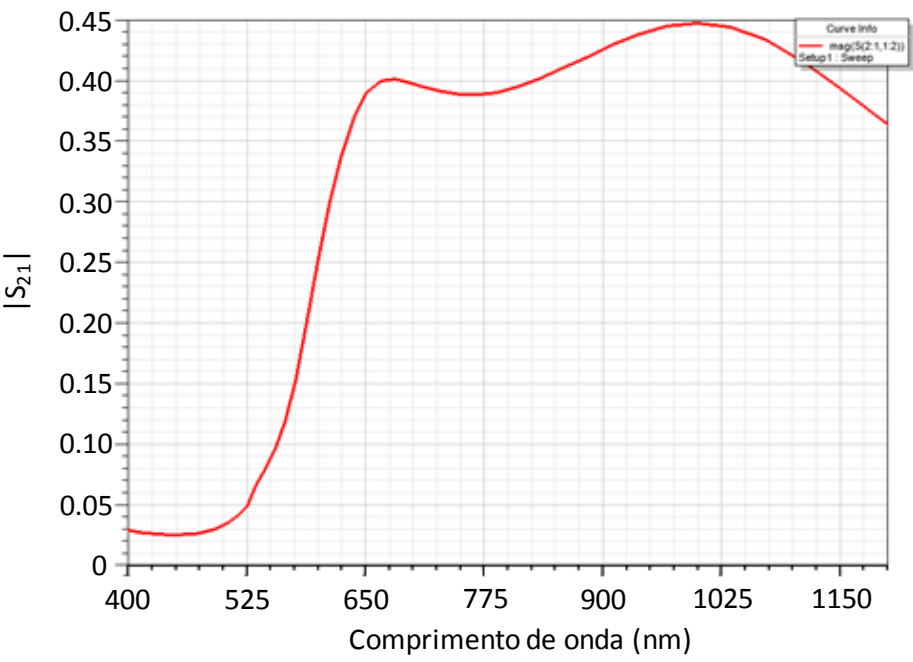

Figura 5.4 - (a) Geometria da célula usada na fabricação e (b) coeficiente de transmissão na polarização cruzada considerando parâmetros dados em (a).

O cálculo do holograma é baseado no algoritmo iterativo da transformada de Fourier, implementado pelo autor durante o mestrado [200], usando o software comercial Matlab [201]. Este algoritmo consiste de uma sequência de transformadas de Fourier com restrições no plano do holograma e da imagem. A imagem inicial a ser reconstruída é usada na entrada do algoritmo, e ao final o holograma é obtido na forma de uma matriz binária (0 e 1) de 256 x 256 elementos. A Fig. 5.5 (a) mostra a matriz obtida para o cálculo de um holograma binário, a Fig. 5.5(b) mostra a ilustração do elemento a ser fabricado, onde os respectivos valores 0 e 1 são associados as células $\operatorname{com} \beta= \pm 45^{\circ}$, e a Fig. 5.5(c) mostra a reconstrução simulada da imagem.

(a)

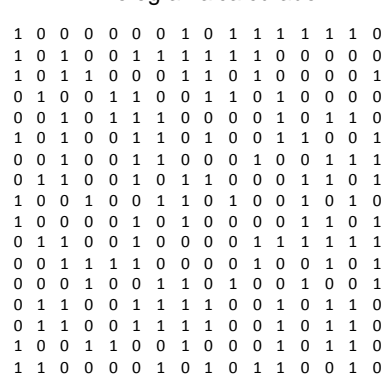

(b)

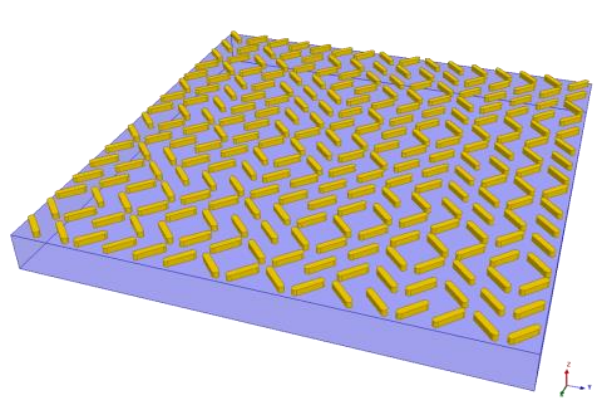

(c)

Reconstrução simulada

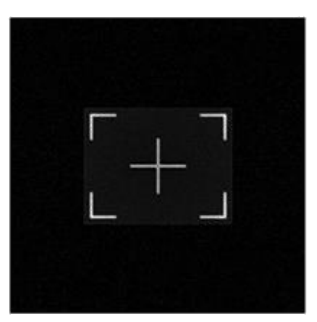

Figura 5.5 - (a) holograma binário calculado, (b) ilustração do holograma baseado em metassuperfície a ser fabricado e (c) reconstrução simulada da imagem. 


\subsection{FABRICAÇÃO (EM ANDAMENTO)}

O processo empregado na fabricação do holograma baseado em metassuperfície foi a litografia por feixe de elétrons (EBL). Devido às dimensões reduzidas dos elementos foi aplicada a técnica conhecida como bilayer [76,77], onde dois resistes de diferentes taxas de dissolução no solvente (PMMA 495 e 950 [75]) são usados para facilitar o processo de liftoff, como ilustrado na Fig. 5.6.

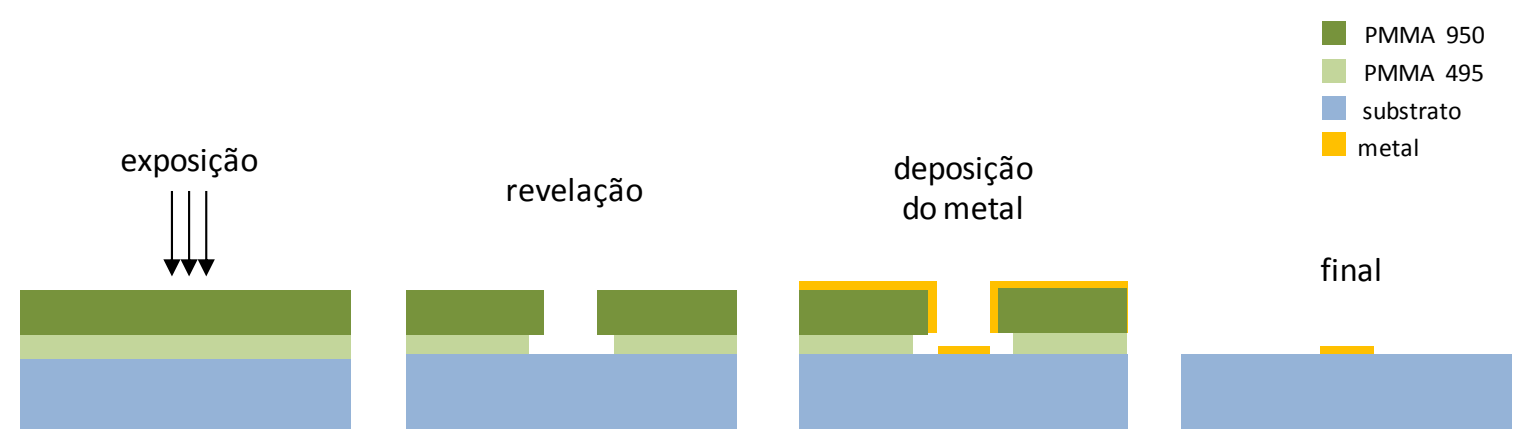

Figura 5.6 - Processo de fabricação usando técnica litográfica conhecida como bilayer.

A fabricação do holograma segue as seguintes etapas: (1) o processo de spin coating é realizado duas vezes, primeiro com o resiste PMMA 495 e em seguida com o resiste PMMA 950 (3000 rotações por minuto); (2) exposição por feixe de elétrons; (3) revelação em MIBK/IPA, 3:1, durante 30 segundos; (4) amostra é levada para uma placa quente por 90 segundos a $100{ }^{\circ} \mathrm{C} ;(5)$ corrosão por plasma (descum), (6) deposição do metal (ouro) e (7) processo de lift-off.

A exposição da amostra contendo as duas camadas de eletroresiste foi realizada usando o equipamento Zeiss 1540XB [202]. Inicialmente, o holograma calculado é convertido no desenho da estrutura usando o sistema NPGS. Na Fig. 5.7 é mostrado o desenho da estrutura, considerando holograma com um pixel (a) $2 \times 2$ células e (b) $5 \times 5$ células.
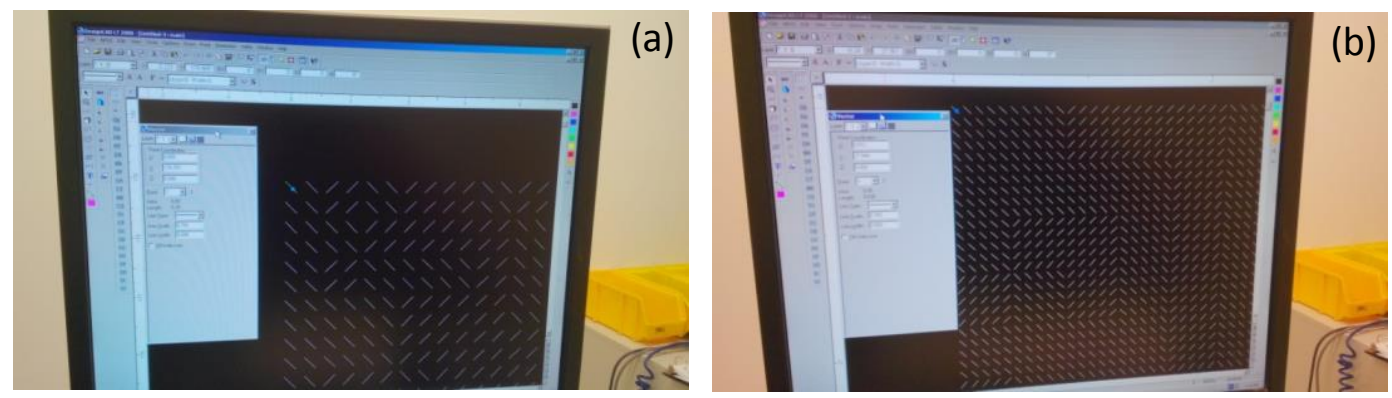

Figura 5.7 - Imagem do software usado no desenho do padrão a ser exposto pelo feixe de elétrons (Nanometer Pattern Generation System, NPGS). Desenho do holograma calculado cujo pixel contém (a) $2 \times 2$ células e (b) $5 \times 5$ células. 
O suporte no qual a amostra é fixada possui um conjunto de nanoesferas de ouro. A obtenção de uma imagem ampliada e nítida das nanoesferas é usada para minimizar o astigmatismo do feixe de elétrons, aumentando a resolução da exposição. Na Fig. 5.8(a) pode-se visualizar a amostra posicionada dentro da câmara de vácuo, abaixo do canhão de elétrons, e na Fig. 5.8(b) é mostrada uma imagem amplificada das nanoesferas de ouro usada na correção do astigmatismo do feixe de elétrons.
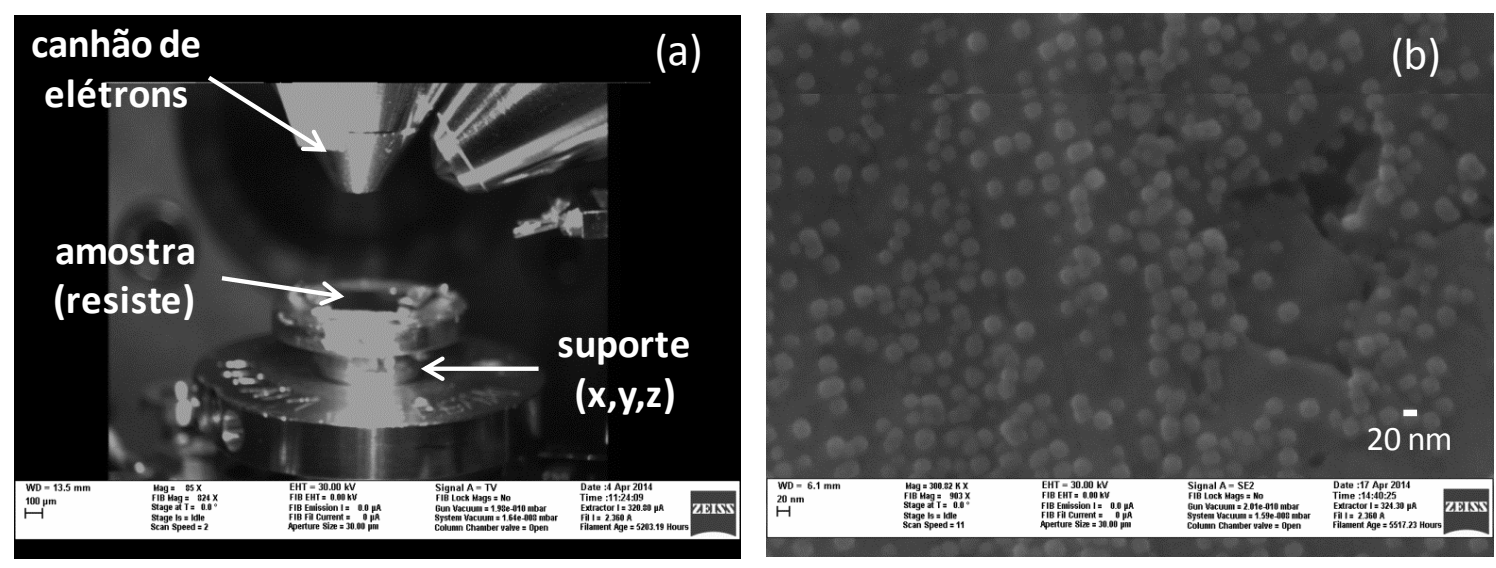

Figura 5.7 - (a) Imagem mostrando a amostra com as duas camadas de eletroresiste na câmara de vácuo. No detalhe, o canhão de elétrons, a amostra e o suporte com controle $(x, y, z)$. (b) Imagem obtida das nanoesferas de ouro presente no suporte, usada para minimizar o astigmatismo do feixe de elétrons. A barra de escala representada em (b) tem $20 \mathrm{~nm}$.

O procedimento de exposição usando EBL pode ser resumido nas seguintes etapas:

- a amostra contendo as duas camadas de fotoresiste é presa ao suporte e colocada na câmara de vácuo;

- $\quad$ o suporte é posicionado $(x, y, z)$ com a região contendo as nanoesferas de ouro abaixo do canhão de elétrons, com distância WD = $6 \mathrm{~mm}$.

- o feixe de elétrons é ligado; é obtida uma imagem ampliada e nítida das nanoesferas de ouro, usada na correção do astigmatismo do feixe de elétrons;

- $\quad$ mede-se a corrente do feixe de elétrons;

- suporte $(x, y)$ é posicionado de tal modo a obter uma imagem da borda da amostra, onde o foco é ajustado;

- feixe de elétrons é interrompido (beam blanked);

- $\quad$ suporte é movido lateralmente para que o canhão de elétrons fique acima do centro da amostra; 
- arquivo CAD contendo o padrão a ser transferido é executado (nanometer pattern generation system, NPGS). A dose é fixada de acordo com a corrente medida; - $\quad$ após a exposição, o feixe de elétrons é desligado e o suporte contendo a amostra exposta é retirado.

A amostra é então revelada e caracterizada usando AFM. Para determinar a dose linear do feixe de elétrons que resulta na espessura projetada para o elemento $(w=120 \mathrm{~nm})$ foi realizado um estudo paramétrico, variando a dose linear de $0.5 \mathrm{nC} / \mathrm{cm}$ a $3.1 \mathrm{nC} / \mathrm{cm}$, mantendo as condições de exposição e revelação constantes. Verificou-se que a espessura desejada é obtida com dose linear em torno de $2 \mathrm{nC} / \mathrm{cm}$. Na Fig. 5.9 são mostradas as imagens AFM obtidas considerando diferentes doses lineares do feixe de elétrons. Verifica-se que quanto maior a dose linear do feixe de elétrons, maior a espessura obtida, para um mesmo comprimento.
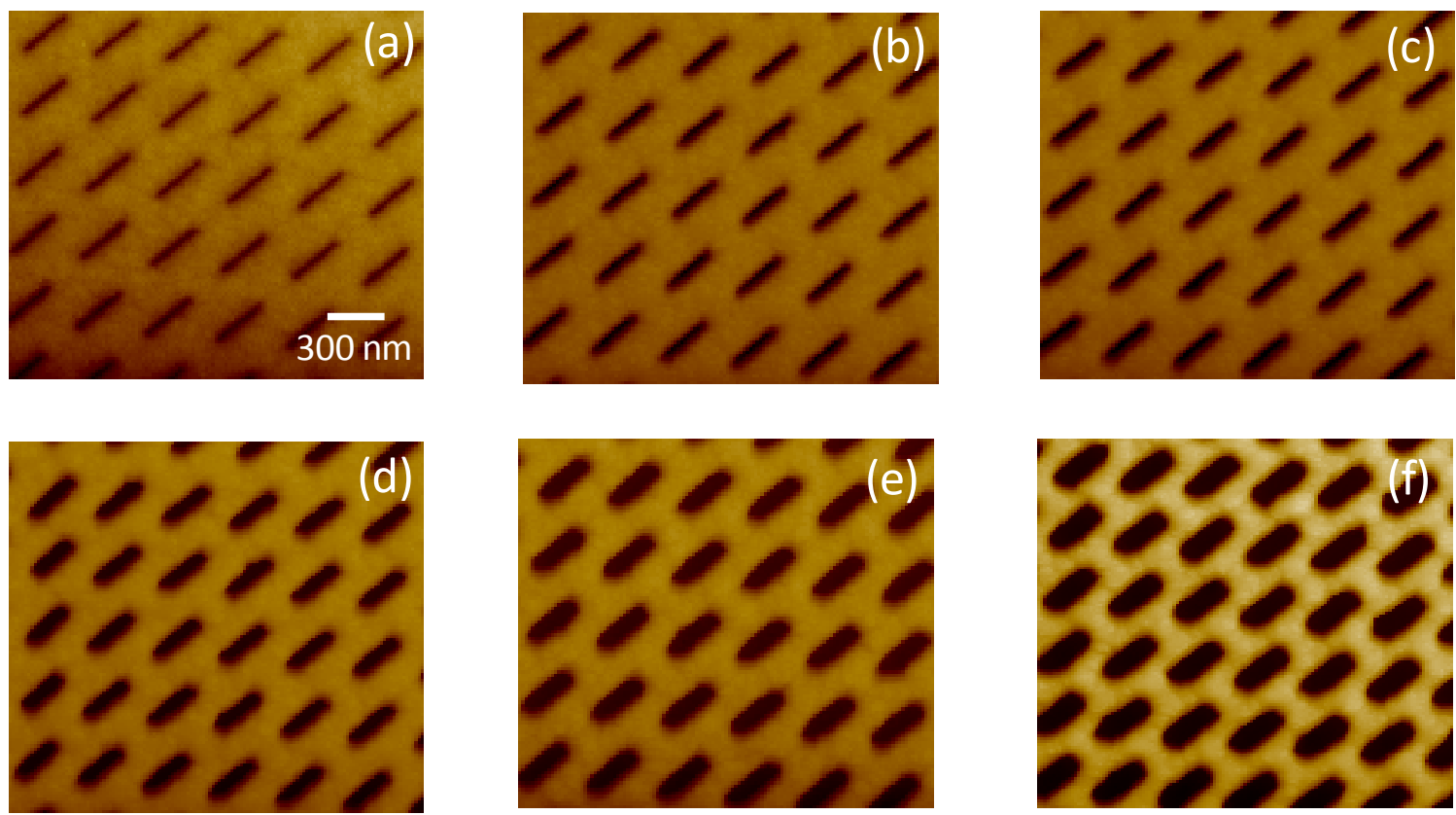

Figura 5.8 - Estudo da dose linear do feixe de elétrons para um padrão composto por linhas de comprimento $L \approx 300 \mathrm{~nm}$ e período $\Lambda \approx 350$. Procedimento realizado para encontrar a espessura $w \approx 120 \mathrm{~nm}$. Doses lineares iguais a (a) $0.5 \mathrm{nC} / \mathrm{cm}$, (b) 1.1 $\mathrm{nC} / \mathrm{cm}$, (c) $1.5 \mathrm{nC} / \mathrm{cm}$, (d) $2.1 \mathrm{nC} / \mathrm{cm}$, (e) $2.5 \mathrm{nC} / \mathrm{cm}$ e (f) $3.1 \mathrm{nC} / \mathrm{cm}$, onde $\mathrm{nC}$ significa nanoCoulumb. Imagens de microscopia de força atômica após a revelação. A barra de escala representada em (a) tem $300 \mathrm{~nm}$ de comprimento e vale para todas as imagens. 
A fabricação do holograma encontra-se no estágio pré-deposição do metal (ouro). Os processos subsequentes são a deposição de ouro e lift-off. A figura 5.10(a) mostra a imagem AFM do holograma fabricado, e as Figs. 5.10(b) e 5.10(c) mostram algumas dificuldades enfrentadas, como bolhas no resiste e problemas de alinhamento entre as sucessivas exposições.
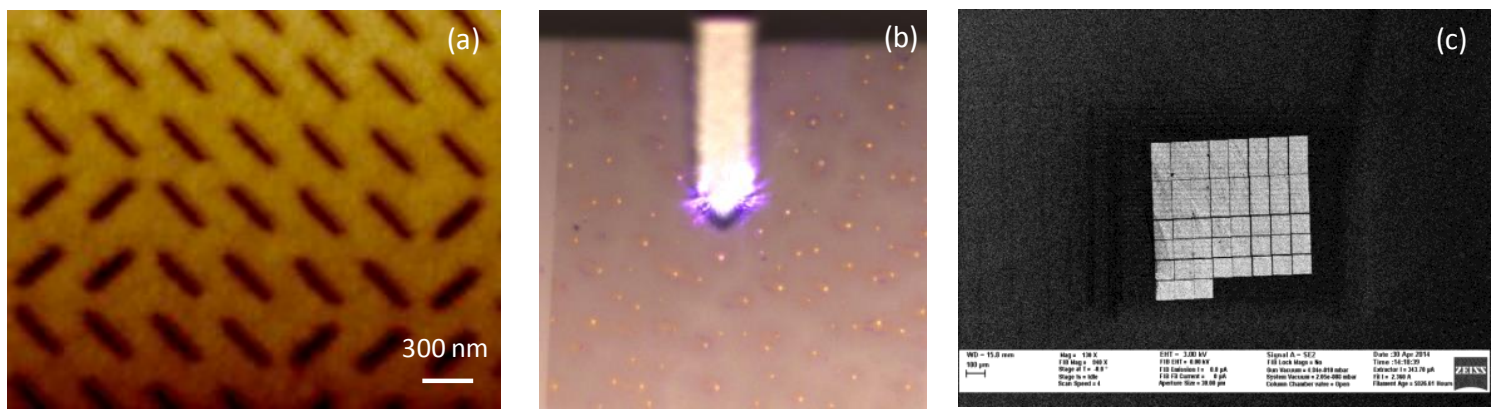

Figura 5.9 - (a) imagem de microscopia de força atômica do holograma exposto, com as dimensões próximas à simulada. A barra de escala representada tem $300 \mathrm{~nm}$ de comprimento. (b) Imagem obtida durante medida de microscopia de força atômica mostrando dificuldade enfrentada durante a fabricação: bolhas no resiste após a revelação. (c) Sucessivas exposições do padrão calculado para o holograma, com o intuito de aumentar o tamanho do elemento e facilitar sua caracterização; imagem mostra erros de alinhamento. 


\section{CONCLUSÕES E TRABALHOS FUTUROS}

Neste trabalho foi realizado o estudo de diferentes nanoestruturas metálicas. Inicialmente foi feita uma extensa análise bibliográfica, que possibilitou tanto o aprendizagem do software usado nas simulações como uma referência para a proposição de estruturas que apresentassem melhor desempenho em comparação com trabalhos previamente reportados. A principal contribuição deste trabalho foi o projeto e a fabricação de três filtros ópticos operando no azul, verde e vermelho, com largura de banda experimental aproximadamente 3 vezes menor que a reportada anteriormente na literatura usando estrutura semelhante. A análise numérica mostrou que a resposta dos filtros é uma combinação de ressonância de modo guiado com ressonância plasmônica, além de ser influenciado pela anomalia Rayleigh. O ajuste do espectro inicial da fonte de luz permitiu a geração das três cores RGB usando apenas o filtro vermelho. O contato com todas as etapas da fabricação e caracterização destes elementos propiciou ao autor um enorme aprendizado experimental. Além dos filtros ópticos, também foi analisado uma estrutura baseada em zonas de Fresnel integrada com filme metálico, que pode reduzir por um fator 3.0 e 4.8 os lóbulos laterais produzidas pela lente na polarização TM e TE, respectivamente. A fabricação usando litografia por nanoimpressão mostrou inconveniências como o não-controle apurado da distância FZP-filme, além da dificuldade em se fazer o polimento para obtenção da estrutura final. Como alternativa, é sugerido a fabricação usando o equipamento FIB. O processo de deposição por sputtering permite um controle mais preciso da distância FZP-filme, um parâmetro fundamental na melhora do padrão transmitido pela lente desde que a estrutura apresente um comportamento do tipo Fabry-Perot. Por fim, foi iniciado o estudo de um holograma binário que possui a característica de operar em mais de um comprimento de onda. A análise numérica permitiu definir uma geometria na qual a estrutura possui aceitável eficiência na região do vermelho. A célula básica consiste de um ressoador metálico tipo nanorod. Apesar do desafio experimental, a fabricação deste elemento foi iniciada usando litografia por feixe de elétrons. O padrão do holograma foi transferido para o resiste, restando por concluir as etapas de deposição do metal e o processo de lift-off. 
Com relação aos trabalhos futuros têm-se as seguintes perspectivas associadas às estruturas abordadas neste trabalho:

- para o filtro vermelho gerando as três cores RGB: medir os espectros da cor vermelha associado ao modo guiado e da cor azul pura, cujo feixe emerge praticamente rasante à estrutura;

- fabricar a lente FZP integrada com o filme metálico usando FIB; caracterizar a estrutura e mostrar experimentalmente a redução dos lóbulos laterais geradas pela lente;

- finalizar a fabricação do holograma binário. 


\section{APÊNDICE}

A seguir são apresentados os resultados numéricos para a estrutura fabricada no capítulo 4 usando litografia por nanoimpressão. Neste caso, as fendas também estão preenchidas com o polímero, como mostrado na Fig. A1. A análise numérica foi realizada usando o software comercial Comsol 3.5a. A distância FZP-filme foi variada de 410 a $470 \mathrm{~nm}$. O índice de refração do polímero é igual a 1.533 [175] em $\lambda_{0}=633 \mathrm{~nm}$. Os demais parâmetros são os mesmos apresentados na seção 4.2.

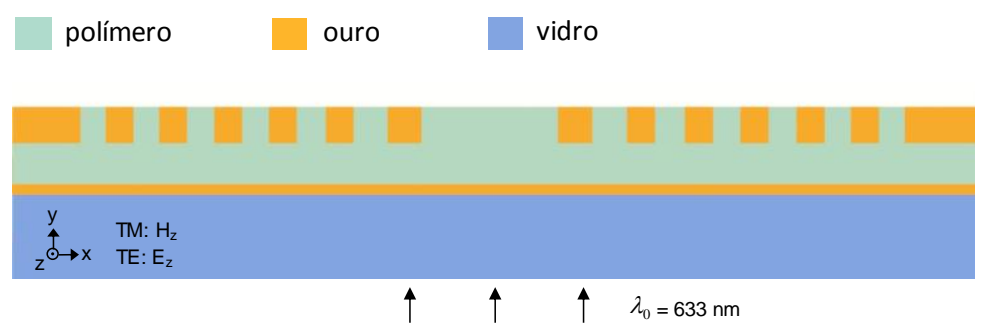

Figura 7.1 - Configuração proposta para a fabricação da lente FZP integrada com o filme metálico usando litografia por nanoimpressão.

A Fig. A2 mostra o cálculo da razão entre a intensidade no foco e a intensidade do maior lóbulo lateral, como função da distância FZP-filme. O parâmetro $R$ aumentou de 1.81 para 5.72 para polarização TM, e de 2.94 para 7.25 para polarização TE. Os lóbulos laterais foram reduzidos por um fator 3.2 para TM e 2.5 para TE com a inserção do filme.

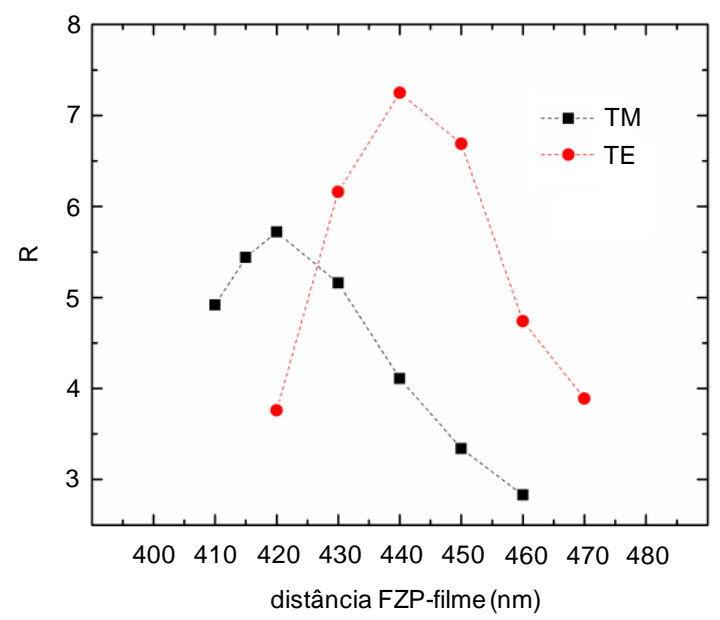

Figura 7.2 - Cálculo do parâmetro R, definido como a razão entre a intensidade no foco e a intensidade do maior lóbulo lateral, como função da distância FZP-filme. 
A Fig. A1.3 mostra os padrões da intensidade transmitida correspondente aos picos de $R$, para polarização incidente TM e TE, em comparação com a estrutura sem filme.

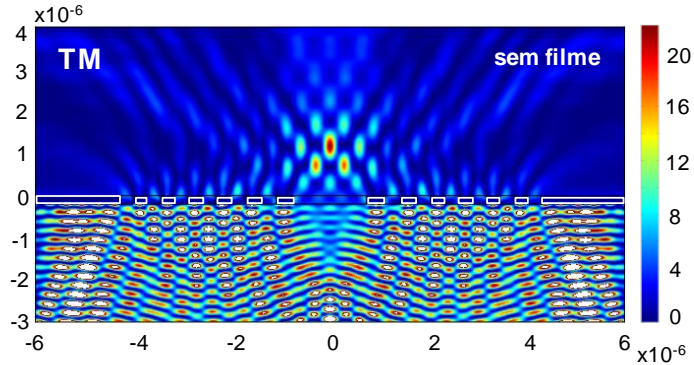

(a)

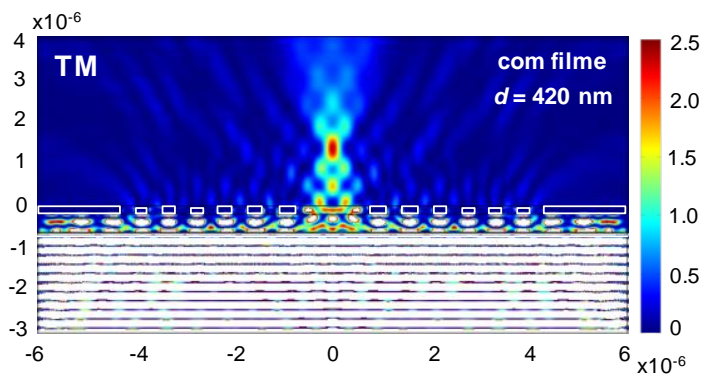

(b)

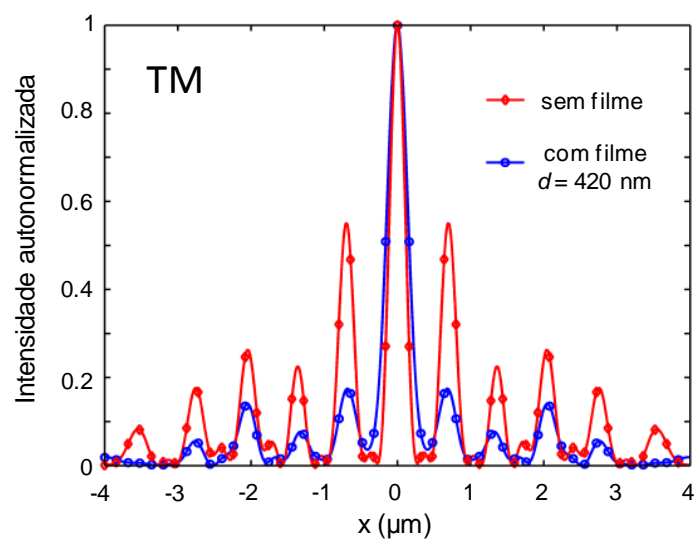

(e)

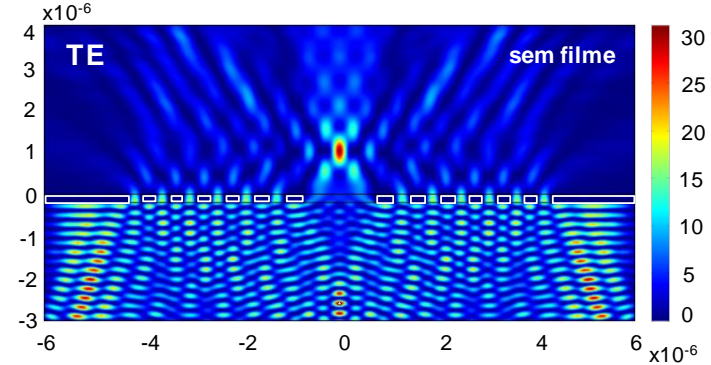

(c)

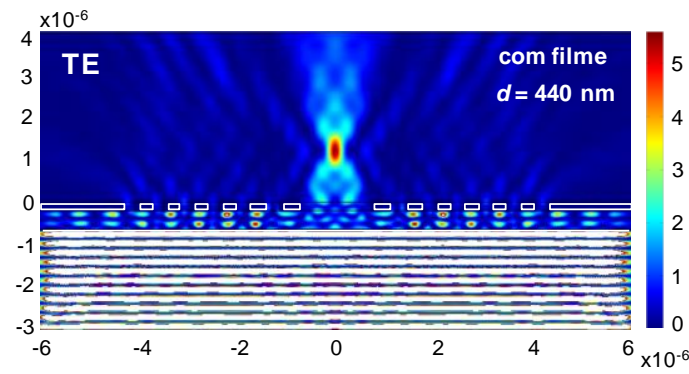

(d)

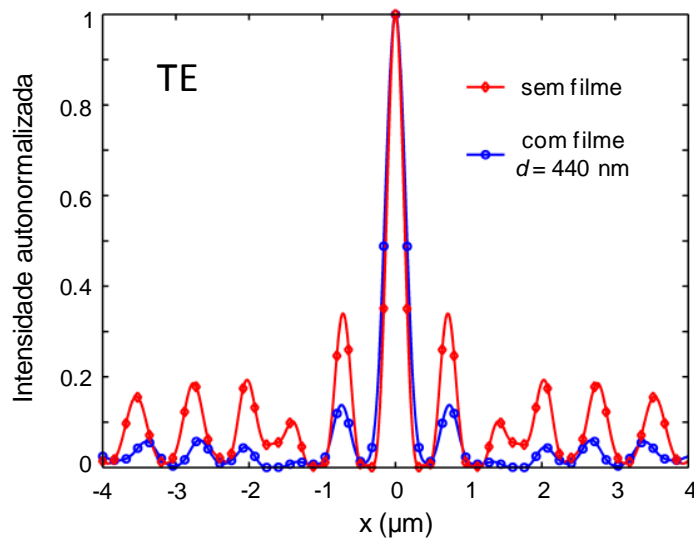

(f)

Figura 7.3 - Padrão de intensidade sem o filme (a) e (b) e correspondendo aos picos de R (c) e (d), para polarização TM e TE, respectivamente. Perfil da intensidade na posição focal ao longo do eixo x para polarização incidente (e) TM e (f) TE. Os retângulos brancos em $(a, b, c, d)$ indicam a seção transversal da FZP 


\section{REFERÊNCIAS BIBLIOGRÁFICAS}

[1] B. Doyle, et al., "Transistor Elements for 30nm Physical Gate Lengths," Intel Technol. J., $6,42-54(2002)$.

[2] M. J. Kubrinsky, et al., "On-Chip Optical Interconnects," Intel Technol. J., 8, 129-141 (2004).

[3] G. P. Agrawal, Fiber-Optic Communiation Systems, 3rd ed., (Wiley, New York, 2002).

[4] M. Born and E. Wolf, Principles of Optics, 7th ed., (Cambridge Univ. Press, 1999).

[5] E. Abbe, "Beiträge zur Theorie des Mikroskops und der mikroskopischen Wahrnehmung," Arch. Mikroskop. Anat. 9, 413-420 (1873).

[6] L. Rayleigh, "Investigations in optics, with special reference to the spectroscope," Phil. Mag. 8, 261-274, 403-411, and 477-486 (1879).

[7] E. Ozbay, "Plasmonics: Merging photonics and electronics at nanoscale dimensions," Science 311, 189-193 (2006).

[8] D. K. Gramotnev and S. I. Bozhevolnyi, "Plasmonics beyond the diffraction limit," Nat. Photonics 4, 83-91 (2010).

[9] J. A. Schuller, E. S. Barnard, W. Cai, Y. C. Jun, J. S. White, and M. L. Brongersma, "Plasmonics for extreme light concentration and manipulation," Nat. Mater. 9, 193-204 (2010).

[10] M. L. Brongersma and V. M. Shalaev, "Applied physics. The case for plasmonics," Science 328(5977), 440-441 (2010).

[11] E. N. Photonics, “Surface Plasmon Resurrection,” Nat. Photonics, 6, 707 (2012).

[12] H. A. Atwater, “The promise of plasmonics,” Sci. Am. 296, 38-45 (2007).

[13] S. A. Maier, M. L. Brongersma, P. G. Kik, S. Meltzer, A. A. G. Requicha, and H. A. Atwater, "Plasmonics - A route to nanoscale optical devices," Adv. Mat. 13, 1501 (2001).

[14] M. Dragoman and D. Dragoman, "Plasmonics: applications to nanoscale terahertz and optical devices," Prog. Quantum Electron. 32(1), 1-41 (2008).

[15] R. W. Wood, "On a remarkable case of uneven distribution of light in a diffraction grating spectrum," Proceedings of the Physical Society of London, 18(1), 269-275 (1902). 
[16] Lord Rayleigh, "Note on the remarkable case of diffraction spectra described by Prof. Wood," Philos. Mag. 14, 60-65 (1907).

[17] Lord Rayleigh, "On the dynamical theory of gratings," Proc. R. Soc. Lond. 79, 399-416 (1907)

[18] J. Strong, "Effect of evaporated films on energy distribution in grating spectra," Phys. Rev. 49, 291-296 (1936).

[19] U. Fano, The theory of anomalous diffraction gratings and of quasi-stationary waves on metallic surfaces (Sommerfeld's waves). J. Opt. Soc. Am. 31, 213-222 (1941).

[20] D. Pines, “Collective energy losses in solids,” Rev. Mod. Phys. 28, 184-199 (1956).

[21] U. Fano, "Atomic theory of electromagnetic interactions in dense materials," Phys. Rev. 103(5), 1202-1218 (1956).

[22] R.H. Ritchie, "Plasma Losses by Fast Electrons in Thin Films," Phys. Rev. 106, 874 (1957).

[23] C. J. Powell and J. B. Swan, "Origin of the characteristic electron energy losses in aluminum," Physical Review, 115, 869-875 (1959).

[24] C. J. Powell and J. B. Swan, "Origin of the characteristic electron energy losses in magnesium," Physical Review, 116, 81-83 (1959).

[25] E. A. Stern and R. A. Ferrell, "Surface plasma oscillations of a degenerate electron gas," Physical Review, 120, 130-136 (1960).

[26] A. Otto, "Excitation of nonradiative surface plasma waves in silver by the method of frustrated total reflection," Z. Phys. 216(4), 398-410 (1968).

[27] E. Kretschmann and H. Raether, "Radiative decay of non-radiative surface plasmons excited by light,” Z. Naturf. 23A, 2135-2136 (1968).

[28] J. Takahara, Y. Suguru, T. Hiroaki, A. Morimoto, and T. Kobayashi, "Guiding of a onedimensional optical beam with nanometer diameter," Opt. Lett 22, 475-477 (1997).

[29] T.W. Ebbesen, H.J. Lezec, H.F. Ghaemi, T. Thio, and P.A. Wolff, "Extraordinary optical transmission through sub-wavelength hole arrays," Nature 391, 667-669 (1998).

[30] J. B. Pendry, "Negative refraction makes a perfect lens", Physical Review Letters, 85, pp. 3966-3969 (2000). 
[31] N. Fang, H. Lee, C. Sun, and X. Zhang, "Sub-Diffraction-Limited Optical Imaging with a Silver Superlens" Science 308, 534-537 (2005).

[32] Zhaowei Liu, Hyesog Lee, Yi Xiong, Cheng Sun, and Xiang Zhang, "Far-Field Optical Hyperlens Magnifying Sub-Diffraction-Limited Objects.” Science 315, 1699-1701 (2007).

[33] Z. Liu, S. Durant, H. Lee, Y. Pikus, N. Fang, Y. Xiong, C. Sun, and X. Zhang, "Far-field optical superlens," Nano Lett. 7, 403-408 (2007).

[34] H. A. Atwater and A. Polman, "Plasmonics for improved photovoltaic devices," Nat. Mater. 9(3), 205-213 (2010).

[35] V. E. Ferry, J. N. Munday, and H. A. Atwater, "Design considerations for plasmonic photovoltaics,” Adv. Mater. 22, 4794-4808 (2010).

[36] J. N. Anker, W. P. Hall, O. Lyandres, N. C. Shah, J. Zhao, and R. P. Van Duyne, “Biosensing with plasmonic nanosensors," Nat. Mater. 7(6), 442-453 (2008).

[37] A. G. Brolo, "Plasmonics for future biosensors," Nature Photon. 6, 709-713 (2012).

[38] M. S. Tame, K. R. McEnery, S. K. Ozdemir, J. Lee, S. A. Maier, and M. S. Kim, “Quantum plasmonics,” Nat. Phys. 9(6), 329-340 (2013).

[39] Z. Jacob and V. M. Shalaev, "Physics. Plasmonics goes quantum," Science 334(6055), 463-464 (2011).

[40] A. N. Grigorenko, M. Polini, and K. S. Novoselov, "Graphene plasmonics," Nature Photonics 487, 749-758 (2012).

[41] S. A. Maier, "Graphene plasmonics: all eyes on flatland," Nat. Phys. 8 581-2 (2012).

[42] E. Shamonina and L. Solymar, "Metamaterials: how the subject started," Metamaterials (Amst.) 1(1), 12-18 (2007).

[43]T. Cui, D. Smith, and R. Liu, Metamaterials: Theory, Design, and Applications (Springer, 2009).

[44] W. Cai and V. Shalaev, Optical Metamaterials: Fundamentals and Applications (Springer, 2010).

[45] A. Sihvola, "Metamaterials in electromagnetics," Metmat. 1, 2-11 (2007). 
[46] D. R. Smith, W. J. Padilla, D. C. Vier, S. C. Nemat-Nasser, and S. Schultz, "A composite medium with simultaneously negative permeability and permitivity," Phys. Rev. Lett. 84, 4184-4187 (2000).

[47] R. A. Shelby, D. R. Smith, and S. Schultz, "Experimental verification of a negative index of refraction," Science 292, 77-79 (2001).

[48] V. M. Shalaev, W. Cai, U. K. Chettiar, H.-K. Yuan, A. K. Sarychev, V. P. Drachev, and A. V. Kildishev, "Negative index of refraction in optical metamaterials," Opt. Lett. 30, 3356 -3358 ( 2005).

[49] G. Dolling, M. Wegener, C. M. Soukoulis, and S. Linden, "Negative-index metamaterial at $780 \mathrm{~nm}$ wavelength," Opt. Lett. 32, 53-55 (2007).

[50] A. C. Atre, A. García-Etxarri, H. Alaeian, and J. A. Dionne, "A broadband negative index metamaterial at optical frequencies," Adv. Opt. Mat. 1(4), 327-333 (2013).

[51] E. Plum, V. A. Fedotov, and N. I. Zheludev, "Optical activity in extrinsically chiral metamaterial,” Appl. Phys. Lett. 93(19), 191911 (2008).

[52] Y. P. Jia, Y. L. Zhang, X. Z. Dong, M. L. Zheng, J. Li, J. Liu, Z. S. Zhao, and X. M. Duan, "Complementary chiral metasurface with strong broadband optical activity and enhanced transmission,” Appl. Phys. Lett. 104(1), 011108 (2014).

[53] A. Alu and N. Engheta, "Achieving transparency with plasmonic and metamaterial coatings," Phys. Rev. E 72, 016623 (2005).

[54] D. Schurig, J. B. Pendry, and D. R. Smith. "Calculation of material properties and ray tracing in transformation media." Opt. Express 14, 9794-9840 (2006).

[55] W. Cai, U. K. Chettiar, A. V. Kildishev, and V. M. Shalaev, "Optical cloaking with metamaterials," Nature Photonics, vol.1, 224-227 (2007).

[56] T. Ergin, N. Stenger, P. Brenner, J. B. Pendry, and M. Wegener, "Three-dimensional invisibility cloak at optical wavelengths," Science 328(5976), 337 (2010).

[57] N. I. Zheludev and Y. S. Kivshar, "From metamaterials to metadevices," Nat. Mater. 11, 917-924 (2012).

[58] J. W. Goodman. Introduction to Fourier Optics, Second Edition, New York, McGrawHill Publishing Company (1996). 
[59] N. Yu, P. Genevet, M. A. Kats, F. Aieta, J. Tetienne, F. Capasso, and Z. Gaburro, "Light propagation with phase discontinuities: Generalized laws of reflection and refraction," Science 334, 333-337 (2011).

[60] X. Ni, N. K. Emani, A. V. Kildishev, A. Boltasseva, and V. M. Shalaev, "Broadband light bending with plasmonic nanoantennas," Science 335(6067), 427 (2012).

[61] F. Aieta, P. Genevet, M. A. Kats, N. Yu, R. Blanchard, Z. Gaburro, and F. Capasso, "Aberration-Free Ultrathin Flat Lenses and Axicons at Telecom Wavelengths Based on Plasmonic Metasurfaces," Nano Lett. 12, 4932-4936 (2012).

[62] X. Ni, S. Ishii, A. V. Kildishev, and V. M. Shalaev, "Ultra-thin, planar, Babinet-inverted plasmonic metalenses. Light: Sci. Appl. 2, e27 (2013).

[63] Q. Wang, X. Zhang, Y. Xu, Z. Tian, J. Gu, W. Yue, S. Zhang, J. Han, and W. Zhang, "A broadband metasurface-based terahertz flat-lens array," Adv. Opt. Mater. 3, 779-785 (2015).

[64] P. Genevet, N. F. Yu, F. Aieta, J. Lin, M. A. Kats, R. Blanchard, M. O. Scully, Z. Gaburro, and F. Capasso, "Ultra-thin plasmonic optical vortex plate based on phase discontinuities,” Appl. Phys. Lett. 100,013101 (2012).

[65] N. Yu, F. Aieta, P. Genevet, M. A. Kats, Z. Gaburro, and F. Capasso, "A broadband, background-free quarter-wave plate based on plasmonic metasurfaces," Nano Lett. 12, 63286333 (2012).

[66] Y. Zhao and A. Alù, "Tailoring the Dispersion of Plasmonic Nanorods To Realize Broadband Optical Meta-Waveplates,” Nano Lett. 13(3), 1086-1091 (2013).

[67] X. Ni, A. V. Kildishev, and V. M. Shalaev, "Metasurface holograms for visible light," Nature Comm. 4, 2807 (2013).

[68] L. L. Huang, X. Chen, H. Muhlenbernd, H. Zhang, S. Chen, B. Bai, Q. Tan, G. Jin, K.W. Cheah, C.-W. Qiu, J. Li, T. Zentgraf, and S. Zhang, "Three-dimensional optical holography using a plasmonic metasurface," Nature Comm. 4, 2808 (2013).

[69] W. T. Chen, K.-Y. Yang, C.-M. Wang, Y.-W. Huang, G. Sun, I.-D. Chiang, C. Y. Liao, W.-L. Hsu, H. T. Lin, S. Sun, L. Zhou, A. Q. Liu, and D. P. Tsai, "High-efficiency broadband meta-hologram with polarization-controlled dual images," Nano Lett. 14(1), 225-230 (2014). 
[70] J. Lin, P. Genevet, M. A. Kats, N. Antoniou, and F. Capasso, "Nanostructured holograms for broadband manipulation of vector beams," Nano Lett. 13(9), 4269-4274 (2013).

[71] P. Bharadwaj, B. Deutsch, and L. Novotny, "Optical antennas," Adv. Opt. Photon. 1, 438-483 (2009).

[72] L. Novotny and N. V. Hulst, "Antennas for light," Nature Photon. 5, 83-90 (2011).

[73] A. V. Kildishev, A. Boltasseva, and V. M. Shalaev, "Planar photonics with metasurfaces," Science 339(2013).

[74] N. C. Lindquist, P. Nagpal, K. M. McPeak, D. J. Norris, and S.-H. Oh, "Engineering metallic nanostructures for plasmonics and nanophotonics,” Rep. Prog. Phys. 75(3), 036501 (2012).

[75 ] http://microchem.com/pdf/PMMA_Data_Sheet.pdf. Acessado em 01/02/2016.

[76] L. An, Y. Zheng, K. Li, P. Luo, and Y. Wu, " Nanometer metal line fabrication using a ZEP 520 / 50 K PMMA bilayer resist by e-beam lithography," J. Vac. Sci. Technol. B 23, 1603 (2005).

[77] J. Park, R. D. Yang, C. N. Colesniuc, A. Sharoni, S. Jin, I. K. Schuller, W. C. Trogler, and A. C. Kummel, " Bilayer processing for an enhanced organic-electrode contact in ultrathin bottom contact organic transistors," Appl. Phys. Lett. 92, 193311(2008).

[78] S. Cabrini and S. Kawata. Nanofabrication Handbook, CRC Press, 2012.

[79] https://snf.stanford.edu/SNF/processes/process-modules/photolithography/lift-off-lolprocedures/liftoff. Acessado em 02/02/2016.

[80] H. H. Gatzen, V. Saile, and J. Leuthold. Micro and Nano Fabrication: Tools and Process, Springer-Verlag Berlin Heidelberg, 2015.

[81] Y. Weisheng, W. Zhihong, Y. Yang, C. Longqing, S. Ahad, W. Kimchong, and W. Xianbin, "Electron-beam lithography of gold nanostructures for surface-enhanced Raman scattering," J. Micromech. Microeng. 22(12), 125007 (2012).

[82] G. Lérondel, S. Kostcheev, and J. Plain, "Nanofabrication for plasmonics," Springer Se. Opt. Sci. 167, 269-316 (2012).

[83] A. Pimpin, W. Srituravanich, "Review on Micro- and Nanolithography Techniques and Their Applications," Eng. J., 16, 37- 55 (2012). 
[84] M. J. Madou, Fundamentals of Microfabrication: The Science of Miniaturization, 2nd ed. New York: CRC, 2002.

[85] B. D. Gates, Q. Xu, M. Stewart, D. Ryan, C. G. Willson, and G. M. Whitesides, "New approaches to nanofabrication: Molding, printing, and other techniques," Chem. Rev., vol. 105, pp. 1171-96 (2005).

[86] M. Altissimo, "E-beam lithography for micro-/nanofabrication," Biomicrofluidics, vol. 4, pp. 3-6 (2010).

[87] S. Y. Chou, P. R. Krauss, and P. J. Renstrom, "Imprint lithography with 25-nanometer resolution," Science, vol. 272, pp. 85-87 (1996).

[88] S. R. J. Brueck, “Optical and Interferometric Lithography - Nanotechnology Enablers," Proc. IEEE 93, 1704-1721 (2005).

[89] Joong-Mok Park, Wai Leung, Kristen Constant, Sumit Chaudhary, Tae-Geun Kim and Kai-Ming Ho, "Laser Interference Lithography for Fabricating Nanowires and Nanoribbons, Nanowires - Implementations and Applications," in Nanowires: Implementations and Applications, InTech, 2011.

[90] J. A. Hoffnagle, W. D. Hinsberg, M. Sanchez, and F. A. Houle, "Liquid immersion deep-ultraviolet interferometric lithography,” J. Vac. Sci. Technol., vol. B17, pp. 3306-3309 (1999).

[91] M. A. McCord and M. Rooks. Electron beam lithography. In: Rai-Choudury P, editor. Handbook of microlithography, micromachining and microfabrication, vol. 1. Bellingham: SPIE; 1997. ISBN 978-081-942-378-8.

[92] C. S. Wu, Y. Makiuchi, C. D. Chen, In: M. Wang, editors. Lithography. High-energy electron beam lithography for nanoscale fabrication. Croatia: InTech; 2010, ISBN 978-953307-064-3.

[93] M. Altissimo, "E-beam lithography for micro-nanofabrication," Biomicrofluidics 4(2), 026503 (2010).

[94] M. A. Mohammad, M. Muhammad, S. K. Dew, and M. Stepanova, "Fundamentals of electron beam exposure and development," in Nanofabrication, Springer, 11-41 (2012).

[95] G. Venugopal and S. Kim, "Nanolithography," in Advances in micro/nano Electromechanical Systems and Fabrication Technologies, Intech, 2013. 
[96] S. Y. Chou, P. R. Krauss, and P. J. Renstrom, "Imprint of sub-25 nm vias and trenches in polymers," Appl. Phys. Lett. 67,3114-3117 (1995).

[97] R. d'Agostino. Plasma deposition, treatment and etching of polymers. New York: Academic Press, 1990

[98] http://www.microchem.com/PDFs_MRT/Ormocomp\%20Overview.pdf. Acessado em 03/02/2016.

[99] L. J. Guo, "Nanoimprint Lithography: Methods and Material Requirements," Adv. Mater. 19(4), 495-513 (2007).

[100] L Jay Guo, "Recent progress in nanoimprint technology and its applications," J. Phys. D Appl. Phys. 37, R123 (2004) .

[101] www.comsol.com

[102] http://www.ansys.com/Products/Electronics/ANSYS-HFSS

[103] C. Kittel. Introduction to Solid State Physics. Wiley New York, 1995.

[104] J.D. Jackson. Classical Electrodynamics, (J.Wiley\&Sons, Inc, 1999)

[105] S. A. Maier, Plasmonics: Fundamentals and Applications (Springer, 2007).

[106] A. Alabastri, S. Tuccio, A. Giugni, A. Toma, C. Liberale, G. Das; F. De Angelis, E. Di Fabrizio and R. Proietti Zaccaria, "Molding of Plasmonic Resonances in Metallic Nanostructures: Dependence of the Non-Linear Electric Permittivity on System Size and Temperature". Materials,6 (11), 4879-49100 (2013).

[107] H.Kaatuzian and A. N. Taher, "Applications of Nano-Scale Plasmonic Structures in Design of Stub Filters - A Step Towards Realization of Plasmonic Switches ", in Photonic Crystal, Intech, 2015.

[108] P. B. Johnson and R. W. Christy. Optical-constants of noble-metals. Physical Review B, 6(12):4370-4379 (1972).

[109] D. Y. Smith, E. Shiles, and M. Inokuti, "The optical properties of metallic aluminum," E. D. Palik ed., in Handbook of Optical Constants of Solids (Academic Press 1998).

[110] G. V. Naik, V. M. Shalaev, and A. Boltasseva, “Alternative plasmonic materials: beyond gold and silver,” Adv. Mater. 25(24), 3264-3294 (2013). 
[111] A. Boltasseva and H. A. Atwater, "Low-loss plasmonic metamaterials," Science 331, 290-291 (2011).

[112] P. R. West, S. Ishii, G. V. Naik, N. K. Emani, V. M. Shalaev, and A. Boltasseva, “Searching for better plasmonic materials," Laser Photon. Rev. 4(6), 795-808 (2010).

[113] G. V. Naik, J. Kim, and A. Boltasseva, "Oxides and nitrides as alternative plasmonic materials in the optical range," Opt. Mater. Express 1(6), 1090-1099 (2011).

[114] G. Naik and A. Boltasseva, "Ceramic plasmonic components for optical metamaterials," in "Quantum Electronics and Laser Science Conference" (Optical Society of America, 2011).

[115] S. Enoch and N. Bonod. Plasmonics: from Basics to Advanced Topics, Chap. 4 (Springer, 2012).

[116] B. Lee, S. Kim, H. Kim, and Y. Lim, "The use of plasmonics in light beaming and focusing," Prog. Quantum Electron. 34(2), 47-87 (2010).

[117] K. A. Willets and R. P. Van Duyne, "Localized Surface Plasmon Resonance Spectroscopy and Sensing," Annu. Rev. Phys. Chem. 58, 267-297 (2007).

[118] L. Novotny, "Effective Wavelength Scaling for Optical Antennas," Phys. Rev. Lett. 98(26), 266802 (2007).

[119] K. L. Kelly, E. Coronado, L. L. Zhao, and G. C. Schatz, "The optical properties of metal nanoparticles: The influence of size, shape, and dielectric environment," Journal of Physical Chemistry B 107, 668-677 (2003).

[120] H. Koo, M. Chen, and P. Pan, "LCD-based color filter films fabricated by a pigmentbased colorant photo resist inks and printing technology," Thin Solid Films, vol. 515, no. 3, pp. 896- 901 (2006).

[121] R. W. Sabnis, “Color filter technology for liquid crystal displays,” Displays 20(3), 119129 (1999).

[122] Yan Yu, L. Wen, S. Song, and Q. Chen, "Transmissive/Reflective Structural Color Filters: Theory and Applications," J. Nano Mat. 212637 (2014).

[123] M. J. Uddin and R. Magnusson, "Efficient guided-mode resonant tunable color filter," IEEE Photon. Technol. Lett. 24(17), 1552-1554 (2012). 
[124] M. J. Uddin and R. Magnusson, "Highly efficient color filter array using resonant $\mathrm{Si}_{3} \mathrm{~N}_{4}$ gratings,” Opt. Express 21(10), 12495-12506 (2013).

[125] M. J. Uddin, T. Khaleque, and R. Magnusson, "Guided-mode resonant polarizationcontrolled tunable color filters," Opt. Express 22(10), 12307-12315 (2014).

[126] Y. T. Yoon and S. S. Lee, "Transmission type color filter incorporating a silver film based etalon,” Opt. Express 18(5), 5344-5349 (2010).

[127] V. R. Shrestha, S. S. Lee, E. S. Kim, and D. Y. Choi, "Non-iridescent transmissive structural color filter featuring highly efficient transmission and high excitation purity," Sci Rep 4, 4921 (2014).

[128] K. T. Lee, S. Seo, J. Y. Lee, and L. J. Guo, "Ultrathin metal-semiconductor-metal resonator for angle invariant visible band transmission filters,” Appl. Phys. Lett. 104(23), 231112 (2014).

[129] H. Lee, Y. Yoon, S. Lee, S. Kim, and K. Lee, "Color filter based on a subwavelength patterned metal grating," Optics Express, 15, 23, 15457-15463 (2007).

[130] Q. Chen and D. R. S. Cumming, "High transmission and low color cross-talk plasmonic color filters using triangular-lattice hole arrays in aluminum films," Opt. Express 18(13), 14056-14062 (2010).

[131] S. Yokogawa, S. P. Burgos, and H. A. Atwater, "Plasmonic color filters for CMOS image sensor applications," Nano Lett. 12(8), 4349-4354 (2012).

[132] F. Przybilla, A. Degiron, C. Genet, T. W. Ebbesen, F. Leon-Perez, J. Bravo-Abad, F. J. Gracia-Vidal, L. Martin-Moreno, "Efficiency and finite size effects in enhanced transmission through subwavelength apertures," Optics Express, 16(13), 9571-9579 (2008).

[133] S. P. Burgos, S. Yokogawa, and H. A. Atwater, "Color imaging via nearest neighbor hole coupling in plasmonic color filters integrated onto a complementary metal-oxide semiconductor image sensor," Acs Nano, 7(11), 10038-10047 (201)3.

[134] K. Walls, Q. Chen, S. Collins, D. R. S. Cumming, and T. D. Drysdale, "Automated design, fabrication, and characterization of color matching plasmonic filters," IEEE Photonics Technology Letters, 24(7), 602-604 (2012). 
[135] Y. S. Do, J. H. Park, B. Y. Hwang, S. M. Lee, B. K. Ju, and K. C. Choi, "Plasmonic color filter and its fabrication for large-area applications," Adv. Opt. Mater. 1(2), 133-138 (2013).

[136] W. Li and S. Y. Chou, "Solar-blind deep-UV band-pass filter (250-350 nm) consisting of a metal nano-grid fabricated by nanoimprint lithography," Optics Express, vol. 18, no. 2, pp. 931- 937 (2010).

[137] G. Si, Y. Zhao, H. Liu, S. Teo, M. Zhang, T. J. Huang, A. J. Danner, and J. Teng, “Annular aperture array based color filter,” Appl. Phys. Lett. 99(3), 033105 (2011).

[138] D. van Labeke, D. Gerard, B. Guizal, F. I. Baida, and F. Li, “An angle-independent frequency selective surface in the optical range," Optics Express, 14(25), 11945-11951 (2006).

[139] D. Inoue, A. Miura, T. Nomura et al., "Polarization independent visible color filter comprising an aluminum film with surface-plasmon enhanced transmission through a subwavelength array of holes,” Applied Physics Letters, 98(9), Article ID 093113 (2011).

[140] R. Girard-Desprolet, S. Boutami, S. Lhostis, and G. Vitrant, "Angular and polarization properties of cross-holes nanostructured metallic filters," Opt. Express 21(24), 29412-29424 (2013).

[141] L. Lin and A. Roberts, "Angle-robust resonances in crossshaped aperture arrays," Applied Physics Letters, 97(6), Article ID 061109 (2010).

[142] A. F. Kaplan, T. Xu, and L. J. Guo, "High efficiency resonance-based spectrum filters with tunable transmission bandwith fabricated using nanoimprint lithography,” Appl. Phys. Lett. 99(14), 143111 (2011).

[143] C. H. Park, Y. T. Yoon, and S. S. Lee, "Polarization-independent visible wavelength filter incorporating a symmetric metal-dielectric resonant structure," Opt. Express 20(21), 23769-23777 (2012).

[144] C. H. Park, Y. T. Yoon, V. R. Shrestha, C. S. Park, S. S. Lee, and E. S. Kim, "Electrically tunable color filter based on a polarization-tailored nano-photonic dichroic resonator featuring an asymmetric subwavelength grating," Opt. Express 21(23), 2878328793 (2013). 
[145] V. R. Shrestha, C. S. Park, and S. S. Lee, "Enhancement of color saturation and color gamut enabled by a dualband color filter exhibiting an adjustable spectral response," Opt. Express 22(3), 3691-3704 (2014).

[146] Y. T. Yoon, C. H. Park, and S. S. Lee, "Highly efficient color filter incorporating a thin metal-dielectric resonant structure,” Appl. Phys. Express 5(2), 022501 (2012).

[147] M. S. Amin, J. W. Yoon, and R. Magnusson, "Optical transmission filters with coexisting guided-mode resonance and Rayleigh anomaly," Appl. Phys. Lett. 103(13), $131106(2013)$.

[148] http://guidedmoderesonance.com. Acessado em 12/02/2016.

[149] W. Chao, J. Kim, S. Rekawa, P. Fischer, E. H. Anderson, "Demonstration of 12 nm resolution Fresnel zone plate lens based soft X-ray microscopy," Opt Express 17(20), 17669_ 17677 (2009).

[150] J. Overbuschmann, J. Hengster, S. Irsen and T. Wilhein, "Fabrication of Fresnel Zone Plates by Ion-Beam Lithography and Application as Objective Lenses in Extreme Ultraviolet Microscopy at $13 \mathrm{~nm}$ Wavelength," Opt. Lett., 37, 5100-5102 (2012).

[151] K. Keskinbora, C. Grévent, U. Eigenthaler, M. Weigand, and G. Schütz, "Rapid Prototyping of Fresnel Zone Plates via Direct $\mathrm{Ga}^{+}$Ion Beam Lithography for HighResolution X-ray Imaging," ACS Nano, 7(11), 9788-9797 (2013).

[152] N. Fang, Z. W. Liu, T. J. Yen, and X. Zhang, "Regenerating evanescent waves from a silver superlens," Opt. Express 11, 682-687 (2003).

[153] N. Fang, H. Lee, C. Sun, and X. Zhang, "Sub-diffraction-limited optical imaging with a silver superlens," Science 308, 534 (2005).

[154] Z. Liu, S. Durant, H. Lee, Y. Pikus, N. Fang, Y. Xiong, C. Sun, and X. Zhang, "FarField Optical Superlens,” Nano Lett. 7, 403-408 (2007)

[155] H. Lee, Z. Liu, Y. Xiong, C. Sun, and X. Zhang, "Development of optical hyperlens for imaging below the diffraction limit," Opt. Express 15, 15886-15891 (2007).

[156] H. Shi, C. Wang, C. Du, X. Luo, X. Dong and H. Gao, "Beam manipulating by metallic nano-slits with variant widths," Opt. Express 13, 6815-6820 (2005). 
[157] L. Verslegers, P. B. Catrysse, Z. Yu, J. S. White, E. S. Barnard, M. L. Brongersma and S. Fan, "Planar Lenses Based on Nanoscale Slit Arrays in a Metallic Film", Nano Letters, 9, 235-238 (2009).

[158] S. Kim, Y. Lim, H. Kim, J. Park and B. Lee, "Optical beam focusing by a single subwavelength metal slit surrounded by chirped dielectric surface gratings," Appl. Phys. Lett., 92, 013103 (2008).

[159] S. Kim, H. Kim, Y. Lim and B. Lee, "Off-axis directional beaming of optical field diffracted by a single subwavelength metal slit with asymmetric dielectric surface gratings", Appl. Phys. Lett., 90, 05113 (2007).

[160] B. Jia, H. Shi, J. Li, Y. Fu, C. Du and M. Gu, "Near-field visualization of focal depth modulation by step corrugated plasmonic slits," Appl. Phys. Lett., 94, 151219 (2009).

[161] W. Chen, D. C. Abeysinghe, R. L. Nelson and Q. Zhan, "Plasmonic Lens Made of Multiple Concentric Metallic Rings under Radially Polarized Illumination," Nano Letters, 9, 4320-4325 (2009).

[162] W. Chen and Q. Zhan, "Realization of an evanescent Bessel beam via surface plasmon interference excited by a radially polarized beam," Optics Letters, 34, 722-724 (2009).

[163] D. Lin, C. Chen, C. Chang, T. Cheng, C. Yeh and C. Lee, "Subwavelength nondiffraction beam generated by a plasmonic lens," Appl. Phys. Lett., 92, 233106 (2008).

[164] T. Cheng, D. Lin, J. Yeh and J. Liu, "Propagation characteristics of silver and tungsten subwavelength annular aperture generated sub-micron non-diffraction beams," Opt. Express, 7, 5330-5339 (2009).

[165] Y. Yu, D. Lin, L. Huang and C. Lee, "Effect of subwavelength annular aperture diameter on the nondiffracting region of generated Bessel beams," Optics Express, 17, 27072713 (2009).

[166] Y. Fu, W. Zhou, L. E. N. Lim, C. L. Du, and, X. G. Luo, "Plasmonic microzone plate: Superfocusing at visible regime," Appl. Phys. Lett., 91:061124 (2007).

[167] H. C. Kim, H. Ko, and M. Cheng, "High efficient optical focusing of a zone plate composed of metal/dielectric multilayer," Opt Express 17, 3078-3083 (2009).

[168] Y. Fu, W. Zhou, L. E. N Lim, "Near-field behavior of zone-plate-like plasmonic nanostructures," J Opt Soc Am A 25:238-249 (2008). 
[169] Y. Fu, W. Zhou, L. E. N Lim "Propagation properties of plasmonic micro-zone plates with and without fractals," Appl Phys B 90:421-425 (2008).

[170] R. G. Mote, S. F Yu, B. K. Ng, W. Zhou, and S. P. Lau, "Near-field focusing properties of zone plates in visible regime - New insights," Opt Express 16:9554-9564 (2008).

[171] H. C. Kim, H. Ko, M. Cheng, "Optical focusing of plasmonic Fresnel zone plate-based metallic structure covered with a dielectric layer," J. Vac. Sci. Technol. B 26:2197-2203 (2008).

[172] J. H. Li, Y. W. Cheng, Y. C. Chue, C. H. Lin, and T. W. Sheu, "The influence of propagating and evanescent waves on the focusing properties of zone plate structures," Opt Express 17:18462-18468 (2009).

[173] J. Wang, W. Zhou, E. Li, D. H. Zhang, "Subwavelength focusing using plasmonic wavelength-lauched zone plate lenses," Plasmonics, 6:269, 272 (2011).

[174] D. Feng, C. X. Zhang, and Y. H. Yang, "Comparison of subwavelength focusing properties of diffraction and Fresnel zone plate plasmonic planar lenses," Optik 124, 44934497 (2013).

[175] D. Marks and P. S. Carney, "Near-field diffractive elements," Opt Lett 30:1870-1872 (2005).

[176] M. Young, "Zone plates and their aberrations," J Opt Soc Am 62:972-976 (1972).

[177] B. Xiao, "Equivalent field of paraxial diffraction of a zone plate," Opt Lett 19:19401942 (1994).

[178]http://www.microchem.com/PDFs_MRT/Ormocore\%20+\%200rmoclad\%20Overview. pdf. Acessado em 10/02/2016.

[179] http://www.dowcorning.com/content/publishedlit/11-1547e-01.pdf. Acessado em $11 / 02 / 2016$.

[180] F. Aieta, P. Genevet, N. F. Yu, M. A. Kats, Z. Gaburro, and F. Capasso, “Out-of-Plane Reflection and Refraction of Light by Anisotropic Optical Antenna Metasurfaces with Phase Discontinuities," Nano Lett. 12(3), 1702-1706 (2012).

[181] G. W. Bryant, F. J. García de Abajo, and J. Aizpurua, "Mapping the plasmon resonances of metallic nanoantennas," Nano Lett. 8, 631-636 (2008). 
[182] G. Pellegrini, G. Mattei, and P. Mazzoldi, "Tunable, directional and wavelength selective plasmonic nanoantenna arrays," Nanotechnology 20(6), 065201 (2009).

[183] N. Yu, P. Genevet, F. Aieta, M. A. Kats, R. Blanchard, G. Aoust, J.-P. Tetienne, Z. Gaburro, and F. Capasso, "Flat optics: controlling wavefronts with optical antenna metasurfaces,” IEEE J. Sel. Top. Quantum Electron. 19(3), 4700423 (2013).

[184] L. Novotny and N. van Hulst, “Antennas for light,” Nat. Photonics 5, 83-90 (2010).

[185] P. Bharadwaj, B. Deutsch, and L. Novotny, "Optical Antennas," Adv. Opt. Photon.1, 438 (2009).

[186] A. E. Krasnok, I. S. Maksymov, A. I. Denisyuk, P. A. Belov, A. E. Miroshnichenko, C. R. Simovski, and Y. S. Kivshar, “Optical nanoantennas,” Physics-Uspekhi 56(6), 539-564 (2013).

[187] P. Biagioni, J. S. Huang, and B. Hecht, "Nanoantennas for visible and infrared radiation,” Rep. Prog. Phys. 75, 024402 (2012).

[188] A. Alu and N. Engheta, "Theory, modeling and features of optical nanoantennas," IEEE Trans. Antennas Propag. 61, 1508-1517 (2013).

[189] T. Milligan. Modern Antenna Design (John Wiley \& Sons, 2005).

[190] N. Yu and F. Capasso, "Flat optics with designer metasurfaces," Nat. Mater. 13(2), 139-150 (2014).

[191] C. Pfeiffer, N. K. Emani, A. M. Shaltout, A. Boltasseva, V. M. Shalaev, and A. Grbic, "Efficient light bending with isotropic metamaterial Huygens' surfaces," Nano Lett. 14, 2491-2497 (2014).

[192] M. Khorasaninejad, F. Aieta, P. Kanhaiya, M. A. Kats, P. Genevet, D. Rousso, F. Capasso, "Achromatic Metasurface Lens at Telecommunication Wavelengths," Nano Lett. $15,5358-5362(2015)$.

[193] Y. Zhao and A. Alu, "Manipulating light polarization with ultrathin plasmonic metasurfaces,” Phys. Rev. B 84, 205428 (2011).

[194] G. Zheng, H. Mühlenbernd, M. Kenney, G. Li, T. Zentgraf, and S. Zhang, "Metasurface holograms reaching 80\% efficiency," Nat. Nanotechnol. 10(4), 308-312 (2015). 
[195] D. Wen, F. Yue, G. Li, G. Zheng, K. Chan, S. Chen, M. Chen, K. F. Li, P. HanWong, K. Cheah, E. Y. B. Pun, S. Zhang, and X. Chen, "Helicity multiplexed broadband metasurface holograms," Nature Comm. 6, 8241 (2015).

[196] Y. Huang, W. T. Chen, W. Tsai, P. C. Wu, C. Wang, G. Sun, and D. P. Tsai, "Aluminum plasmonic multicolor meta-hologram," Nano Lett. 15, 3122-3127 (2015).

[197] Y. Montelongo, J. O. Tenorio-Pearl, C. Williams, S. Zhang, W. I. Milne, and T. D. Wilkinson, "Plasmonic nanoparticle scattering for color holograms," Proc. Natl. Acad. Sci. USA 111, 12697 (2014).

[198] L. Huang, H. Mühlenbernd, X. Li, X. Song, B. Bai, Y. Wang, and T. Zentgraf, "Broadband hybrid holographic multiplexing with geometric metasurfaces," Adv. Opt. Mater. 27, 6444-6449 (2015).

[199] F. Zhou, Y. Liu, and W. Cai, "Plasmonic holographic imaging with V-shaped nanoantenna array," Opt. Express 21(4), 4348-4354 (2013).

[200] D. B. Mazulquim. Aplicação da óptica escalar na modulação de frentes de onda e em medidas de ressonância de moduladores de ferroeletretos. Dissertação de mestrado, Escola de Engenharia de São Carlos (2011).

[201] http://www.mathworks.com/products/matlab

[202] http://www.uta.edu/sirt/nano/equipment/zeiss1540xb/zeiss1540xb.php. Acessado em 20/02/2016. 